\title{
HPV infection and integration in oropharyngeal squamous cell carcinomas
}

Citation for published version (APA):

Olthof, N. C. (2013). HPV infection and integration in oropharyngeal squamous cell carcinomas. [Doctoral Thesis, Maastricht University]. Maastricht University. https://doi.org/10.26481/dis.20131203no

Document status and date:

Published: 01/01/2013

DOI:

10.26481/dis.20131203no

Document Version:

Publisher's PDF, also known as Version of record

\section{Please check the document version of this publication:}

- A submitted manuscript is the version of the article upon submission and before peer-review. There can be important differences between the submitted version and the official published version of record.

People interested in the research are advised to contact the author for the final version of the publication, or visit the DOI to the publisher's website.

- The final author version and the galley proof are versions of the publication after peer review.

- The final published version features the final layout of the paper including the volume, issue and page numbers.

Link to publication

\footnotetext{
General rights rights.

- You may freely distribute the URL identifying the publication in the public portal. please follow below link for the End User Agreement:

www.umlib.nl/taverne-license

Take down policy

If you believe that this document breaches copyright please contact us at:

repository@maastrichtuniversity.nl

providing details and we will investigate your claim.
}

Copyright and moral rights for the publications made accessible in the public portal are retained by the authors and/or other copyright owners and it is a condition of accessing publications that users recognise and abide by the legal requirements associated with these

- Users may download and print one copy of any publication from the public portal for the purpose of private study or research.

- You may not further distribute the material or use it for any profit-making activity or commercial gain

If the publication is distributed under the terms of Article $25 \mathrm{fa}$ of the Dutch Copyright Act, indicated by the "Taverne" license above, 


\section{HPV infection and integration in oropharyngeal squamous cell carcinomas}

Nadine C. Olthof 



\title{
HPV infection and integration in oropharyngeal squamous cell carcinomas
}

\author{
Proefschrift \\ ter verkrijging van de graad van doctor \\ aan de Universiteit Maastricht, \\ op gezag van de Rector Magnificus, \\ Prof. Dr. L.L.G. Soete, \\ volgens het besluit van het College van Decanen, \\ in het openbaar te verdedigen op \\ 3 december 2013 om 14.00 uur
}

door

Nadine Cathérine Olthof

Geboren op 4 februari 1980

te Stadskanaal 


\section{Promotores:}

Prof. Dr. B. Kremer

Prof. Dr. F.C.S. Ramaekers

Prof. Dr. E.J.-M. Speel

\section{Beoordelingscommissie:}

Prof. Dr. J.P.M. Geraedts (voorzitter)

Prof. Dr. R.H. Brakenhoff (VUMC Amsterdam)

Prof. Dr. C.A. Bruggeman

Prof. Dr. B.F.A.M. van der Laan (UMCG Groningen)

Prof. Dr. A. zur Hausen

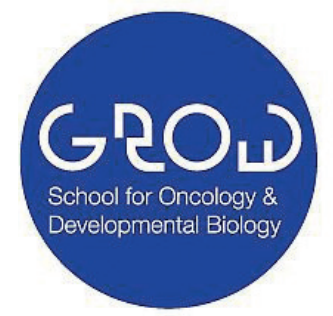

The study presented in this thesis was performed within GROW- School for Oncology and Developmental Biology.

(c) Copyright Nadine Habets-Olthof, Maastricht 2013

ISBN

Cover design:

Layout and typesetting:

Printed in Poland
Alexandra Buskens-Heinzmann

${ }^{*}$ studio Michał Sławiński, thesisprint.eu

All rights reserved to the author with the exception of those chapters published by the journals referred to. No part of this publication may be produced, stored in a retrieval system or transmitted in any form or by any means, without written permission of the authors or the copyright-owning journal. 
INTRODUCTION 9

ChAPTER 1

Next generation treatment strategies for human papillomavirus-related head and neck squamous cell carcinoma: where do we go?

ChAPTER 2

Human papillomavirus reduces the prognostic value of nodal involvement in tonsillar squamous cell carcinomas

\section{ChAPTER 3}

Human papillomavirus type 16 integration in oropharyngeal squamous cell carcinomas often occurs in genes involved in tumorigenesis

\section{CHAPTER 4}

Comprehensive analysis of HPV16 integration in oropharyngeal squamous cell carcinomas reveals no significant impact of physical status on viral oncogene and virally disrupted human gene expression

\section{CHAPTER 5}

Viral load, gene expression and mapping of viral integration sites

in HPV16-associated head and neck squamous cell carcinoma cell lines

\section{CHAPTER 6}

Radiosensitivity and effect of hypoxia in HPV positive head and neck cancer cells

General Discussion and Future Prospects

SAMENVATTING

DANKWOORD / ACKNOWLEDGEMENTS

Curriculum VitaE 



\section{List of abbreviations}

\begin{tabular}{|c|c|}
\hline ANP & Acyclic nucleoside phosphonate \\
\hline AP1 & Adapter primer 1 \\
\hline APOT-PCR & Amplification of papillomavirus oncogene transcripts PCR \\
\hline AZF & Artificial zinc fingers \\
\hline $\mathrm{BAC}$ & Bacterial artificial clone \\
\hline $\mathrm{BP}$ & Basepair \\
\hline CEP & Centromere \\
\hline $\mathrm{CGH}$ & Comparative genomic hybridization \\
\hline $\mathrm{CIN}$ & Cervical intraepithelial neoplasia \\
\hline $\mathrm{CPP}$ & Cell-penetrating peptide \\
\hline $\mathrm{CR} / \mathrm{RT}$ & Combined resection plus radiotherapy \\
\hline CT & Chemotherapy \\
\hline DAPI & 4',6-diamidino-2-phenylindole \\
\hline DFS & Disease-free survival \\
\hline DIPS-PCR & Detection of integrated papillomavirus sequences PCR \\
\hline DSS & Disease-specific survival \\
\hline EGFR & Epithelial growth factor receptor \\
\hline EMT & Endothelial-to-mesenchymal transition \\
\hline E-proteins & Early proteins \\
\hline FISH & Fluorescence in situ hybridisation \\
\hline $\mathrm{H}_{2} \mathrm{O}_{2}$ & Hydrogen peroxide \\
\hline HNSCC & Head and neck squamous cell carcinoma \\
\hline HPMPC & [(S)-1-(3-hydroxy-2-phosphonylmethoxypropyl)cytosine] \\
\hline HPRT & Hypoxanthine guanine phosphoribosyl transferase \\
\hline $\mathrm{HPV}$ & Human papillomavirus \\
\hline HR-HPV & High-risk human papillomavirus \\
\hline IFN & Interferon \\
\hline IQR & Interquartile range \\
\hline ISH & In situ hybridisation \\
\hline
\end{tabular}




\begin{tabular}{|c|c|}
\hline L-proteins & Late proteins \\
\hline LR-HPV & Low-risk human papillomavirus \\
\hline $\mathrm{Mb}$ & Megabase \\
\hline $\mathrm{NaSCN}$ & Sodium thiocyanate \\
\hline NCBI & National Centre for Biotechnology Information \\
\hline NFDM & Nonfat dry milk \\
\hline NS & Not significant \\
\hline OER & Oxygen enhancement ratio \\
\hline OPSCC & Oropharyngeal squamous cell carcinoma \\
\hline ORF & Open reading frame \\
\hline OS & Overall survival \\
\hline OSCC & Oral squamous cell carcinoma \\
\hline PBS & Phosphate-buffered saline \\
\hline PCR & Polymerase chain reaction \\
\hline PI & Protease inhibitors \\
\hline $\mathrm{pRb}$ & Retinoblastoma tumor suppressor protein \\
\hline RNAi & RNA interference (small interfering RNA) \\
\hline RRP & Recurrent respiratory papillomatosis \\
\hline RT & Radiotherapy \\
\hline SER & Sensitivity enhancement ratio \\
\hline SPT & Second primary tumor \\
\hline SSC & Saline-sodium citrate \\
\hline TORS & Transoral robotic surgery \\
\hline TP63 & Tumor protein $\mathrm{p} 63$ \\
\hline Tregs & $\mathrm{CD} 4+/ \mathrm{CD} 25+$ regulatory T-cells \\
\hline TSCC & Tonsillar squamous cell carcinoma \\
\hline UCSCC & Uterine cervical squamous cell carcinoma \\
\hline VLP & Virus-like particles \\
\hline
\end{tabular}




\section{Introduction}





\section{Viral carcinogenesis}

A wild cottontail rabbit was shot in 1931 which carried three prominent subcutaneous tumors but otherwise appeared in good general condition. The rabbit was taken to the lab of Dr. Richard Shope at The Rockefeller Institute for Medical Research in Princeton, New Jersey, who studied hog cholera at that time. He discovered that this tumor-like condition could be transmitted to laboratory and wild cottontail rabbits by inserting small bits of the original tumor under the skin ${ }^{1}$. The nature of the etiological agent causing these tumors was identified as a virus, not related to myxomatosis ${ }^{2}$, which was known to cause nodules in the skin in the neighborhood of the eyes, ears, nose, mouth and genitalia ${ }^{3}$. Around the same time, dr. Shopes attention was drawn to a group of wild cottontail rabbits that carried horn-like outgrowths on the $\operatorname{skin}^{4}$ (figure 1).

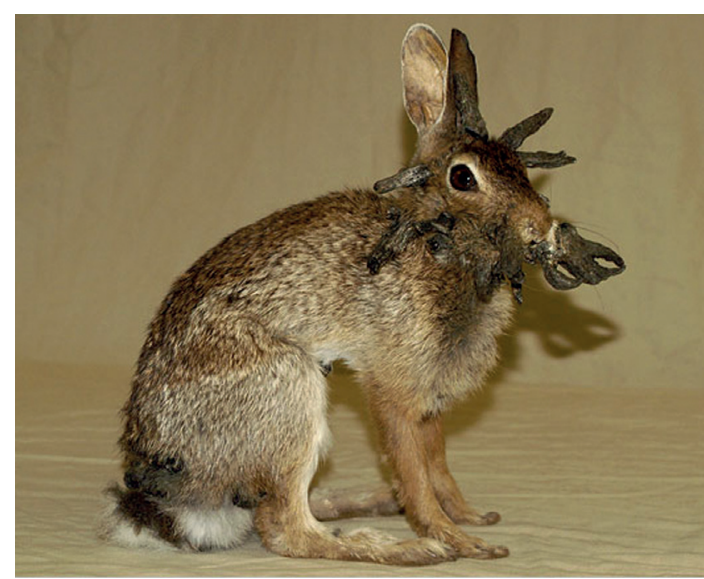

Figure 1. Wild cottontail rabbit with papillomas (www.nytimes.com)

Transplants of these "warts" were transmissible to both wild and domestic rabbits and the properties of the papilloma-inducing agent proved to be a filterable virus. Dr. Shope decided to ask his Rockefeller collegue Dr. Peyton Rous to further investigate these rabbits, who showed that the outgrowths were in fact a benign tumor type ${ }^{5}$. When infecting domestic rabbits with the virus, the papillomas often transformed into epidermoid carcinomas, thereby demonstrating a link between papillomavirus infection and carcinogenesis in animals ${ }^{6}$. Dr. Rous was awarded the Nobel Prize in Physiology or Medicine in 1966 for his discovery of tumor-inducing viruses ${ }^{7}$.

The first human virus with oncogenic properties was described more than 20 years later. Two research groups, i.e. Trentin and collegues ${ }^{8}$, and Huebner and collegues ${ }^{9}$, independently showed that when human adenovirus was injected in newborn hamsters, 
they regularly produced visible tumors. Especially adenovirus types 12 and 18 proved to have oncogenic properties. However, only rodents seem to be susceptible to adenovirusinduced carcinogenesis, and infection has not been linked to human cancer ${ }^{10}$.

In 1965, persistent viral infection was shown in a cell line derived from Burkitt's lymphoma ${ }^{11}$. DNA of this virus, later known as Epstein-Barr virus (EBV), was also shown in a Burkitt's lymphoma cell line that was thought to be virus-free ${ }^{12}$. The link between infection with EBV and the development of Burkitt's lymphoma and nasopharyngeal carcinomas was shown in $1970^{13}$.

\section{HPV and human cancer}

The cause of cervical cancer has long suspected to be a sexually transmittable virus, since it was observed that especially married women and prostitutes developed this disease and that cervical cancer was virtually non-existent in nuns. When dr. Harald zur Hausen was appointed chairman of the newly established Institute of Clinical Virology in Erlangen-Nürnberg in 1972 he tried to identify the causative agent. The main suspect at this time was Herpes Simplex type 2 (HSP-2). However, attempts to amplify HSP2 sequences from cervical cancer biopsies failed. When he observed that genital warts could progress to squamous cell carcinomas in some cases ${ }^{14}$, he hypothesized that the papillomavirus identified in these warts might be the causative agent in cervical cancers. However, viral DNA extracted from plantar warts could not be detected in either genital warts or cervical biopsies. He further hypothesized that more types of papillomaviruses existed. In 1979 his group succeeded in isolating HPV6 from genital warts ${ }^{15}$, and isolation of HPV 11 followed a little later from a laryngeal papilloma ${ }^{16}$. Research on cervical cancer biopsies showed that these sequences could be identified in these malignant lesions as well ${ }^{16}$. In $1983^{17}$ and $1984^{18}$ HPV16 and -18 were successfully cloned and were shown to be present in about $50 \%$ and $20 \%$ of cervical cancer biopsies, respectively. Later research showed the presence of HPV in precursor lesions, indicating a prominent role for HPV in cervical carcinogenesis.

Since the discovery of HPV the link between HPV infection and carcinogenesis became convincingly established and HPV was identified in more carcinomas. HPV infection was first linked to laryngeal cancers ${ }^{19}$, to esophageal cancer ${ }^{20}$ and oral cancer ${ }^{21}$, before being associated with oropharyngeal cancers ${ }^{22}$. Later studies revealed that particularly HPV16 is involved in head and neck cancers and that the presence of the virus is especially common in the oropharyn $\mathrm{x}^{23-25}$ (see chapter 2 ).

To date, many advances have been made in the characterization and identification of HPVs, and currently around 200 types of HPV are known, of which 15 are characterized as high risk, or oncogenic types. The identification of a consistent expression of the 
viral genes E6 and E7 eventually lead to the development of an HPV vaccine. In 2008, professor Harald zur Hausen was awarded the Nobel-prize in Physiology or Medicine for his discovery of human papilloma viruses causing cervical cancer ${ }^{26}$.

\section{Transmission of HPV}

HPV is the most common sexually transmitted virus. Having multiple sex partners has been linked to an increased risk of developing cervical and oral cancer (see chapter 2). It has even been shown that husbands of wives with cervical carcinoma have a higher risk for developing head and neck squamous cell carcinomas (HNSCC). HPV can also be acquired via non-sexual contact such as deep kissing ${ }^{27}$ and may even be transmitted via hands ${ }^{28}$. In addition, it can be transmitted from mother to child during delivery. This has been shown to result in a 33\% higher chance of oral HPV infection in newborn infants born to an HPV-positive mother as compared to children born to HPV-negative moth$\mathrm{ers}^{29}$. In addition, several reports have shown the presence of HPV in umbilical cord blood and placenta ${ }^{30}$. Another possible route of transmission is via blood, since the presence of HPV was detected in blood of healthy male blood donors ${ }^{31}$. HPV particles are suspected to adhere to peripheral blood mononuclear cells, which might represent a so far unknown reservoir for HPV particles ${ }^{31}$.

\section{HPV infection}

HPVs are non-enveloped double-stranded DNA viruses that infect the basal cells of cutaneous and mucosal epithelia (see chapter 2). Infection with HPV can occur when microlesions expose the basal epithelial (stem) cell layer. The basal compartment contains the dividing cells in the epithelium, and generates other basal cells by sideways division and keratinocytes by upward division ${ }^{32}$. Following cell division, one daughter cell detaches from the basement membrane, migrates towards the suprabasal layers and begins terminal differentiation. During this process the cell exits the cell cycle. The papillomavirus life cycle is tightly linked to the differentiation program of the infected epithelium. After infection, viral DNA is maintained in the basal cells as nuclear episomes at approximately 50-100 copies/cell. Viral DNA is partitioned equally during cell division ${ }^{33}$. This requires the expression of the viral $E 1$ and $E 2$ genes. When the keratinocyte reaches the suprabasal layer and starts terminal differentiation, expression of the viral oncogenes E6 and E7 drives the cells into S-phase, causing increased proliferation of the suprabasal cells and replication of the viral genome above the basal cell layer. Eventually, productive infection is initiated when the two capsid proteins L1 and L2 are synthesized and the 


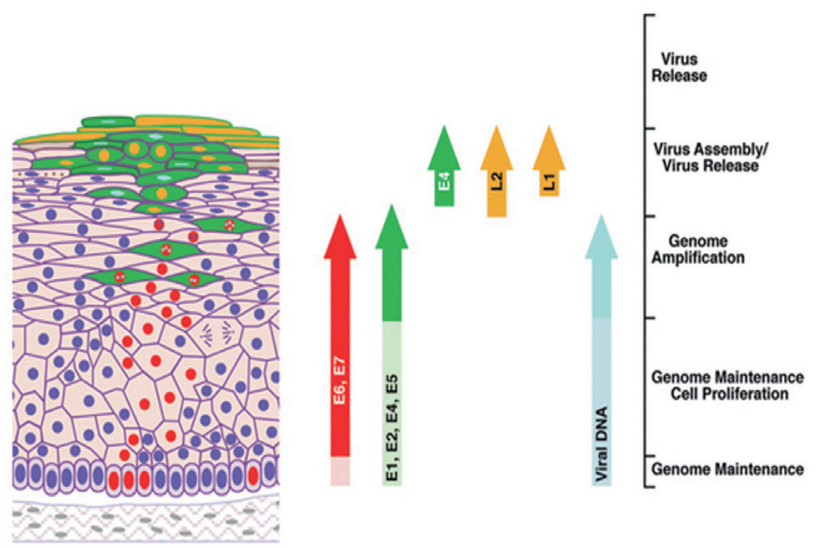

Figure 2. Life cycle of HPV with the timing of viral gene expression during epithelial differentiation (adapted from Doorbar et al., 2006) $)^{33}$.

replicated viral genome is packaged into infectious particles. HPV is a non-lytic virus and infectious particles are present in cells that are shed from the epithelial surface at the end of their life $\operatorname{span}^{33}$ (see figure 2).

Under normal circumstances, HPV remains in an episomal state and infection with the virus is transient. However, due to reasons that are so far not understood, the viral DNA can break and integrate into the host genome. This is believed to be an important step in cellular transformation of HPV-infected mucosa. Integration is thought to induce a deregulation of the cell cycle control and therefore uncontrolled cellular proliferation, dependent on constitutive expression of the viral oncogenes $E 6$ and $E 7^{34}$. However, although the relation between integration and increased viral oncogene expression has been clearly shown in cell line models, it is still unclear whether it exists in primary carcinomas ${ }^{35-39}$.

Much of the current information on HPV-associated carcinogenesis is based on information provided by studies in cervical dysplasias and cervical carcinomas, as well as cell lines derived thereof. HPV infection is an imperative, albeit not sufficient, cause for the development of cervical carcinomas. Despite several etiological similarities, our knowledge on the role of HPV in cervical (pre)malignancies cannot be translated one-toone to the head and neck region.

Although there is an evident association of HPV with HNSCC in a subgroup of patients, infection with HPV is not an essential factor in most HNSCC. The classical risk factors, such as tobacco and alcohol consumption, are still responsible for a large fraction of these cancers. Morphological and physiological characteristics of different anatomical 
sites affected by HPV-related carcinomas differ considerably, and therefore it is perilous to extrapolate thoughtlessly information on HPV infection and the effects on tumor biology from cervical carcinomas to HNSCC.

This thesis will focus on oropharyngeal cancer since a large proportion of HPVinduced HNSCC originate from this anatomical location ${ }^{23-25}$. For clarity, the term oropharynx refers to the anatomic region that includes the soft palate and uvula, tonsils, posterior pharyngeal wall and the base of tongue (see figure 3 ).

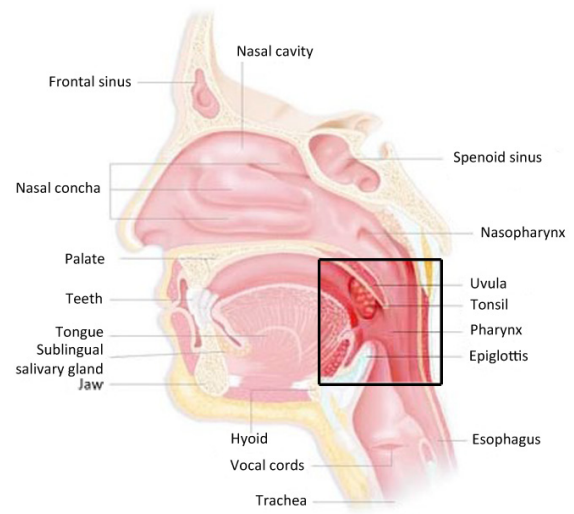

Figure 3. Cross-cut of the human head and neck region. The oropharynx is indicated by the black rectangle. Copyright (c) 2013, ec-europe. Http://apps.ec-europe.com 


\section{Aim of the thesis}

The aim of this thesis is to enhance our understanding of clinical and biological features of HPV-associated oropharyngeal carcinomas. For this purpose, HPV-associated HNSCC tumor samples, as well as established cell lines derived from such tumors, were analyzed. The presence and/or physical status of the virus was correlated to their clinical and biological behavior.

The following questions were addressed:

1. Do HPV-associated HNSCC exhibit different molecular and clinical features as compared to HPV-negative HNSCC and if so, do these features offer possible therapeutic targets?

Chapter 1 contains a review on the clinical and molecular characteristics of HPV-positive and -negative HNSCC and possible ways to target specifically the HPV-infected cells to improve therapy for this group of patients. This clearly indicated that HPV-associated HNSCC form an etiologically distinct group of carcinomas in the head and neck region. Patients with HPV-associated carcinomas generally have a better prognosis and response to treatment. In HNSCC in general, N-status is considered to be the most reliable prognostic marker ${ }^{40-42}$. The literature is, however, not consistent in confirming its prognostic value in tonsillar carcinomas ${ }^{43-45}$. Therefore, the question was raised:

2. What is the prognostic value of N-status in relation to HPV positivity in tonsillar squamous cell carcinomas?

Chapter 2 involves a clinical study in which the prognostic value of $\mathrm{N}$-status in a cohort of 81 patients with tonsillar cancer was examined. Nodal involvement was shown to correlate to an unfavourable prognosis in HPV-negative patients, but this effect was not seen in HPV-positive patients. HPV integration into the host genome is closely linked to progression in cervical cancers, and integration is found in approximately 55\% of HPV 16 positive uterine cervical carcinomas ${ }^{46}$. However, high variation in integration frequencies has been reported in $\mathrm{HNSCC}^{24,47}$, which led to the following question:

3. What is the frequency and genomic site of HPV-integration in HPV-associated HNSCC?

Chapter 3 describes the analysis of tumor biopsies from a cohort of 75 patients with HPVassociated HNSCC to assess integration frequency and identify integration loci. Integration could be detected in $39 \%$ of the tumours, with integration loci distributed througout 
the entire genome. Although studies in cell lines have shown that HPV integration results in higher expression of the viral oncogenes $E 6$ and $E 7^{38}$, this information is lacking for primary HNSCC, giving rise to the question:

4. Is there a correlation between the viral integration status and the expression of the viral genes?

In chapter 4 the viral physical status was correlated to the expression of the viral E2, E6 and $E 7$ genes and to a number of virally-disrupted human genes. This showed a large variation in viral gene expression, independent of the physical status of HPV. Finally, well-established cell line models are important tools in the development of antiviral therapies that might improve prognosis of patients suffering from these carcinomas. The question therefore emerged:

5. Can cell lines derived from HPV-associated HNSCC tumors be employed in the research for therapeutic options beneficial for HPV-positive HNSCC?

Chapter 5 involves the characterization of $7 \mathrm{HPV}$-associated HNSCC cell lines to further study integration and to establish a reliable cell line model for HPV-associated HNSCC cancers. This indicated that these cell line models exhibit characteristics that are associated with a poor prognosis in primary HPV-positive HNSCC, such as EGFR overexpression and aneusomy ${ }^{48,49}$. This indicates that these cell lines represent proper model systems for in vitro testing of treatment modalities. Previous studies have shown enhanced radiosensitivity for HPV-positive HNSCC ${ }^{50}$. Since the efficiency of radiotherapy is dependent on the tissue oxygenation, this might indicate that HPV-positive tumors are less hypoxic. In contrast, PET/CT showed that HPV-positive and -negative tumors were equally hypoxic ${ }^{51}$. The purpose of the study described in chapter 6 was to:

6. Examine the biological background for these clinical observations.

The study described in chapter 6, using a panel of HPV-positive and -negative HNSCC cell lines, shows that, although HPV-positive cells had a markedly higher radiosensitivity compared to HPV-negative cells, they displayed the same relative radioresistance under hypoxia and the same relative sensitizer effect of Nimorazole. No difference was found in the expression levels of hypoxia-inducible genes between HPV-positive and -negative cell lines. 


\section{References}

1 Shope RE. A transmissible tumor-like condition in rabbits. J Exp Med 1932; 56: 793-802.

2 Shope RE. A filtrable virus causing a tumor-like condition in rabbits and its relationship to virus myxomatosum. J Exp Med 1932; 56: 803-822.

3 Rivers TM. Infectious myxomatosis of rabbits: observations on the pathological changes induced by virus myxomatosum (Sanarelli). J Exp Med 1930; 51: 965-976.

4 Shope RE and Hurst EW. Infectious papillomatosis of rabbits : with a note on the histopathology. J Exp Med 1933; 58: 607-624.

5 Rous P and Beard JW. A virus-induced mammalian growth with the characters of a tumor (the Shope rabbit papilloma). J Exp Med 1934; 60: 701-722.

6 Rous P and Beard JW. The progression to carcinoma of virus-induced rabbit papillomas (Shope). $J$ Exp Med 1935; 62: 523-548.

7 Peyton Rous - Facts. Nobelprize.org. Nobel Media AB 2013; http://www.nobelprize.org/nobel_prizes/ medicine/laureates/1966/rous-facts.html.

8 Trentin JJ, Yabe Y and Taylor G. The quest for human cancer viruses. Science 1962; 137: 835-841.

9 Huebner RJ, Rowe WP and Lane WT. Oncogenic effects in hamsters of human adenovirus types 12 and 18. Proc Natl Acad Sci U S A 1962; 48: 2051-2058.

10 Mackey JK, Rigden PM and Green M. Do highly oncogenic group A human adenoviruses cause human cancer? Analysis of human tumors for adenovirus 12 transforming DNA sequences. Proc Natl Acad Sci U S A 1976; 73: 4657-4661.

11 Henle G and Henle W. Evidence for a persistent viral infection in a cell line derived from Burkitt's Lymphoma. J Bacteriol 1965; 89: 252-258.

12 Zur Hausen H and Schulte-Holthausen H. Presence of EB virus nucleic acid homology in a "virusfree" line of Burkitt tumor cells. Nature 1970; 227: 245-248.

13 Henle W and Henle G. Evidence for a relation of Epstein-Barr virus to Burkitt's lymphoma and nasopharyngeal carcinoma. Bibl Haematol 1970; 706-713.

14 Kovi J, Tillman RL and Lee SM. Malignant transformation of condyloma acuminatum. A light microscopic and ultrastructural study. Am J Clin Pathol 1974; 61: 702-710.

15 Gissmann L and zur Hausen H. Partial characterization of viral DNA from human genital warts (Condylomata acuminata). Int J Cancer 1980; 25: 605-609.

16 Gissmann L, Wolnik L, Ikenberg H, Koldovsky U, Schnurch HG and zur Hausen H. Human papillomavirus types 6 and 11 DNA sequences in genital and laryngeal papillomas and in some cervical cancers. Proc Natl Acad Sci U S A 1983; 80: 560-563.

17 Durst M, Gissmann L, Ikenberg H and zur Hausen H. A papillomavirus DNA from a cervical carcinoma and its prevalence in cancer biopsy samples from different geographic regions. Proc Natl Acad Sci U S A 1983; 80: 3812-3815.

18 Boshart M, Gissmann L, Ikenberg H, Kleinheinz A, Scheurlen W and zur Hausen H. A new type of papillomavirus DNA, its presence in genital cancer biopsies and in cell lines derived from cervical cancer. EMBO J 1984; 3: 1151-1157. 
19 Syrjanen K, Syrjanen S and Pyrhonen S. Human papilloma virus (HPV) antigens in lesions of laryngeal squamous cell carcinomas. ORL J Otorhinolaryngol Relat Spec 1982; 44: 323-334.

20 Syrjanen K, Pyrhonen S, Aukee S and Koskela E. Squamous cell papilloma of the esophagus: a tumor probably caused by human papilloma virus (HPV). Diagn Histopathol 1982; 5: 291-296.

21 Syrjanen K, Syrjanen S, Lamberg M, Pyrhonen S and Nuutinen J. Morphological and immunohistochemical evidence suggesting human papillomavirus (HPV) involvement in oral squamous cell carcinogenesis. Int J Oral Surg 1983; 12: 418-424.

22 Kiyabu MT, Shibata D, Arnheim N, Martin WJ and Fitzgibbons PL. Detection of human papillomavirus in formalin-fixed, invasive squamous carcinomas using the polymerase chain reaction. Am J Surg Pathol 1989; 13: 221-224.

23 Gillison ML, Koch WM, Capone RB, Spafford M, Westra WH, Wu L et al. Evidence for a causal association between human papillomavirus and a subset of head and neck cancers. J Natl Cancer Inst 2000; 92: 709-720.

24 Hafkamp HC, Speel EJ, Haesevoets A, Bot FJ, Dinjens WN, Ramaekers FC et al. A subset of head and neck squamous cell carcinomas exhibits integration of HPV 16/18 DNA and overexpression of $p 16^{\text {INK4A }}$ and $p 53$ in the absence of mutations in $p 53$ exons 5-8. Int J Cancer 2003; 107: 394-400.

25 Kreimer AR, Clifford GM, Boyle P and Franceschi S. Human papillomavirus types in head and neck squamous cell carcinomas worldwide: a systematic review. Cancer Epidemiol Biomarkers Prev 2005; 14: $467-475$.

26 Harald zur Hausen - Facts. Nobelprize.org. Nobel Media AB 2013; http://www.nobelprize.org/nobel_prizes/medicine/laureates/2008/hausen-facts.html.

27 D'Souza G, Agrawal Y, Halpern J, Bodison S and Gillison ML. Oral sexual behaviors associated with prevalent oral human papillomavirus infection. J Infect Dis 2009; 199: 1263-1269.

28 Hernandez BY, Wilkens LR, Zhu X, Thompson P, McDuffie K, Shvetsov YB et al. Transmission of human papillomavirus in heterosexual couples. Emerg Infect Dis 2008; 14: 888-894.

29 Merckx M, Liesbeth WV, Arbyn M, Meys J, Weyers S, Temmerman M et al. Transmission of carcinogenic human papillomavirus types from mother to child: a meta-analysis of published studies. Eur J Cancer Prev 2013; 22: 277-285.

30 Rombaldi RL, Serafini EP, Mandelli J, Zimmermann E and Losquiavo KP. Transplacental transmission of human papillomavirus. Virol J 2008; 5: 106.

31 Chen AC, Keleher A, Kedda MA, Spurdle AB, McMillan NA and Antonsson A. Human papillomavirus DNA detected in peripheral blood samples from healthy Australian male blood donors. J Med Virol 2009; 81: 1792-1796.

32 Munger K, Baldwin A, Edwards KM, Hayakawa H, Nguyen CL, Owens Met al. Mechanisms of human papillomavirus-induced oncogenesis. J Virol 2004; 78: 11451-11460.

33 Doorbar J. Molecular biology of human papillomavirus infection and cervical cancer. Clin Sci 2006; 110: $525-541$.

34 von Knebel Doeberitz M. Papillomaviruses in human disease: Part II. Molecular biology and immunology of papillomavirus infections and carcinogenesis. Eur J Med 1992; 1: 485-491. 
35 Bernard BA, Bailly C, Lenoir MC, Darmon M, Thierry F and Yaniv M. The human papillomavirus type 18 (HPV18) E2 gene product is a repressor of the HPV18 regulatory region in human keratinocytes. J Virol 1989; 63: 4317-4324.

36 Hwang ES, Riese DJ, 2nd, Settleman J, Nilson LA, Honig J, Flynn S et al. Inhibition of cervical carcinoma cell line proliferation by the introduction of a bovine papillomavirus regulatory gene. $J$ Virol 1993; 67: 3720-3729.

37 Thierry F and Howley PM. Functional analysis of E2-mediated repression of the HPV18 P105 promoter. New Biol 1991; 3: 90-100.

38 Jeon S, Allen-Hoffmann BL and Lambert PF. Integration of human papillomavirus type 16 into the human genome correlates with a selective growth advantage of cells. J Virol 1995; 69: 2989-2997.

39 Rampias T, Sasaki C, Weinberger P and Psyrri A. E6 and E7 gene silencing and transformed phenotype of human papillomavirus 16-positive oropharyngeal cancer cells. J Natl Cancer Inst 2009; 101: 412-423.

40 Mukherji SK, Armao D and Joshi VM. Cervical nodal metastases in squamous cell carcinoma of the head and neck: what to expect. Head Neck 2001; 23: 995-1005.

41 Ferlito A, Rinaldo A, Silver CE, Shah JP, Suarez C, Medina JE et al. Neck dissection: then and now. Auris Nasus Larynx 2006; 33: 365-374.

42 Takes RP. Staging of the neck in patients with head and neck squamous cell cancer: imaging techniques and biomarkers. Oral Oncol 2004; 40: 656-667.

43 Friesland S, Fernberg JO, Lundell G, Munck-Wikland E, Strander H and Lewensohn R. Prognostic impact of complete remission after preoperative irradiation of tonsillar carcinoma: a retrospective analysis of the radiumhemmet data, 1980-1995. Int J Radiat Oncol Biol Phys 1999; 45: 1259-1266.

44 al-Abdulwahed S, Kudryk W, al-Rajhi N, Hanson J, Jenkins H, Gaedke H et al. Carcinoma of the tonsil: prognostic factors. J Otolaryngol 1997; 26: 296-299.

45 Hafkamp HC, Manni JJ, Haesevoets A, Voogd AC, Schepers M, Bot FJ et al. Marked differences in survival rate between smokers and nonsmokers with HPV 16-associated tonsillar carcinomas. Int J Cancer 2008; 122: 2656-2664.

46 Vinokurova S, Wentzensen N, Kraus I, Klaes R, Driesch C, Melsheimer P et al. Type-dependent integration frequency of human papillomavirus genomes in cervical lesions. Cancer Res 2008; 68: $307-$ 313.

47 Mellin H, Dahlgren L, Munck-Wikland E, Lindholm J, Rabbani H, Kalantari M et al. Human papillomavirus type 16 is episomal and a high viral load may be correlated to better prognosis in tonsillar cancer. Int J Cancer 2002; 102: 152-158.

48 Mooren JJ, Kremer B, Claessen SM, Voogd AC, Bot FJ, Peter Klussmann J et al. Chromosome stability in tonsillar squamous cell carcinoma is associated with HPV16 integration and indicates a favorable prognosis. Int J Cancer 2013; 132: 1781-1789.

49 Olthof NC, Straetmans JM, Snoeck R, Ramaekers FC, Kremer B and Speel EJ. Next-generation treatment strategies for human papillomavirus-related head and neck squamous cell carcinoma: where do we go? Rev Med Virol 2012; 22: 88-105. 
50 Lassen P, Eriksen JG, Hamilton-Dutoit S, Tramm T, Alsner J and Overgaard J. HPV-associated p16expression and response to hypoxic modification of radiotherapy in head and neck cancer. Radiother Oncol 2010; 94: 30-35.

51 Mortensen LS, Johansen J, Kallehauge J, Primdahl H, Busk M, Lassen P et al. FAZA PET/CT hypoxia imaging in patients with squamous cell carcinoma of the head and neck treated with radiotherapy: results from the DAHANCA 24 trial. Radiother Oncol 2012; 105: 14-20. 



\section{Chapter 1}

\section{Next generation treatment strategies for human papillomavirus-related head and neck squamous cell carcinoma:}

where do we go?

Nadine C. Olthof ${ }^{1,2}$, Jos M.J.A.A. Straetmans ${ }^{1}$, Robert Snoeck ${ }^{3}$, Frans C.S. Ramaekers' ${ }^{2}$, Bernd Kremer ${ }^{1}$ and Ernst-Jan M. Spee ${ }^{2,4}$

Departments of ${ }^{1}$ Otorhinolaryngology and Head and Neck Surgery,

${ }^{2}$ Molecular Cell Biology and ${ }^{4}$ Pathology, GROW - School for Oncology and Developmental Biology, Maastricht University Medical Centre, Maastricht, the Netherlands,

${ }^{3}$ Rega Institute for Medical Research, Catholic University Leuven, Leuven, Belgium

Nadine C. Olthof, Jos M.J.A.A. Straetmans, Ernst-Jan M. Speel, and Bernd Kremer contributed equally to this work as first and last authors respectively 


\section{Abstract}

Oncogenic human papillomavirus (HPV) is currently recognised as a major risk factor for the development of head and neck squamous cell carcinomas (HNSCC). HPV is mostly detected in tumours arising from the oropharynx and more specifically from the tonsil. HPV-related tumours display clinical and molecular characteristics that are distinct from HPV-unrelated tumours, which are generally induced by alcohol and tobacco abuse. Detection of biologically active HPV in HNSCC has prognostic relevance, which warrants the separate classification of HPV-induced tumours, and is a prerequisite for further optimisation of treatment protocols for this distinct group. Current guidelines for the treatment of oropharyngeal squamous cell carcinoma (OPSCC) have not incorporated specific treatment modalities for HPV-related tumours. The development of such treatment options is still in a preclinical phase or in early clinical trials. Recent data on treatment response of OPSCC have been obtained by retrospectively analysing HPVstatus and indicate that patients with HPV-related tumours show a favourable prognosis, independent of the type of treatment. These patients may benefit from de-intensified treatment, which should be assessed in prospective clinical trials. The development and future use of new antiviral and immunomodulatory therapeutics may be instrumental in this approach to improve survival rates and decrease disease- and treatment-related morbidity. In this review we will focus on present therapeutic HPV-targeting strategies and discuss future directions for de-intensified treatment of HPV-positive HNSCC. 


\section{Introduction}

Head and neck cancer is a serious health care problem in many parts of the world ${ }^{1}$. The vast majority of head and neck cancers are squamous cell carcinomas originating from the mucosal epithelium lining the oral cavity, nasal cavity, pharynx and larynx ${ }^{2}$. In 2008, head and neck squamous cell carcinomas (HNSCC) were estimated to cause 480.000 new cancer cases and 273.000 cancer deaths worldwide ${ }^{1}$. Despite the fact that advances have been made in diagnosis and treatment, mortality rates have only marginally decreased over the last decades and the 5-year survival rate currently ranges between $40 \%-60 \%{ }^{3}$. Approximately $80 \%-90 \%$ of HNSCC develop in patients with a history of alcohol and tobacco abuse, including tobacco and betel quid chewing and snuff dipping ${ }^{4}$. These factors are also responsible for the process of "field cancerization" in the entire head and neck region ${ }^{5}$, leading to multiple primary tumours in up to $40 \%$ of patients ${ }^{6}$. Patients without exposure to these risk factors account for 10-20\% of HNSCC. These tumours are predominantly associated with viral carcinogenesis, including infection with EBV in nasopharyngeal carcinomas ${ }^{7}$ and, to a greater extent, infection with oncogenic human papillomavirus (HPV) in the oropharynx, in particular in the lingual and palatine tonsils. In the last decade the incidence of HPV-related oropharyngeal squamous cell carcinoma (OPSCC) has increased relative to the total group of $\mathrm{HNSCC}^{4,8}$. Infection rates in OPSCC range from 20 to more than $90 \%$ in different studies, depending on geographical factors and the detection method used ${ }^{9-12}$.

In this review we will present the clinical and molecular features of HPV-positive HNSCC. Subsequently we will focus on the current knowledge of potential anti-HPV strategies and discuss the most promising modalities for the treatment of HPV-positive HNSCC.

\section{Methods}

Besides relevant articles selected from the general literature concerning HPV-related carcinogenesis and references therein, specific literature on treatment options for HPV-related HNSCC was obtained by a bibliographical search in Pubmed, Medline and Embase, from inception to May 2011, using the search term (HPV OR papillomavirus OR papilloma) AND (HNSCC OR "head and neck cancer" OR oropharyngeal OR oropharynx OR oral OR pharyngeal OR pharynx OR buccal OR base of tongue OR tongue OR tonsillar OR tonsil OR floor of mouth OR mouth OR vallecula) AND (treatment OR antiviral OR therapy) AND (cancer OR carcinoma OR tumor OR tumor OR neoplasm). This search yielded 1246 results in PubMed, 137 in Medline and 309 in Embase. Based on inspection of the title and/or abstract of these publications, 63 relevant papers on treatment options and some references therein were included in this review. Moreover, ongoing clinical 
trials concerning new therapeutic options for HPV-related HNSCC were identified from the Cochrane Controlled Trial Register and from the US National Institute of Health Clinical Trials (www.clinicaltrials.gov), yielding 5 relevant results.

\section{HPV and tumourigenesis}

\section{Human papillomavirus}

HPVs are non-enveloped viruses, containing circular double-stranded DNA of approximately $8 \mathrm{~kb}$, that are highly epitheliotropic and known to infect both mucosal and cutaneous epithelia ${ }^{13}$. Papillomaviruses are species-specific and the human papillomavirus family can be classified into 5 genera and subdivided into 31 species and 120 types $^{14}$. A subgroup of $15 \mathrm{HPV}$ types is linked to the development of malignant lesions of mucosal and cutaneous epithelia, and is considered to comprise high-risk (HR) HPVs ${ }^{15}$. All HRHPVs belong to the alpha-genus, including HPV-16 and - 18 which are found in $~ 50 \%$ and $\sim 20 \%$ of cervical malignancies, respectively ${ }^{16}$. Differences in the capacity to deregulate cellular protein function by viral oncogenes E6 and E7 account for the carcinogenic properties of HR-HPV in comparison with low risk (LR) HPV ${ }^{17,18}$. LR-HPV types, such as HPV-6 and -11, are often found in benign mucosal lesions and are only sporadically associated with carcinomas. Human lesions in which HPV types of the alpha-genus appear to be involved are summarised in table 1 .

\section{Human papillomavirus replication and integration}

The HPV life cycle is linked to the differentiation of the infected epithelial cell. HPV infection is initiated by binding of the virion L1 protein to heparan sulphate proteoglycans (HSPG) on segments of the basement membrane, which are exposed at sites of (micro) injury. This induces conformational changes and L2 cleavage finally resulting in binding of the L1 capsid protein to a so far undetermined cell surface receptor ${ }^{19}$. The cell adhesion receptor a6-integrin has been implicated to be this receptor ${ }^{20}$, but does not seem to be essential for HPV infection. However, a6-integrin might be a matrix component closely associated with $\mathrm{HSPG}^{21}$. The circular HPV DNA codes for 6 early (E) and 2 late (L) proteins (figure 1). The E-proteins regulate and facilitate virus-replication and are expressed early after infection ${ }^{22}$. Oncoproteins E6 and E7 have a direct effect on several essential cellular processes, such as cell cycle and apoptosis regulation. E6 promotes degradation of p53 through interaction with E6-associated protein (E6AP), an E3 ubiquitin ligase, and subsequent ubiquitination and proteasomal degradation. Amongst others, this alters transcription of p53 target genes and activates human telomerase reverse transcriptase (hTERT), resulting in cell survival and ultimately in genetic instability ${ }^{23,24}$. The oncopro- 
tein E7 binds to the unphosphorylated retinoblastoma tumor suppressor protein (pRb), which promotes the release of transcription factor E2F, leading to activation of the cell cycle and transition through the G1/S-phase, needed for DNA-replication ${ }^{25-27}$.

As a consequence, $\mathrm{p} 16^{\mathrm{INK} 4 \mathrm{~A}}$ is upregulated but is unable to properly inhibit the cell cycle. Expression of oncoproteins E6 and E7 is tightly regulated by E2, the main regulator of viral gene transcription ${ }^{28}$. Molecular studies have shown that integration of HPV often leads to a disruption in the E1/E2 open reading frame, and concurrent loss of the E4 and E5 and parts of the $E 2$ and $L 2$ genes $^{29}$. E2 function can moreover be abrogated by epigenetic alterations of the viral genome such as methylation of the E2 binding site in the long control region $^{30}$. Absence of $\mathrm{E} 2$ function results in upregulation of the expression of oncoproteins E6 and E7, which in turn leads to uncontrolled cell cycle progression (see figure 1).

The major structural protein L1 of the HPV capsid is sufficient for self-assembly into a capsid, but entry of the virus into the cell is co-dependent on L2, the minor structural protein ${ }^{19,31}$.

Under normal circumstances HPV maintains an episomal state, and infection with HPV is transient. In a recent prospective cohort study, the reported average duration of active episomal infection in the uterine cervix appears to be approximately 8 months $\mathrm{s}^{32}$. Although uterine cervical HPV infection prevalence decreases with increasing age ${ }^{33}$, it is unclear whether age affects the duration of infection. Persistent infection, however, might lead to integration of the virus ${ }^{34,35}$. 
Table 1. Involvement of HPV-types of the alpha-genus in benign and malignant human lesions. The major HPV types for the different lesions are indicated in bold.

\begin{tabular}{|c|c|c|}
\hline Lesion & HPV types found & References \\
\hline \multicolumn{3}{|l|}{ Head and neck benign } \\
\hline Focal Epithelial Hyperplasia & 13,32 & {$[176,177]$} \\
\hline Sinonasal papilloma & $6,11,18$ & {$[178,179]$} \\
\hline Laryngeal papilloma and dysplasia & $\mathbf{6}^{1)}, \mathbf{1 1}, 16,18$ & {$[180,181]$} \\
\hline Oral leukoplakia and lichen planus & $6,16,18,31,33$ & {$[182,183]$} \\
\hline \multicolumn{3}{|l|}{ Head and neck malignant } \\
\hline Oropharyngeal squamous cell carcinoma & $6,11,16,18,31,33,35$ & [52], this review \\
\hline Oral squamous cell carcinoma & 16,18 & {$[52,60]$} \\
\hline Laryngeal squamous cell carcinoma & $6,11,16,30$ & {$[52,60]$} \\
\hline Sinonasal carcinoma & 16,18 & {$[179]$} \\
\hline \multicolumn{3}{|l|}{ Anogenital } \\
\hline Anogenital $^{2)}$ benign lesions ${ }^{3)}$ & $6,11,16,18,31,33,56,56,58,66,70$ & {$[36,184]$} \\
\hline Anogenital $^{2)}$ (squamous cell) carcinoma & $6,11,16,18,31,33,45$ & {$[36,184]$} \\
\hline $\begin{array}{l}\text { Cervical intraepithelial neoplasia and } \\
\text { uterine cervical squamous cell carcinoma }\end{array}$ & $\begin{array}{l}6,11,16,18,31,33,35,39,45,51 \\
52,56,58,59,66,68,70,73,82\end{array}$ & {$[16,37]$} \\
\hline $\begin{array}{l}\text { Adenocarcinoma in situ and uterine } \\
\text { cervical adenocarcinoma }\end{array}$ & $\mathbf{1 6}, \mathbf{1 8}, 33,35,45,51,58,59$ & {$[185,186]$} \\
\hline \multicolumn{3}{|l|}{ Cutaneous } \\
\hline Common skin warts & $2,3,7,10,27,28$ & {$[15,187]$} \\
\hline Periungual squamous cell carcinoma & $16,26,33,51,56,73$ & {$[188,189]$} \\
\hline
\end{tabular}

1) The major HPV types for the different lesions are indicated in bold; ${ }^{2)}$ including anal, vulvar, vaginal and penile lesions; ${ }^{3)}$ including warts, lichen sclerosis, squamous cell carcinoma in situ, adenocarcinoma in situ and intraepithelial neoplasia.

Numerous investigations have shown an etiological relationship between infection with HR-HPV infection and the development of uterine cervical squamous cell carcinomas (UCSCC) and other anogenital squamous cell carcinomas ${ }^{36,37}$. More than $90 \%$ of UCSCC contain and express HR-HPV sequences, which are predominantly present in an integrated form ${ }^{38,39}$. HPV-16 is the most common HPV type and is detected in more than $50 \%$ of UCSCC, followed by HPV-18, -33 and $-45^{37,40}$ (table 1 ).

The precise relationship between HR-HPV integration and head and neck carcinogenesis is less clear, partly because primary premalignant lesions of the oropharynx are seldom detected. Although controversial data have been reported ${ }^{41-44}$, integration of HR-HPV in OPSCC is a prevailing finding. 


\section{HR-HPV in HNSCC}

Patients with a history of HPV-related anogenital carcinomas, patients seropositive for HPV-16, and husbands of patients diagnosed with uterine cervical dysplasia or carcinoma in situ all show increased risk rates for developing OPSCC ${ }^{45-47}$.

The involvement of HPV in head and neck tumourigenesis was first proposed by Syrjänen et al. $^{48}$, who showed histopathological features of HPV infections in $40 \%$ of patients, and HPV-positive nuclei in $20 \%$ of patients using immunohistochemistry. Since then many studihave provided evidence that infection with HR-HPV is a significant independent risk factor for HNSCC and is associated with high risk sexual behaviour $^{9,10,49-51}$. HR-HPV positive tumours are most frequently found in the oropharynx, and are associated with HPV-16 in $>90 \%$ of cases $^{9,49,52,53}$. Because patients with OPSCC often present with metastatic disease at first diagnosis, information on the persistence of oropharyngeal HPV infections and premalignant lesions in this region is scarce ${ }^{54-56}$. HPV prevalences of less than $1 \%$ have been found in tumor-negative tonsillar tissue samples, screened for HPV with PCR ${ }^{51,57,58}$.

\section{HR-HPV detection and tumor characteristics}

The reported overall incidence of HPV in OPSCC ranges from less than $20 \%$ to more than $90 \%$ in different studies. This variation depends on several factors, including geographical features, sample preparation and detection methods used, but also the amount and manner of tobacco consumption depending on geographical location ${ }^{9,12,54,59-61}$. It has been shown that not all tumours tested positive for HPV DNA can be regarded as etiologically HPV-related ${ }^{50,62}$. A clinically relevant infection, i.e. a transcriptionally active infection should be present, which can be demonstrated by detectable expression of the viral oncogenes $E 6$ and $E 7^{63}$. This correlates strongly with overexpression of the CDK inhibitor p16 ${ }^{\mathrm{INK} 4 \mathrm{~A}}$, which is considered a reliable surrogate marker for HR-HPV infection in most cases $^{41,64}$. A reliable algorithm for HPV detection should thus start with p16 $6^{\mathrm{INK} 4 \mathrm{~A}}$ detection, followed by in situ hybridisation (ISH) and/or RT-PCR analysis of E6/E7 transcripts after HPV typing ${ }^{41}$, as suggested by two recent reports ${ }^{59,65}$. A representative example of these analyses is shown in figure 2 .

HPV-associated OPSCC are now considered to comprise a separate entity with typical clinical and molecular features. Table 2 summarises the major differences between $\mathrm{HPV}$-positive and -negative OPSCC.

HPV-positive OPSCC are characterised by overexpression of oncoproteins E6 and E7 leading to degradation of p53 and pRb, thereby inducing cell cycle and apoptosis deregulation. As a result, CDK inhibitors including $\mathrm{p} 16^{\mathrm{INK} 4 \mathrm{~A}}, \mathrm{p} 14^{\mathrm{ARF}}, \mathrm{p} 18^{\mathrm{INK} 4 \mathrm{C}}$ and $\mathrm{p} 21^{\mathrm{Cip} 1 / \mathrm{WAF} 1}$ are upregulated, which subsequently leads to downregulation of cyclin D1 and inhibition of complex formation with CDK42,62,66,67. In HPV-negative tumours cell cycle deregula- 


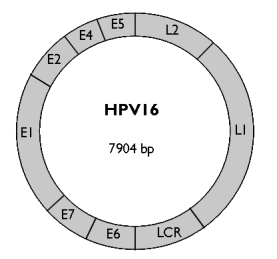

\section{Integrated HPV}

Genomic integration:

- Opening of circular DNA within E2

- E4, E5 and parts of E2 and L2 often deleted

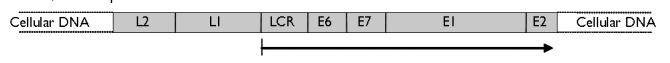

Replication
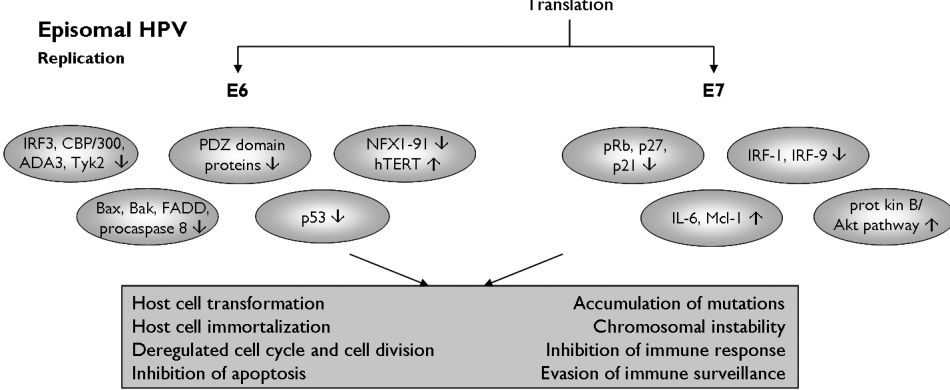

Figure 1. Structure of circular episomal and linear integrated HPV DNA. The HPV genome is usually present in many episomal copies in the nucleus of infected cells. In the transition to cancer, viral DNA often integrates in 1 or more copies into the host genomic DNA. During this process, the ring structure of the HPV-DNA molecule is most often opened within the E2 reading frame, frequently leading to deletion of E4 and E5 and part of E2 and L2. The subsequent upregulation of E6 and E7 oncoproteins results in deregulation of cell signalling pathways which, amongst others, leads to increased cellular proliferation and inhibition of apoptosis. Based on [172-175].
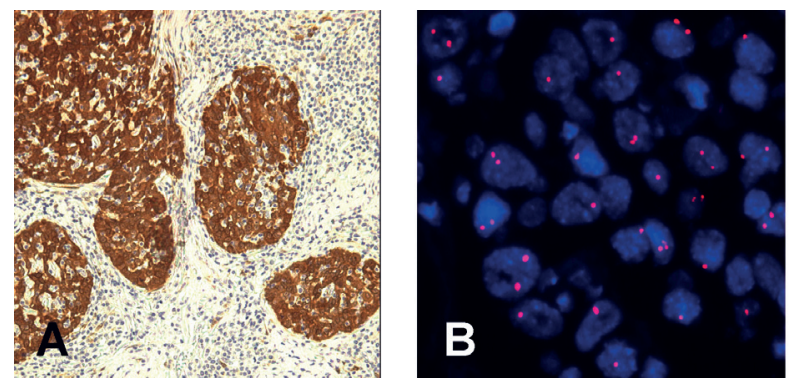

M 123345678

Figure 2. Representative examples of strong nuclear and cytoplasmic p $16^{\mathrm{INK} 4 \mathrm{~A}}$ immunostaining (A) and punctate nuclear HPV-16 FISH signals indicating viral integration (B) shown on paraffin embedded, formalin fixed tissue sections of OPSCC. An example of E6-specific HPV-16 RT-PCR products on a 1\% agarose gel, on RNA extracted from cell lines and fresh-frozen OPSCC tumor tissues, are shown in (C). 
tion is established by $p 53$ and $p R b$ gene mutations, or alternatively by inactivation of $p 16^{I N K 4 A}$ and $p 14^{A R F}$ gene expression through mutation, promoter hypermethylation or homozygous deletion ${ }^{22}$, or activation of cyclin D1 expression via 11q13 amplification ${ }^{68}$. High expression of EGFR by transcriptional upregulation is generally present in this OPSCC subgroup ${ }^{22,56,62,66-68}$. Upregulation of EGFR expression is usually not seen in HPVpositive OPSCC ${ }^{56,67,69-71}$.

In addition, global genome and protein scanning approaches have been and are being used to unravel DNA, mRNA, microRNA and protein signatures specific for HPVpositive and - negative OPSCC. So far these studies revealed that HPV-positive tumours exhibit a relatively stable genome with $11 \mathrm{q}$ and $16 \mathrm{q} \operatorname{loss}^{72-74}$, and upregulate transcriptional activity of cell cycle regulators (as mentioned above), transcription factors (e.g. TFDP2, ZNF238, TAF7L and RPA2) and DNA repair proteins (e.g. RFC4 and RFC5). Also, HPVpositive tumours show decreased expression of genes involved in immune responses (e.g. IFIT1, IFITM1-3, IFI6-16, IFI44L, OAS2, and IFN- $\kappa)^{68,75-79}$. In addition, these tumours differentially express microRNAs, and for example upregulate miR-363 (belonging to the oncogenic miR-106a-363 cluster), and downregulate miR-218 . A recent proteome analysis comparing HPV-positive and -negative oral squamous cell carcinomas (OSCC) reported upregulation of thioredoxin and epidermal-fatty acid binding protein ${ }^{80}$. Thioredoxin is an important redox-mediator that stimulates cell growth and inhibits apoptosis under adverse conditions, apparently including HPV infections, as also seen in cervical carcinomas. Epidermal fatty-acid binding protein, although mainly involved in fatty acid uptake, transport and metabolism, also functions in cellular signalling, affecting differentiation, growth regulation and gene expression ${ }^{80}$. Although expression of 3q-specific genes has been reported as being specific for HPV-positive OPSCC, this finding remains to be confirmed, since extra copies of 3q-genes have been found in both HPV-positive and -negative tumours ${ }^{68,77}$.

\section{Current treatment of OPSCC and effect of HR-HPV status on treatment response}

\section{Current treatment modalities}

Current international clinical guidelines for HNSCC treatment mention HPV as a risk factor for OPSCC. The American National Comprehensive Cancer Network has suggested to include HPV detection in the diagnostic work-up of these tumours ${ }^{81}$. However, the treatment guidelines do not offer therapeutic modalities specific for HPV-related tumours. Current therapeutic options include surgery, radiotherapy chemotherapy (CT), immunomodulatory therapies or combinations of the foregoing. Surgery as primary treatment avoids toxicity caused by radiotherapy and CT, but causes loss of function, par- 
ticularly in patients with larger tumours. The development of laser surgery and transoral robotic surgery (TORS) for OPSCC reduces functional morbidity as a consequence of three-dimensional visualization and the ability to manipulate and perform reconstruction of the oropharynx without the need for an open surgical approach ${ }^{82,83}$. Regional infiltration of critical structures, and thus unacceptable loss of function after surgery can classify a tumor as functionally or technically unresectable. In those cases radiotherapy and/or CT is the treatment of choice ${ }^{84}$ when aiming at restoring function, however with the disadvantage of therapy-related local and systemic side effects ${ }^{85}$. The final choice of treatment is based upon clinical variables such as tumor type, localisation and stage ${ }^{86}$, age of the patient, general medical and psychomedical condition ${ }^{81}$ and individual preferences of the patient.

\section{Effect of HR-HPV status on outcome}

In retrospective studies, HR-HPV- and/or $p 16^{\mathrm{INK} 4 \mathrm{a}}$ positive tumours have been found to respond better to multimodal therapies as compared to HPV-negative tumours, thereby favouring patient survival ${ }^{41,42,53,64,87,88}$. More recent retrospective studies have shown that this favourable outcome is independent of treatment modalities ${ }^{89-95}$. However, the heterogeneity of the HNSCC patient populations, and consequent variability with regard to the HPV and/or p16 ${ }^{\mathrm{INK} 4 \mathrm{~A}}$ status, as well as applied treatment protocols has most probably negatively influenced the association between HR-HPV status and outcome in these studies. It can be anticipated that the actual difference in clinical outcome between HPV-positive and -negative cases will become even more pronounced when comparing a homogeneous population of OPSCC and application of reliable detection methods for clinically relevant HPV-infections. Prospective clinical trials are required to further validate HR-HPV presence as predictive factor for therapy outcome and to determine whether treatment de-intensification might improve quality of life while preserving the favourable clinical outcome in HPV-positive OPSCC patients ${ }^{96,97}$.

An explanation for the favourable response may lie in the fact that, although the pRb- and p53-pathways are compromised in HPV-positive tumours, they retain some function, such that under the pressure of radiotherapy and/or CT, p53-mediated apoptotic pathways may still function. The presence of wild-type p53 in combination with low levels of Bcl-2/Bcl-xL and EGFR, which are features of HPV-positive tumours in nonsmokers, may enhance this treatment advantage ${ }^{9,53,63,67,69,71}$. Moreover, limited tobacco and/or alcohol use reduces field cancerisation and the chance of developing a second primary tumor or distant metastasis in HPV-positive tumours ${ }^{41,53,93}$, which underscores the need to investigate the effect of tobacco and alcohol exposure on the biological behaviour of HPV-positive OPSCC, as recently proposed ${ }^{41,94}$.

Besides the overall better survival of patients with HPV-positive tumours, their treatment may be further improved by the implementation of strategies that either 1) promote 
the immune response to eradicate the virus, 2) inhibit viral DNA replication, 3) specifically target viral oncoproteins or 4) have an effect on deregulated signal transduction pathways specific for HPV-positive tumor cells. In the following section we review these strategies, their mode of action and possible benefits for patients with HPV-induced HNSCC.

\title{
Prophylactic and therapeutic alternatives for HPV-positive OPSCC
}

\author{
Immunomodulating therapies
}

\section{Vaccination}

Two prophylactic vaccines, containing recombinant virus-like particles (VLP) composed of the L1 proteins of the respective HPV types ${ }^{31}$, have been marketed recently, i.e. Cervarix ${ }^{\circledast}$ (GlaxoSmithKline) and Gardasil ${ }^{\circledR}$ (Merck). Both vaccines have been FDA-approved for use in girls and young women ${ }^{98,99}$ and Gardasil ${ }^{\circledR}$ has also been approved for use in men ${ }^{100}$.

Cervarix $^{\oplus}$ is a bivalent vaccine that protects against infection with HPV-16 and -18 whereas the quadrivalent vaccine Gardasil $^{\circledR}$ provides protection against HPV-6, -11, -16 and -18

Reports indicate that Cervarix also offers cross-protection against HPV-31, -45 and $-52^{101,102}$, and Gardasil possibly against HPV-31 ${ }^{103}$. More robust cross-protection may be induced by adding $L 2$ minor capsid proteins to the vaccine ${ }^{104}$. Both vaccines induce high antibody titers, seem to be well-tolerated and safe and provide $>90 \%$ protection in HPV-16 and -18 naïve females when given in three doses within six months ${ }^{102,105}$. Currently only young HPV-naïve females are vaccinated, since vaccination of women actively expressing HPV-16 or -18 at study entry did not result in decreased development of cervical intraepithelial neoplasia (CIN) lesions ${ }^{102,105}$ However, vaccination with Gardasil ${ }^{\circ}$ also provided $>90 \%$ protection in women with evidence of past infection (seropositive and HPV DNA negative) with one or more of the HPV-types against which the vaccine is directed ${ }^{106,107}$. Long-term benefits of vaccination are not yet known, but it is hypothesised that vaccination could also strongly reduce the number of HPV-related OPSCC. This would indicate that HPV-naive boys and young men should be vaccinated as well, since HPV-related OPSCC is diagnosed in males more often than in females ${ }^{61,69}$. However, seeing that patients usually present with HPV-related head and neck tumours from the fifth decennium of life onwards, the efficiency of vaccination in these patients will only become evident within a few decades.

Patients with HPV-related disease may benefit from the development of therapeutic vaccines. These vaccines are designed to induce cell-mediated immunity against 
the overexpressed foreign viral oncoproteins, particularly E6 and E7. There are four classes of therapeutic vaccines: 1) live-vector based, 2) peptide/protein based, 3) nucleic acid based and 4) whole cell vaccines (for a comprehensive review see ${ }^{108}$ ). In anogenital and uterine cervical lesions therapeutic vaccination has shown to generate specific immunological and clinical responses, including complete regression of the lesion in $22 \%$ of patients with CIN III lesions as reported in a study using a fusion-protein based vaccine ${ }^{109-111}$. A preclinical study using a DNA-based vaccine demonstrated that such an approach for therapeutic vaccination efficacious in a mouse model of HPV-related HN$\mathrm{SCC}^{112}$. Clinical trials to evaluate the effectiveness of therapeutic vaccination in HPVrelated HNSCC are ongoing ${ }^{113,114}$.

\section{Interferon}

Interferons (IFNs) are cytokines that are produced by many cell types in response to infection with bacteria, viruses and parasites ${ }^{115}$. Two classes of IFNs can be distinguished: class I consists of IFN- $\alpha$ and $-\beta$ and class II of IFN $\gamma$. Class I IFNs are secreted from infected cells and bind to the ubiquitously expressed heterodimeric interferon receptor. Binding of IFN $\alpha / \beta$ to the interferon receptor induces the transcription of several host cell proteins that inhibit viral replication in the infected epithelial cell, and leads to activation and the production of IFN $\gamma$ in dendritic cells. IFN $\gamma$ can also be produced by activated Th1 cells. Both classes of IFNs possess antiviral and antiproliferative properties. IFN $\gamma$ can also activate macrophages and natural killer lymphocytes, and induce translocation of the major histocompatibility complex class I and II to the cell membrane ${ }^{115}$. The interferon response, however, is suppressed upon HPV infection, because several HPV proteins (E1, E6 and E7) interfere with the IFN signal transduction cascade by binding to e.g. Tyk2 kinase, IRF-1 and -3, p48 and p56, leading to downregulation of the levels of IFN-inducible genes such as TNSFS10, IFIT1 and IFI54 ${ }^{78,116,117}$.

Despite this, a successful immune response to HPV is generally seen in healthy individuals, as for example reported in the studies of van der Burg and co-workers ${ }^{118,119}$, showing high frequencies of circulating CD4+ T-helper cells reacting with HPV16 E2 and E6, indicating a cell-mediated Th1 immune response. In persisting lesions, application of IFN therapy may restore antiviral defence mechanisms, thereby supporting effective treatment of HPV-infected lesions. IFN therapy proved to be beneficial in HPV infections like condylomata acuminata ${ }^{119,120}$, while the use of IFN therapy in HPV-associated anogenital intraepithelial neoplasia has been assessed in several studies with contradicting results. Improved outcome for IFN-treated patients was shown in some studies $^{121,122}$, while others reported no change in response rates between treated patients and controls ${ }^{123,124}$. This might be attributed to the fact that local application seems to achieve better responses than systemic application ${ }^{120}$. In addition, it seems that IFN therapy can eradicate episomal HPV infection, but leads to growth advantage for cells containing 
integrated $\mathrm{HPV}^{125,126}$. IFN-induced upregulation of p56, which blocks HPV replication by binding to the E1 protein and inhibits its helicase activity, may explain this effect on episomal infection ${ }^{127,128}$. Loss of (parts of) E1 and E2 by viral integration, resulting in upregulation of E6 and E7 as stated above, could explain the lack of effect of IFN treatment in these cells and their selective growth advantage. On the contrary, IFN was also shown to increase viral early gene transcription in a cell model ${ }^{129}$. In recurrent respiratory papillomatosis (RRP) a long-term response to IFN- $\alpha$ therapy was seen in patients with HPV-6 related papillomas, but patients with HPV-11 related papillomas were much less responsive to IFN therapy ${ }^{130}$. In conclusion, the beneficial effects of IFN therapy seem to be limited to episomal infections, which limits the applicability of this therapy in HPVpositive carcinomas.

\section{Antiviral therapy}

\section{Cidofovir}

Cidofovir [(S)-1-(3-hydroxy-2-phosphonylmethoxypropyl)cytosine] (HPMPC) is a nucleoside analogue of deoxycitidine monophosphate with a remarkably broad spectrum of antiviral activities directed against DNA viruses, including HPV and polyoma ${ }^{131}$. After intracellular double phosphorylation the structure resembles dCTP and can act as a competitive substrate. After removal of the diphosphate group cidofovir can be incorporated into viral DNA during replication, resulting in selective antiviral activity for those viruses encoding their own DNA polymerase. Viral DNA polymerases, of for instance cytomegalovirus, display greater affinity for cidofovir than human cellular DNA polymerases. Although HPVs do not produce viral DNA polymerases, cells infected with HPV show enhanced susceptibility to cidofovir-induced apoptosis as compared to non-infected cells for a yet unknown reason ${ }^{132,133}$.

In 1998 it was shown by Andrei et al. that acyclic nucleoside phosphonate (ANP) analogues such as cidofovir show a selective antiproliferative effect in HPV-bearing tumor cell lines CK-1, SiHa, CaSki and $\mathrm{HeLa}^{134}$.This effect is partly induced by its nonselective toxicity to rapidly dividing cells ${ }^{134,135}$. Apoptosis might also be induced by accumulation of the tumor suppressor proteins $\mathrm{p} 53$ and p $21^{\mathrm{Cip} 1 / \mathrm{WAF} 1} 132,133$, although an increase in $p 53$ expression was not found in the HNSCC cell line UPCI:SCC090 ${ }^{136}$. However, by combining cidofovir with radiotherapy, the radiosensitivity of UPCI:SCC090 and other HPV-containing cell lines could be enhanced in vitro ${ }^{132,136}$, as well as in vivo in nude mouse xenografts ${ }^{132}$. CT combined with cidofovir also yielded a synergystic effect in an HNSCC cell line model ${ }^{137}$. One study expressed concern about using cidofovir for the treatment of $\mathrm{RRP}^{138}$, as it demonstrated high malignancy transformation rates in rats and cell lines. In humans this effect has not been reported, and cidofovir is already applied as an effective adjuvant therapy for HPV-induced RRP in humans ${ }^{139}$. 
For the treatment of various HPV-related lesions the route of administration may be an important factor. Cidofovir can be applied systemically or topically or injected intralesionally. Although concern was raised about possible nephrotoxicity in systemic use, this side-effect can be greatly diminished by administration of probenecid and prehydration with saline solution ${ }^{140}$.

In a clinical setting it was shown that local therapy with cidofovir gel resulted in complete or partial regression of uterine CIN II and III lesions ${ }^{141,142}$ as well as vulvar and other intraepithelial neoplasms ${ }^{143,144}$. On the other hand, intralesional treatment with cidofovir of one patient with an invasive carcinoma in the respiratory tract and a history of RRP only lead to minor clinical effects, limited to the superficial portion of the tumour ${ }^{145}$.

Clinical trials using cidofovir as an adjuvant therapy in cervical cancer have start$\mathrm{ed}^{146}$, but trials for its application in HNSCC have to be initiated.

\section{Interfering RNAs}

RNA interference (RNAi) can be used to inactivate gene expression and so far encouraging results have been reported for the treatment of HPV-related carcinomas in vitro as well as in vivo. Chen and co-workers, for example, reported a $50 \%$ reduction of E7 mRNA expression in HPV-6b/11 E7-expressing mouse tumor models ${ }^{147}$. RNAi against HPV-16 E6 and/or E7 has been shown to degrade these mRNAs leading to decreased expression of the gene products in both cervical as well as HNSCC cell line models. This resulted in restoration of $\mathrm{pRb}$ function and upregulation of $\mathrm{p} 53$ and $\mathrm{p} 21^{\text {Cip1/WAF1 }}$, leading to substantial apoptotic cell death ${ }^{148-150}$. RNAi against HPV-18 E6 and E7 has also seem to possess antitumour activity by retarding the growth of HeLa-cell induced tumours in NOD-SCID mice ${ }^{151}$ and to enhance the chemotherapeutic effect of cisplatin in HeLa cells in vitro ${ }^{152}$.

\section{Molecular therapy based on cellular targets}

Because inactivated tumor suppressor gene products such as $p 53$ and $p 16^{I N K 4 A}$ are difficult to restore by molecular therapy, many studies have focussed on the identification of oncogenes and deregulated cell signalling pathways in HNSCC. Key pathways involved in HNSCC include EGFR, PI3K-PTEN-AKT, TGF $\beta$ and NF- $\kappa B$ signalling, for which inhibitors are available, for example the anti-EGFR antibody cetuximab ${ }^{153}$, or being tested in several clinical trials (for reviews, see $^{72,73}$ ).

In cervical cancer EGFR overexpression has been shown to negatively affect overall survival in patients treated with $\mathrm{RT}^{154}$. Anti-EGFR therapy using cetuximab lead to a therapeutic response in $12.5 \%$ of patients with uterine cervical SCC ${ }^{155}$. Also in HNSCC, including HPV-positive OPSCC, overexpression of EGFR correlates with poor progno$\operatorname{sis}^{67,70,71}$, although only a small subgroup of HPV-positive OPSCC exhibit EGFR protein 
accumulation $^{67,71}$. Large prospective trials with anti-EGFR therapy in HPV-positive HNSCC have been initiated ${ }^{97}$, although its efficacy is most probably limited to the small subgroup of EGFR-expressing tumours.

Alternatively, the PI3K-PTEN-AKT pathway might be an efficient target because HPV-positive OPSCC show extra copies of chromosome $3 q$ in up to two-thirds of cases $^{68}$, including the 3q26 locus, harbouring the PI3K gene.

Tumor angiogenesis and metastases are correlated to upregulation of the TGF- $\beta$ and $N F \kappa B$ pathways ${ }^{156,157}$. HPV positive OPSCC have been shown to metastasise in an earlier stage compared to HPV negative OPSCC ${ }^{158}$, indicating earlier endothelial-tomesenchymal transition (EMT), which is characterised by the expression of vimentin, dowregulation of E-cadherin and upregulation of $\beta$-catenin ${ }^{159}$. This suggests that EMT might be related to upregulation of these pathways and that particularly HPV-positive OPSCC might be a potentially interesting group for $N F \kappa B$-inhibitors, for which a clinical trial has recently started ${ }^{160}$.

Increased degradation of cell cycle regulatory proteins $\mathrm{p} 53$ and $\mathrm{pRb}$ by the oncoproteins E6 and E7, can be inhibited by targeting the proteasomal pathway. Ritonavir, a protease inhibitor (PI) that is used in HIV-infected patients, inhibits the chemotryptic activity of the human cellular $20 \mathrm{~S}$ proteasome while increasing the tryptic activity ${ }^{161}$, resulting in reduced protein degradation. It was shown to enhance antitumour activity when combined with RT both in vitro and in vivo in a Hep- 2 head and neck carcinoma model ${ }^{161}$, later however shown to be contaminated with Hela cells. The PI Lopinavir was shown to restore p53 expression and to induce apoptosis in SiHa cells ${ }^{162}$. Athough several clinical trials have evaluated the effectiveness of PIs in the treatment of HIV, clinical trials in the treatment of HPV-related disease have not been initiated.

Finally, replication of the HPV virus can be targeted. In episomal HPV infection, replication is initiated by binding of E2 to its origin of replication ${ }^{54}$. In human transcription factors the most commonly found DNA binding motifs are zinc fingers. Recently, artificial zinc fingers (AZF) have been developed as a potent new inhibitor of HPV ${ }^{163}$. When linked to a cell-penetrating peptide (CPP) these AZF were shown to inhibit HPV18 for $97 \%{ }^{164}$. However, since the CPP-AZF are designed to prevent E2 from binding to its origin of replication, they are only effective in episomal HV infection.

\section{Discussion}

The past decade has provided evidence for a biological association between oncogenic HPV and OPSCC. HPV-induced OPSCC show molecular and clinical features that are clearly different from tobacco- and alcohol-induced tumours and these differences seem to underlie prognostic differences between both tumor subgroups. Independent of treatment modality, patients with HPV-positive tumours demonstrate up to $30 \%$ better 
survival rates. In the past decennia intensification of treatment was the most important strategy to improve survival of patients with HNSCC. However intensification of treatment, combined with increased side effects, is finally reaching the maximum tolerance of the patient and this limits the intensity of treatment. Until now, no differentiation of therapeutic strategies is made between the HPV-positive and -negative subgroups in international guidelines on OPSCC treatment ${ }^{81}$. Because of the clinical and molecular differences between both groups the question arises whether HPV-positive tumours need equally intensive treatment protocols as their HPV-negative counterparts. Moreover, additional antiviral therapeutic strategies can possibly improve survival without increasing therapy-related morbidity in HPV-positive tumours. In current and future studies we should therefore aim at improving the quality of life in patients by de-intensification regimens in selected cases. Next-generation treatment strategies for HPV-associated cancers should focus on decreasing adjuvant radio- and chemotherapy, whether or not combined with therapeutic options specifically targeting HPV. Assessing which therapy is most effective will finally lead to a more personalised approach for individual patients.

Immunomodulating therapies like IFN therapy seem to have beneficial effects, but this seems to be limited to episomal infections. This conveys the need to reliably establish the integration status of HPV infection. That this criterion has not yet been met becomes apparent when observing the reported integration frequencies, which range from 0 to $100 \%$, depending on the population studied and methods used ${ }^{41,42}$.

Tumor-specific host responses could also be enhanced by depletion of CD4+/ $\mathrm{CD} 25+$ regulatory $\mathrm{T}$-cells $\left(\mathrm{T}_{\text {regs }}\right)$. Increased expression of $\mathrm{T}_{\text {regs }}$ was shown in patients with $\mathrm{CIN}$ and cervical cancer ${ }^{165,166}$. It is hypothesised that the enlarged population of $\mathrm{T}_{\text {regs }}$ suppresses HPV-specific immunity and inhibits tumor-specific T-cell responses. Upregulated $\mathrm{T}_{\text {regs }}$ have already been depleted using an anti-CD25 antibody, such as PC61 ${ }^{167}$.

Other immunomodulating therapies such as imiquimod, a topical immune response modifier that has successfully been used in the treatment of anogenital lesions with episomal HPV infections ${ }^{168}$, are thought to be unsuitable for application in HPVrelated HNSCC and RRP. Application to cutaneous epithelia is known to induce local inflammatory responses and pain, which will be enhanced in mucosal epithelia. Moreover, the substance cannot be controlled to reach all tumor parts when topically applied, and, like IFN-therapy, will at best lead to eradication of only episomal HPV infections, whereas a large proportion of HPV-positive HNSCC show viral integration ${ }^{169}$.

Antiviral therapies such as cidofovir and RNAi have already shown promising results and are expected to have progressive impact on the treatment of HPV-associated lesions. Cidofovir has been tested in cervical cancers and RRP, where it has been applied topically or intralesionally in most studies. It has been shown that combining IFN therapy with cidofovir could enhance the antiviral and antiproliferative effects of either substance alone, and it is postulated that adding IFN therapy could further improve the auspicious 
effects of cidofovir combined with $\mathrm{CT}$ and/or $\mathrm{RT}^{170}$. Furthermore, it is recommended to assess the effects of cidofovir as adjuvant therapy in the treatment of HPV-associated HNSCC in a larger, prospective clinical trial.

RNAi treatment, although tested in mouse models, has not yet been evaluated for use in human HPV-associated HNSCC. Such studies can, however, be expected in the near future, judging from patents referring to the use of oligonucleotides in the treatment of HPV infections (see for example ${ }^{171}$ ).

Therapeutic approaches based on the molecular profile of the tumours are emerging in an adjuvant setting. However, one of the major drawbacks of such an approach is that the applicability should be assessed for each individual patient. For example cetuximab can only be applied in a small subgroup of patients with HNSCC, since HPV-positive tumours tend to show a low EGFR expression. In the current practice Cetuximab is already used for larger, non-resectable head and neck tumors, irrespective of HPV status. With regard to PIs and AZFs, no clinical studies have yet tested the applicability of these therapeutic options in the treatment of HPV-related carcinomas.

Since therapeutic vaccination is expected to have minimal side effects it can be combined with other therapeutic approaches, such as RT and/or CT, to obtain synergistic effects. However, therapeutic vaccines are still in a developmental stage.

Although a significant reduction in the burden of HPV-related diseases can be anticipated if prophylactic vaccination will live up to its promises, only HPV-naïve females are currently vaccinated. We firmly believe that young HPV-naïve boys should also be vaccinated in order to achieve optimal protection, although it needs to be validated whether vaccination is cost-effective.

In conclusion we can state that, although is has become evident that HPV-positive HNSCC have a better prognosis that their HPV-negative counterparts, the choice of therapy for these two subgroups of HNSCC will strongly depend on the outcome of ongoing clinical trials, including de-intensification protocols and implementation of treatment options based on new insights into the molecular biology of HPV-infection. 


\section{References}

1 Ferlay J, Shin HR, Bray F, Forman D, Mathers C and Parkin DM. Estimates of worldwide burden of cancer in 2008: GLOBOCAN 2008. Int J Cancer 2010; 127: 2893-2917.

2 Johnson N, Franceschi S, Ferlay J, Ramadas K, Schmid S, MacDonald D et al. in Pathology and Genetics Head and Neck Tumours World Health Organization Classification of Tumours (eds Barnes L, Eveson J, Reichart P, \& Sidransky D) Ch. 4, 163-208 (IARC Press, 2005).

3 Jemal A, Siegel R, Ward E, Hao Y, Xu J, Murray T et al. Cancer statistics, 2008. CA Cancer J Clin 2008; 58: 71-96.

4 Sturgis EM and Cinciripini PM. Trends in head and neck cancer incidence in relation to smoking prevalence: an emerging epidemic of human papillomavirus-associated cancers? Cancer 2007; 110: 1429-1435.

5 Braakhuis BJ, Tabor MP, Kummer JA, Leemans CR and Brakenhoff RH. A genetic explanation of Slaughter's concept of field cancerization: evidence and clinical implications. Cancer Res 2003; 63: 1727-1730.

6 Haughey BH, Gates GA, Arfken CL and Harvey J. Meta-analysis of second malignant tumors in head and neck cancer: the case for an endoscopic screening protocol. Ann Otol Rhinol Laryngol 1992; 101: 105-112.

7 Pattle SB and Farrell PJ. The role of Epstein-Barr virus in cancer. Expert Opin Biol Ther 2006; 6: 1193 1205.

8 Carvalho AL, Nishimoto IN, Califano JA and Kowalski LP. Trends in incidence and prognosis for head and neck cancer in the United States: a site-specific analysis of the SEER database. Int J Cancer 2005; 114: 806-816.

9 Hafkamp HC, Speel EJ, Haesevoets A, Bot FJ, Dinjens WN, Ramaekers FC et al. A subset of head and neck squamous cell carcinomas exhibits integration of HPV 16/18 DNA and overexpression of $p 16^{I N K 4 A}$ and $p 53$ in the absence of mutations in $p 53$ exons 5-8. Int J Cancer 2003; 107: 394-400.

10 Ragin CC and Taioli E. Survival of squamous cell carcinoma of the head and neck in relation to human papillomavirus infection: review and meta-analysis. Int J Cancer 2007; 121: 1813-1820.

11 Fakhry C and Gillison ML. Clinical implications of human papillomavirus in head and neck cancers. J Clin Oncol 2006; 24: 2606-2611.

12 Nasman A, Attner P, Hammarstedt L, Du J, Eriksson M, Giraud G et al. Incidence of human papillomavirus (HPV) positive tonsillar carcinoma in Stockholm, Sweden: an epidemic of viral-induced carcinoma? Int J Cancer 2009; 125: 362-366.

13 de Villiers EM, Fauquet C, Broker TR, Bernard HU and zur Hausen H. Classification of papillomaviruses. Virology 2004; 324: 17-27.

14 Bernard HU, Burk RD, Chen Z, van Doorslaer K, Hausen H and de Villiers EM. Classification of papillomaviruses (PVs) based on 189 PV types and proposal of taxonomic amendments. Virology 2010; 401: 70-79.

15 World Health Organization. IARC Monographs on the evaluation of carcinogenic risks to humans: Human papillomaviruses. Vol. 90 47-63 Internation Agency for Research on Cancer, 2007. 
16 Munoz N, Bosch FX, de Sanjose S, Herrero R, Castellsague X, Shah KV et al. Epidemiologic classification of human papillomavirus types associated with cervical cancer. N Engl J Med 2003; 348: 518-527.

17 Hiller T, Poppelreuther S, Stubenrauch F and Iftner T. Comparative analysis of 19 genital human papillomavirus types with regard to $p 53$ degradation, immortalization, phylogeny, and epidemiologic risk classification. Cancer Epidemiol Biomarkers Prev 2006; 15: 1262-1267.

18 Pim D and Banks L. Interaction of viral oncoproteins with cellular target molecules: infection with high-risk vs low-risk human papillomaviruses. APMIS 2010; 118: 471-493.

19 Schiller JT, Day PM and Kines RC. Current understanding of the mechanism of HPV infection. Gynecol Oncol 2010; 118: S12-17.

20 Yoon CS, Kim KD, Park SN and Cheong SW. alpha(6) Integrin is the main receptor of human papillomavirus type 16 VLP. Biochem Biophys Res Commun 2001; 283: 668-673.

21 Horvath CA, Boulet GA, Renoux VM, Delvenne PO and Bogers JP. Mechanisms of cell entry by human papillomaviruses: an overview. Virol J 2010; 7: 11.

22 zur Hausen H. Papillomaviruses and cancer: from basic studies to clinical application. Nat Rev Cancer $2002 ; 2: 342-350$.

23 McMurray HR and McCance DJ. Human papillomavirus type 16 E6 activates TERT gene transcription through induction of c-Myc and release of USF-mediated repression. J Virol 2003; 77: 9852-9861.

24 Liu X, Dakic A, Zhang Y, Dai Y, Chen R and Schlegel R. HPV E6 protein interacts physically and functionally with the cellular telomerase complex. Proc Natl Acad Sci U S A 2009; 106: 18780-18785.

25 Funk JO, Waga S, Harry JB, Espling E, Stillman B and Galloway DA. Inhibition of CDK activity and PCNA-dependent DNA replication by $p 21$ is blocked by interaction with the HPV-16 E7 oncoprotein. Genes Dev 1997; 11: 2090-2100.

26 Jones DL, Alani RM and Munger K. The human papillomavirus E7 oncoprotein can uncouple cellular differentiation and proliferation in human keratinocytes by abrogating $p 21 \mathrm{Cip} 1$-mediated inhibition of CDK2. Genes Dev 1997; 11: 2101-2111.

27 Zerfass-Thome K, Zwerschke W, Mannhardt B, Tindle R, Botz JW and Jansen-Durr P. Inactivation of the cdk inhibitor p27KIP1 by the human papillomavirus type 16 E7 oncoprotein. Oncogene 1996; 13: 2323-2330.

28 Dowhanick JJ, McBride AA and Howley PM. Suppression of cellular proliferation by the papillomavirus E2 protein. J Virol 1995; 69: 7791-7799.

29 Ziegert C, Wentzensen N, Vinokurova S, Kisseljov F, Einenkel J, Hoeckel M et al. A comprehensive analysis of HPV integration loci in anogenital lesions combining transcript and genome-based amplification techniques. Oncogene 2003; 22: 3977-3984.

30 Park IS, Chang X, Loyo M, Wu G, Chuang A, Kim MS et al. Characterization of the methylation patterns in human papillomavirus type 16 viral DNA in head and neck cancers. Cancer Prev Res (Phila) 2011; 4: 207-217.

31 Stanley MA. Human papillomavirus vaccines. Rev Med Virol 2006; 16: 139-149.

32 Goodman MT, Shvetsov YB, McDuffie K, Wilkens LR, Zhu X, Thompson PJ et al. Prevalence, acquisition, and clearance of cervical human papillomavirus infection among women with normal cytology: Hawaii human papillomavirus cohort study. Cancer Res 2008; 68: 8813-8824. 
33 Bosch FX, Lorincz A, Munoz N, Meijer CJ and Shah KV. The causal relation between human papillomavirus and cervical cancer. J Clin Pathol 2002; 55: 244-265.

34 Hopman AH, Smedts F, Dignef W, Ummelen M, Sonke G, Mravunac M et al. Transition of high-grade cervical intraepithelial neoplasia to micro-invasive carcinoma is characterized by integration of HPV 16/18 and numerical chromosome abnormalities. J Pathol 2004; 202: 23-33.

35 Vinokurova S, Wentzensen N, Kraus I, Klaes R, Driesch C, Melsheimer P et al. Type-dependent integration frequency of human papillomavirus genomes in cervical lesions. Cancer Res 2008; 68: $307-$ 313.

36 De Vuyst H, Clifford GM, Nascimento MC, Madeleine MM and Franceschi S. Prevalence and type distribution of human papillomavirus in carcinoma and intraepithelial neoplasia of the vulva, vagina and anus: a meta-analysis. Int J Cancer 2009; 124: 1626-1636.

37 Smith JS, Lindsay L, Hoots B, Keys J, Franceschi S, Winer R et al. Human papillomavirus type distribution in invasive cervical cancer and high-grade cervical lesions: a meta-analysis update. Int J Cancer 2007; 121: 621-632.

38 Cricca M, Morselli-Labate AM, Venturoli S, Ambretti S, Gentilomi GA, Gallinella G et al. Viral DNA load, physical status and E2/E6 ratio as markers to grade HPV16 positive women for high-grade cervical lesions. Gynecol Oncol 2007; 106: 549-557.

39 Guo M, Sneige N, Silva EG, Jan YJ, Cogdell DE, Lin E et al. Distribution and viral load of eight oncogenic types of human papillomavirus (HPV) and HPV 16 integration status in cervical intraepithelial neoplasia and carcinoma. Mod Pathol 2007; 20: 256-266.

40 Sigurdsson K, Taddeo FJ, Benediktsdottir KR, Olafsdottir K, Sigvaldason H, Oddsson K et al. HPV genotypes in CIN 2-3 lesions and cervical cancer: a population-based study. Int J Cancer 2007; 121: 2682-2687.

41 Hafkamp HC, Manni JJ, Haesevoets A, Voogd AC, Schepers M, Bot FJ et al. Marked differences in survival rate between smokers and nonsmokers with HPV 16-associated tonsillar carcinomas. Int $J$ Cancer 2008; 122: 2656-2664.

42 Mellin H, Dahlgren L, Munck-Wikland E, Lindholm J, Rabbani H, Kalantari M et al. Human papillomavirus type 16 is episomal and a high viral load may be correlated to better prognosis in tonsillar cancer. Int J Cancer 2002; 102: 152-158.

43 Koskinen WJ, Chen RW, Leivo I, Makitie A, Back L, Kontio R et al. Prevalence and physical status of human papillomavirus in squamous cell carcinomas of the head and neck. Int J Cancer 2003; 107: 401-406.

44 Ukpo OC, Moore EJ and Smith DI. Human papillomavirus and oropharyngeal cancer. N Engl J Med 2007; 357: 1156-1157; author reply 1157-1158.

45 Frisch M and Biggar RJ. Aetiological parallel between tonsillar and anogenital squamous-cell carcinomas. Lancet 1999; 354: 1442-1443.

46 Mork J, Lie AK, Glattre E, Hallmans G, Jellum E, Koskela P et al. Human papillomavirus infection as a risk factor for squamous-cell carcinoma of the head and neck. N Engl J Med 2001; 344: 1125-1131.

47 Hemminki K, Dong C and Frisch M. Tonsillar and other upper aerodigestive tract cancers among cervical cancer patients and their husbands. Eur J Cancer Prev 2000; 9: 433-437. 
48 Syrjanen K, Syrjanen S, Lamberg M, Pyrhonen S and Nuutinen J. Morphological and immunohistochemical evidence suggesting human papillomavirus (HPV) involvement in oral squamous cell carcinogenesis. Int J Oral Surg 1983; 12: 418-424.

49 Klussmann JP, Weissenborn SJ, Wieland U, Dries V, Kolligs J, Jungehuelsing M et al. Prevalence, distribution, and viral load of human papillomavirus 16 DNA in tonsillar carcinomas. Cancer 2001; 92 : 2875-2884.

50 van Houten VM, Snijders PJ, van den Brekel MW, Kummer JA, Meijer CJ, van Leeuwen B et al. Biological evidence that human papillomaviruses are etiologically involved in a subgroup of head and neck squamous cell carcinomas. Int J Cancer 2001; 93: 232-235.

51 D'Souza G, Agrawal Y, Halpern J, Bodison S and Gillison ML. Oral sexual behaviors associated with prevalent oral human papillomavirus infection. J Infect Dis 2009; 199: 1263-1269.

52 Kreimer AR, Clifford GM, Boyle P and Franceschi S. Human papillomavirus types in head and neck squamous cell carcinomas worldwide: a systematic review. Cancer Epidemiol Biomarkers Prev 2005; 14: 467-475.

53 Gillison ML, Koch WM, Capone RB, Spafford M, Westra WH, Wu L et al. Evidence for a causal association between human papillomavirus and a subset of head and neck cancers. J Natl Cancer Inst 2000; 92: 709-720.

54 McKaig RG, Baric RS and Olshan AF. Human papillomavirus and head and neck cancer: epidemiology and molecular biology. Head Neck 1998; 20: 250-265.

55 Chen R, Aaltonen LM and Vaheri A. Human papillomavirus type 16 in head and neck carcinogenesis. Rev Med Virol 2005; 15: 351-363.

56 Mooren JJ, Kremer B, Claessen SM, Voogd AC, Bot FJ, Peter Klussmann J et al. Chromosome stability in tonsillar squamous cell carcinoma is associated with HPV16 integration and indicates a favorable prognosis. Int J Cancer 2013; 132: 1781-1789.

57 Klingenberg B, Hafkamp HC, Haesevoets A, Manni JJ, Slootweg PJ, Weissenborn SJ et al. p16 ${ }^{\text {INK4A }}$ overexpression is frequently detected in tumor-free tonsil tissue without association with HPV. Histopathology 2010; 56: 957-967.

58 Herrero R, Castellsague X, Pawlita M, Lissowska J, Kee F, Balaram P et al. Human papillomavirus and oral cancer: the International Agency for Research on Cancer multicenter study. J Natl Cancer Inst 2003; 95: 1772-1783.

59 Smeets SJ, Hesselink AT, Speel EJ, Haesevoets A, Snijders PJ, Pawlita M et al. A novel algorithm for reliable detection of human papillomavirus in paraffin embedded head and neck cancer specimen. Int J Cancer 2007; 121: 2465-2472.

60 Lajer CB and von Buchwald C. The role of human papillomavirus in head and neck cancer. APMIS 2010; 118: 510-519.

61 Marur S, D'Souza G, Westra WH and Forastiere AA. HPV-associated head and neck cancer: a virusrelated cancer epidemic. Lancet Oncol 2010; 11: 781-789.

62 Wiest T, Schwarz E, Enders C, Flechtenmacher C and Bosch FX. Involvement of intact HPV16 E6/ E7 gene expression in head and neck cancers with unaltered $p 53$ status and perturbed $p R b$ cell cycle control. Oncogene 2002; 21: 1510-1517. 
63 Weinberger PM, Yu Z, Haffty BG, Kowalski D, Harigopal M, Brandsma J et al. Molecular classification identifies a subset of human papillomavirus--associated oropharyngeal cancers with favorable prognosis. J Clin Oncol 2006; 24: 736-747.

64 Klussmann JP, Gultekin E, Weissenborn SJ, Wieland U, Dries V, Dienes HP et al. Expression of p16 protein identifies a distinct entity of tonsillar carcinomas associated with human papillomavirus. Am J Pathol 2003; 162: 747-753.

65 Shi W, Kato H, Perez-Ordonez B, Pintilie M, Huang S, Hui A et al. Comparative prognostic value of HPV16 E6 mRNA compared with in situ hybridization for human oropharyngeal squamous carcinoma. J Clin Oncol 2009; 27: 6213-6221.

66 Hafkamp HC, Mooren JJ, Claessen SM, Klingenberg B, Voogd AC, Bot FJ et al. P21 Cip1/WAF1 expression is strongly associated with HPV-positive tonsillar carcinoma and a favorable prognosis. Mod Pathol 2009; 22: 686-698.

67 Reimers N, Kasper HU, Weissenborn SJ, Stutzer H, Preuss SF, Hoffmann TK et al. Combined analysis of HPV-DNA, 16 and EGFR expression to predict prognosis in oropharyngeal cancer. Int J Cancer 2007; 120: 1731-1738.

68 Klussmann JP, Mooren JJ, Lehnen M, Claessen SM, Stenner M, Huebbers CU et al. Genetic signatures of HPV-related and unrelated oropharyngeal carcinoma and their prognostic implications. Clin Cancer Res 2009; 15: 1779-1786.

69 Kumar B, Cordell KG, Lee JS, Worden FP, Prince ME, Tran HH et al. EGFR, p16, HPV Titer, Bcl-xL and $p 53$, sex, and smoking as indicators of response to therapy and survival in oropharyngeal cancer. J Clin Oncol 2008; 26: 3128-3137.

70 Kim SH, Koo BS, Kang S, Park K, Kim H, Lee KR et al. HPV integration begins in the tonsillar crypt and leads to the alteration of $p 16, E G F R$ and c-myc during tumor formation. Int J Cancer 2007; 120: 1418-1425.

71 Kong CS, Narasimhan B, Cao H, Kwok S, Erickson JP, Koong A et al. The relationship between human papillomavirus status and other molecular prognostic markers in head and neck squamous cell carcinomas. Int J Radiat Oncol Biol Phys 2009; 74: 553-561.

72 Leemans CR, Braakhuis BJ and Brakenhoff RH. The molecular biology of head and neck cancer. Nat Rev Cancer 2011; 11: 9-22.

73 Grimminger CM and Danenberg PV. Update of prognostic and predictive biomarkers in oropharyngeal squamous cell carcinoma: a review. Eur Arch Otorhinolaryngol 2011; 268: 5-16.

74 Jung AC, Briolat J, Millon R, de Reynies A, Rickman D, Thomas E et al. Biological and clinical relevance of transcriptionally active human papillomavirus (HPV) infection in oropharynx squamous cell carcinoma. Int J Cancer 2010; 126: 1882-1894.

75 Rincon-Orozco B, Halec G, Rosenberger S, Muschik D, Nindl I, Bachmann A et al. Epigenetic silencing of interferon-kappa in human papillomavirus type 16-positive cells. Cancer Res 2009; 69: 87188725.

76 Martinez I, Wang J, Hobson KF, Ferris RL and Khan SA. Identification of differentially expressed genes in HPV-positive and HPV-negative oropharyngeal squamous cell carcinomas. Eur J Cancer 2007; 43: 415-432. 
77 Slebos RJ, Yi Y, Ely K, Carter J, Evjen A, Zhang X et al. Gene expression differences associated with human papillomavirus status in head and neck squamous cell carcinoma. Clin Cancer Res 2006; 12: 701-709.

78 Schlecht NF, Burk RD, Adrien L, Dunne A, Kawachi N, Sarta C et al. Gene expression profiles in HPV-infected head and neck cancer. J Pathol 2007; 213: 283-293.

79 Wald AI, Hoskins EE, Wells SI, Ferris RL and Khan SA. Alteration of microRNA profiles in squamous cell carcinoma of the head and neck cell lines by human papillomavirus. Head Neck 2010; 33: $504-$ 512.

80 Melle C, Ernst G, Winkler R, Schimmel B, Klussmann JP, Wittekindt C et al. Proteomic analysis of human papillomavirus-related oral squamous cell carcinoma: identification of thioredoxin and epidermal-fatty acid binding protein as upregulated protein markers in microdissected tumor tissue. Proteomics 2009; 9: 2193-2201.

81 National Comprehensive Cancer Network (NCCN). Clinical practice guidelines in oncology - Head and Neck Cancers. v.2.2010, 22-26 (2010).

82 Moore EJ, Henstrom DK, Olsen KD, Kasperbauer JL and McGree ME. Transoral resection of tonsillar squamous cell carcinoma. Laryngoscope 2009; 119: 508-515.

83 Park YM, Lee JG, Lee WS, Choi EC, Chung SM and Kim SH. Feasibility of transoral lateral oropharyngectomy using a robotic surgical system for tonsillar cancer. Oral Oncol 2009; 45: e62-66.

84 Haigentz M, Jr., Silver CE, Corry J, Genden EM, Takes RP, Rinaldo A et al. Current trends in initial management of oropharyngeal cancer: the declining use of open surgery. Eur Arch Otorhinolaryngol 2009; 266: 1845-1855.

85 Corvo R. Evidence-based radiation oncology in head and neck squamous cell carcinoma. Radiother Oncol 2007; 85: 156-170.

86 Sobin L, Gosposarowics M and Wittekind C. in TNM Classification of malignant Tumors (ed O'sullivan B) 17-50 (Wiley-Blackwell, 2010).

87 Lindel K, Beer KT, Laissue J, Greiner RH and Aebersold DM. Human papillomavirus positive squamous cell carcinoma of the oropharynx: a radiosensitive subgroup of head and neck carcinoma. Cancer 2001; 92: 805-813.

88 Ringstrom E, Peters E, Hasegawa M, Posner M, Liu M and Kelsey KT. Human papillomavirus type 16 and squamous cell carcinoma of the head and neck. Clin Cancer Res 2002; 8: 3187-3192.

89 Fischer CA, Zlobec I, Green E, Probst S, Storck C, Lugli A et al. Is the improved prognosis of p16 positive oropharyngeal squamous cell carcinoma dependent of the treatment modality? Int J Cancer 2010; 126: 1256-1262.

90 Fallai C, Perrone F, Licitra L, Pilotti S, Locati L, Bossi P et al. Oropharyngeal squamous cell carcinoma treated with radiotherapy or radiochemotherapy: prognostic role of TP53 and HPV status. Int J Radiat Oncol Biol Phys 2009; 75: 1053-1059.

91 Lassen P, Eriksen JG, Hamilton-Dutoit S, Tramm T, Alsner J and Overgaard J. Effect of HPV-associated $p 16^{I N K 4 A}$ expression on response to radiotherapy and survival in squamous cell carcinoma of the head and neck. J Clin Oncol 2009; 27: 1992-1998. 
92 Fakhry C, Westra WH, Li S, Cmelak A, Ridge JA, Pinto H et al. Improved survival of patients with human papillomavirus-positive head and neck squamous cell carcinoma in a prospective clinical trial. J Natl Cancer Inst 2008; 100: 261-269.

93 Maxwell JH, Kumar B, Feng FY, Worden FP, Lee JS, Eisbruch A et al. Tobacco use in human papillomavirus-positive advanced oropharynx cancer patients related to increased risk of distant metastases and tumor recurrence. Clin Cancer Res 2010; 16: 1226-1235.

94 Ang KK, Harris J, Wheeler R, Weber R, Rosenthal DI, Nguyen-Tan PF et al. Human papillomavirus and survival of patients with oropharyngeal cancer. N Engl J Med 2010; 363: 24-35.

95 Lassen P. The role of human papillomavirus in head and neck cancer and the impact on radiotherapy outcome. Radiother Oncol 2010; 95: 371-380.

96 Psyrri A, Gouveris P and Vermorken JB. Human papillomavirus-related head and neck tumors: clinical and research implication. Curr Opin Oncol 2009; 21: 201-205.

97 Marur S. Paclitaxel, cisplatin, and cetuximab followed by cetuximab and intensity-modulated radiation therapy in treating patients with HPV-associated stage III or stage IV cancer of the oropharynx that can be removed by surgery. Available from: http://clinicaltrials.gov. Bethesda (MD): National Library of Medicine (US). March 2010. Identifier: NCT01084083

98 Centres for disease control and prevention (CDC). FDA licensure of bivalent human papillomavirus vaccine (HPV2, Cervarix) for use in females and updated HPV vaccination recommendations from the Advisory Committee on Immunization Practices (ACIP). MMWR Morb Mortal Wkly Rep 2010; 59: 626-629.

99 Markowitz LE, Dunne EF, Saraiya M, Lawson HW, Chesson H and Unger ER. Quadrivalent human papillomavirus vaccine: recommendations of the advisory committee on immunization practices (ACIP). MMWR Recomm Rep 2007; 56: 1-24.

100 Centres for disease control and prevention (CDC). FDA licensure of quadrivalent human papillomavirus vaccine (HPV4, Gardasil) for use in males and guidance from the Advisory Committee on Immunization Practices (ACIP). MMWR Morb Mortal Wkly Rep 2010; 59: 630-632.

101 Jenkins D. A review of cross-protection against oncogenic HPV by an HPV-16/18 AS04-adjuvanted cervical cancer vaccine: importance of virological and clinical endpoints and implications for mass vaccination in cervical cancer prevention. Gynecol Oncol 2008; 110: S18-25.

102 Paavonen J, Naud P, Salmeron J, Wheeler CM, Chow SN, Apter D et al. Efficacy of human papillomavirus (HPV)-16/18 AS04-adjuvanted vaccine against cervical infection and precancer caused by oncogenic HPV types (PATRICIA): final analysis of a double-blind, randomised study in young women. Lancet 2009; 374: 301-314.

103 Brown DR, Kjaer SK, Sigurdsson K, Iversen OE, Hernandez-Avila M, Wheeler CM et al. The impact of quadrivalent human papillomavirus (HPV; types 6, 11, 16, and 18) L1 virus-like particle vaccine on infection and disease due to oncogenic nonvaccine HPV types in generally HPV-naive women aged 16-26 years. J Infect Dis 2009; 199: 926-935.

104 Jagu S, Kwak K, Garcea RL and Roden RB. Vaccination with multimeric L2 fusion protein and L1 VLP or capsomeres to broaden protection against HPV infection. Vaccine 2010; 28: 4478-4486. 
105 Joura EA, Kjaer SK, Wheeler CM, Sigurdsson K, Iversen OE, Hernandez-Avila M et al. HPV antibody levels and clinical efficacy following administration of a prophylactic quadrivalent HPV vaccine. Vaccine 2008; 26: 6844-6851.

106 Olsson SE, Kjaer SK, Sigurdsson K, Iversen OE, Hernandez-Avila M, Wheeler CM et al. Evaluation of quadrivalent HPV 6/11/16/18 vaccine efficacy against cervical and anogenital disease in subjects with serological evidence of prior vaccine type HPV infection. Hum Vaccin 2009; 5: 696-704.

107 Munoz N, Manalastas Jr. R, Pitisuttithum P, Tresukosol D, Monsonego J, Ault K et al. Safety, immunogenicity, and efficacy of quadrivalent human papillomavirus (types $6,11,16,18$ ) recombinant vaccine in women aged 24-45 years: a randomised, double-blind trial. Lancet 2009; 373: 1949-1957.

108 Hung CF, Ma B, Monie A, Tsen SW and Wu TC. Therapeutic human papillomavirus vaccines: current clinical trials and future directions. Expert Opin Biol Ther 2008; 8: 421-439.

109 Einstein MH, Kadish AS, Burk RD, Kim MY, Wadler S, Streicher H et al. Heat shock fusion proteinbased immunotherapy for treatment of cervical intraepithelial neoplasia III. Gynecol Oncol 2007; 106: 453-460.

110 Santin AD, Bellone S, Palmieri M, Zanolini A, Ravaggi A, Siegel ER et al. Human papillomavirus type 16 and 18 E7-pulsed dendritic cell vaccination of stage IB or IIA cervical cancer patients: a phase I escalating-dose trial. J Virol 2008; 82: 1968-1979.

111 Trimble CL and Frazer IH. Development of therapeutic HPV vaccines. Lancet Oncol 2009; 10: 975 980.

112 Wu A, Zeng Q, Kang TH, Peng S, Roosinovich E, Pai SI et al. Innovative DNA vaccine for human papillomavirus (HPV)-associated head and neck cancer. Gene Ther 2011; 18: 304-312.

113 Edelman MJ. MAGE-A3/HPV 16 vaccine for squamous cell carcinoma of the head and neck. Available from: http://clinicaltrials.gov. Bethesda (MD): National Library of Medicine (US). November 2005. Identifier: NCT00257738.

114 Edelman MJ. Four doses of MAGE vaccine for patients with squamous cell carcinoma of the head and neck. Available from: http://clinicaltrials.gov. Bethesda (MD): National Library of Medicine (US). June 2008. Identifier: NCT00704041.

115 Mak T and Saunders M. in The immune response - basic and clinical principles (eds Picknett T \& Lebedeva V) Ch. 17, 464-517 (Elsevier Academic Press, 2006).

116 Beglin M, Melar-New M and Laimins L. Human papillomaviruses and the interferon response. J Interferon Cytokine Res 2009; 29: 629-635.

117 Nees M, Geoghegan JM, Hyman T, Frank S, Miller L and Woodworth CD. Papillomavirus type 16 oncogenes downregulate expression of interferon-responsive genes and upregulate proliferationassociated and NF-kappaB-responsive genes in cervical keratinocytes. J Virol 2001; 75: 4283-4296.

118 de Jong A, van der Burg SH, Kwappenberg KM, van der Hulst JM, Franken KL, Geluk A et al. Frequent detection of human papillomavirus 16 E2-specific T-helper immunity in healthy subjects. Cancer Res 2002; 62: 472-479.

119 Welters MJ, de Jong A, van den Eeden SJ, van der Hulst JM, Kwappenberg KM, Hassane S et al. Frequent display of human papillomavirus type 16 E6-specific memory T-helper cells in the healthy population as witness of previous viral encounter. Cancer Res 2003; 63: 636-641. 
120 Yang J, Pu YG, Zeng ZM, Yu ZJ, Huang N and Deng QW. Interferon for the treatment of genital warts: a systematic review. BMC Infect Dis 2009; 9: 156.

121 Gonzalez-Sanchez JL, Martinez-Chequer JC, Hernandez-Celaya ME, Barahona-Bustillos E and Andrade-Manzano AF. Randomized placebo-controlled evaluation of intramuscular interferon beta treatment of recurrent human papillomavirus. Obstet Gynecol 2001; 97: 621-624.

122 Syed TA and Ahmadpour OA. Human leukocyte derived interferon-alpha in a hydrophilic gel for the treatment of intravaginal warts in women: a placebo-controlled, double-blind study. Int J STD AIDS 1998; 9: 769-772.

123 Bornstein J, Pascal B, Zarfati D, Goldshmid N and Abramovici H. Recombinant human interferon-beta for condylomata acuminata: a randomized, double-blind, placebo-controlled study of intralesional therapy. Int J STD AIDS 1997; 8: 614-621.

124 Yliskoski M, Syrjanen K, Syrjanen S, Saarikoski S and Nethersell A. Systemic alpha-interferon (Wellferon) treatment of genital human papillomavirus (HPV) type 6, 11, 16, and 18 infections: double-blind, placebo-controlled trial. Gynecol Oncol 1991; 43: 55-60.

125 Chang YE, Pena L, Sen GC, Park JK and Laimins LA. Long-term effect of interferon on keratinocytes that maintain human papillomavirus type 31. J Virol 2002; 76: 8864-8874.

126 Herdman MT, Pett MR, Roberts I, Alazawi WO, Teschendorff AE, Zhang XY et al. Interferon-beta treatment of cervical keratinocytes naturally infected with human papillomavirus 16 episomes promotes rapid reduction in episome numbers and emergence of latent integrants. Carcinogenesis 2006; 27: 2341-2353.

127 Saikia P, Fensterl V and Sen GC. The inhibitory action of P56 on select functions of E1 mediates interferon's effect on human papillomavirus DNA replication. J Virol 2010; 84: 13036-13039.

128 Terenzi F, Saikia P and Sen GC. Interferon-inducible protein, P56, inhibits HPV DNA replication by binding to the viral protein E1. EMBO J 2008; 27: 3311-3321.

129 Lace MJ, Anson JR, Klingelhutz AJ, Harada H, Taniguchi T, Bossler AD et al. Interferon-beta treatment increases human papillomavirus early gene transcription and viral plasmid genome replication by activating interferon regulatory factor (IRF)-1. Carcinogenesis 2009; 30: 1336-1344.

130 Gerein V, Rastorguev E, Gerein J, Jecker P and Pfister H. Use of interferon-alpha in recurrent respiratory papillomatosis: 20-year follow-up. Ann Otol Rhinol Laryngol 2005; 114: 463-471.

131 De Clercq E. Antiviral drug discovery and development: where chemistry meets with biomedicine. Antiviral Res 2005; 67: 56-75.

132 Abdulkarim B, Sabri S, Deutsch E, Chagraoui H, Maggiorella L, Thierry J et al. Antiviral agent Cidofovir restores $p 53$ function and enhances the radiosensitivity in HPV-associated cancers. Oncogene 2002; 21 : 2334-2346.

133 Andrei G, Snoeck R, Schols D and De Clercq E. Induction of apoptosis by cidofovir in human papillomavirus (HPV)-positive cells. Oncol Res 2000; 12: 397-408.

134 Andrei G, Snoeck R, Piette J, Delvenne P and De Clercq E. Antiproliferative effects of acyclic nucleoside phosphonates on human papillomavirus (HPV)-harboring cell lines compared with HPV-negative cell lines. Oncol Res 1998; 10: 523-531. 
135 Spanos WC, El-Deiry M and Lee JH. Cidofovir incorporation into human keratinocytes with episomal HPV 16 results in nonselective cytotoxicity. Ann Otol Rhinol Laryngol 2005; 114: 840-846.

136 Sirianni N, Wang J and Ferris RL. Antiviral activity of Cidofovir on a naturally human papillomavirus-16 infected squamous cell carcinoma of the head and neck (SCCHN) cell line improves radiation sensitivity. Oral Oncol 2005; 41: 423-428.

137 Park J, Kommareddi P, Nair T, Seo J, Jeon S, Kim S et al. in Proceedings of the American Association for Cancer Research.

138 Donne AJ, Hampson L, He XT, Day PJ, Salway F, Rothera MP et al. Potential risk factors associated with the use of cidofovir to treat benign human papillomavirus-related disease. Antivir Ther 2009; 14: 939-952.

139 Donne AJ, Rothera MP and Homer JJ. Scientific and clinical aspects of the use of cidofovir in recurrent respiratory papillomatosis. Int J Pediatr Otorhinolaryngol 2008; 72: 939-944.

140 Wolf DL, Rodriguez CA, Mucci M, Ingrosso A, Duncan BA and Nickens DJ. Pharmacokinetics and renal effects of cidofovir with a reduced dose of probenecid in HIV-infected patients with cytomegalovirus retinitis. J Clin Pharmacol 2003; 43: 43-51.

141 Snoeck R, Noel JC, Muller C, De Clercq E and Bossens M. Cidofovir, a new approach for the treatment of cervix intraepithelial neoplasia grade III (CIN III). J Med Virol 2000; 60: 205-209.

142 Van Pachterbeke C, Bucella D, Rozenberg S, Manigart Y, Gilles C, Larsimont D et al. Topical treatment of CIN 2+ by cidofovir: results of a phase II, double-blind, prospective, placebo-controlled study. Gynecol Oncol 2009; 115: 69-74.

143 Snoeck R, Bossens M, Parent D, Delaere B, Degreef H, Van Ranst M et al. Phase II double-blind, placebo-controlled study of the safety and efficacy of cidofovir topical gel for the treatment of patients with human papillomavirus infection. Clin Infect Dis 2001; 33: 597-602.

144 Tristram A and Fiander A. Clinical responses to Cidofovir applied topically to women with high grade vulval intraepithelial neoplasia. Gynecol Oncol 2005; 99: 652-655.

145 Petersen BL, Buchwald C, Gerstoft J, Bretlau P and Lindeberg H. An aggressive and invasive growth of juvenile papillomas involving the total respiratory tract. J Laryngol Otol 1998; 112: 1101-1104.

146 Deutsch E. Cidofovir in treating patients with stage IB, stage II, stage III, or stage IVA cervical cancer who are receiving chemotherapy and radiation therapy. Available from: http://clinicaltrials.gov. Bethesda (MD): National Library of Medicine (US). July 2009. Identifier: NCT00811408.

147 Chen XZ, Zhu KJ, Xu Y, Tang XY, Cai XZ, Zhang X et al. RNA interference silences the human papillomavirus 6b/11 early gene E7 in vitro and in vivo. Clin Exp Dermatol 2010; 35: 509-515.

148 Butz K, Ristriani T, Hengstermann A, Denk C, Scheffner M and Hoppe-Seyler F. siRNA targeting of the viral E6 oncogene efficiently kills human papillomavirus-positive cancer cells. Oncogene 2003; 22: 5938-5945.

149 Rampias T, Sasaki C, Weinberger P and Psyrri A. E6 and E7 gene silencing and transformed phenotype of human papillomavirus 16-positive oropharyngeal cancer cells. J Natl Cancer Inst 2009; 101: 412423.

150 Sima N, Wang W, Kong D, Deng D, Xu Q, Zhou J et al. RNA interference against HPV16 E7 oncogene leads to viral E6 and E7 suppression in cervical cancer cells and apoptosis via upregulation of $\mathrm{Rb}$ and p53. Apoptosis 2008; 13: 273-281. 
151 Yamato K, Yamada T, Kizaki M, Ui-Tei K, Natori Y, Fujino M et al. New highly potent and specific E6 and E7 siRNAs for treatment of HPV16 positive cervical cancer. Cancer Gene Ther 2008; 15: 140-153.

152 Putral LN, Bywater MJ, Gu W, Saunders NA, Gabrielli BG, Leggatt GR et al. RNA interference against human papillomavirus oncogenes in cervical cancer cells results in increased sensitivity to cisplatin. Mol Pharmacol 2005; 68: 1311-1319.

153 Merlano M, Russi E, Benasso M, Corvo R, Colantonio I, Vigna-Taglianti R et al. Cisplatin-based chemoradiation plus cetuximab in locally advanced head and neck cancer: a phase II clinical study. Ann Oncol 2011; 22: 712-717.

154 Gaffney DK, Haslam D, Tsodikov A, Hammond E, Seaman J, Holden J et al. Epidermal growth factor receptor (EGFR) and vascular endothelial growth factor (VEGF) negatively affect overall survival in carcinoma of the cervix treated with radiotherapy. Int J Radiat Oncol Biol Phys 2003; 56: 922-928.

155 Kummel S, Heidecke H, Brock B, Denkert C, Hecktor J, Koninger A et al. Imatinib--a possible therapeutic option for cervical carcinoma: results of a preclinical phase I study. Gynakol Geburtshilfliche Rundsch 2008; 48: 94-100.

156 Karin M and Greten FR. NF-kappaB: linking inflammation and immunity to cancer development and progression. Nat Rev Immunol 2005; 5: 749-759.

157 Molinolo AA, Amornphimoltham P, Squarize CH, Castilho RM, Patel V and Gutkind JS. Dysregulated molecular networks in head and neck carcinogenesis. Oral Oncol 2009; 45: 324-334.

158 Straetmans JM, Olthof N, Mooren JJ, de Jong J, Speel EJ and Kremer B. Human papillomavirus reduces the prognostic value of nodal involvement in tonsillar squamous cell carcinomas. Laryngoscope 2009; 119: 1951-1957.

159 Stenner M, Yosef B, Huebbers CU, Preuss SF, Dienes HP, Speel EJ et al. Nuclear translocation of betacatenin and decreased expression of epithelial cadherin in human papillomavirus-positive tonsillar cancer: an early event in human papillomavirus-related tumor progression? Histopathology 2011; 58: 1117-1126.

160 Soo KC. Study of post-op adjuvant concurrent chemo-RT with or without nimotuzumab for head \& neck cancer. Available from: http://clinicaltrials.gov. Bethesda (MD): National Library of Medicine (US). August 2009. Identifier: NCT00957086.

161 Schmidtke G, Holzhutter HG, Bogyo M, Kairies N, Groll M, de Giuli R et al. How an inhibitor of the HIV-I protease modulates proteasome activity. J Biol Chem 1999; 274: 35734-35740.

162 Hampson L, Kitchener HC and Hampson IN. Specific HIV protease inhibitors inhibit the ability of HPV16 E6 to degrade p53 and selectively kill E6-dependent cervical carcinoma cells in vitro. Antivir Ther 2006; 11: 813-825.

163 Mino T, Hatono T, Matsumoto N, Mori T, Mineta Y, Aoyama Y et al. Inhibition of DNA replication of human papillomavirus by artificial zinc finger proteins. J Virol 2006; 80: 5405-5412.

164 Mino T, Mori T, Aoyama Y and Sera T. Cell-permeable artificial zinc-finger proteins as potent antiviral drugs for human papillomaviruses. Arch Virol 2008; 153: 1291-1298.

165 Lepique AP, Daghastanli KR, Cuccovia IM and Villa LL. HPV16 tumor associated macrophages suppress antitumor T cell responses. Clin Cancer Res 2009; 15: 4391-4400. 
166 Visser J, Nijman HW, Hoogenboom BN, Jager P, van Baarle D, Schuuring E et al. Frequencies and role of regulatory T cells in patients with (pre)malignant cervical neoplasia. Clin Exp Immunol 2007; 150: 199-209.

167 Chuang CM, Hoory T, Monie A, Wu A, Wang MC and Hung CF. Enhancing therapeutic HPV DNA vaccine potency through depletion of CD4+CD25+ T regulatory cells. Vaccine 2009; 27: 684-689.

168 Mahto M, Nathan M and O'Mahony C. More than a decade on: review of the use of imiquimod in lower anogenital intraepithelial neoplasia. Int J STD AIDS 2010; 21: 8-16.

169 Lucker GP, Speel EJ, Creytens DH, van Geest AJ, Peeters JH, Claessen SM et al. Differences in imiquimod treatment outcome in two patients with bowenoid papulosis containing either episomal or integrated human papillomavirus 16. J Invest Dermatol 2007; 127: 727-729.

170 Benson J, Bramlage B, Fitzgerald K, Tan P, Vornlocher H-P, inventors; Alnylam Pharmaceuticals Inc., assignee. dsRNA compositions and methods for treating HPV infection. United States patent US 7956177. 2001 July 06.

171 Benson J, Bramlage B, Fitzgerald K, Tan P and Vornlocher H-P. dsRNA compositions and methods for treating HPV infection. United States patent (2011).

172 Doorbar J. Molecular biology of human papillomavirus infection and cervical cancer. Clin Sci (Lond) 2006; 110: 525-541.

173 Ganguly N and Parihar SP. Human papillomavirus E6 and E7 oncoproteins as risk factors for tumorigenesis. J Biosci 2009; 34: 113-123.

174 Hafkamp HC, Manni JJ and Speel EJ. Role of human papillomavirus in the development of head and neck squamous cell carcinomas. Acta Otolaryngol 2004; 124: 520-526.

175 Hamid NA, Brown C and Gaston K. The regulation of cell proliferation by the papillomavirus early proteins. Cell Mol Life Sci 2009; 66: 1700-1717.

176 Beaudenon S, Praetorius F, Kremsdorf D, Lutzner M, Worsaae N, Pehau-Arnaudet G et al. A new type of human papillomavirus associated with oral focal epithelial hyperplasia. J Invest Dermatol 1987; 88: 130-135.

177 Cuberos V, Perez J, Lopez CJ, Castro F, Gonzalez LV, Correa LA et al. Molecular and serological evidence of the epidemiological association of HPV 13 with focal epithelial hyperplasia: a case-control study. J Clin Virol 2006; 37: 21-26.

178 Altavilla G, Staffieri A, Busatto G, Canesso A, Giacomelli L and Marioni G. Expression of p53, p16 ${ }^{I N K 4 A}$, $p R b, p 21$ WAF1/CIP1, p27KIP1, cyclin D1, Ki-67 and HPV DNA in sinonasal endophytic Schneiderian (inverted) papilloma. Acta Otolaryngol 2009; 129: 1242-1249.

179 Syrjanen KJ. HPV infections in benign and malignant sinonasal lesions. J Clin Pathol 2003; 56: 174-181.

180 Goon P, Sonnex C, Jani P, Stanley M and Sudhoff H. Recurrent respiratory papillomatosis: an overview of current thinking and treatment. Eur Arch Otorhinolaryngol 2008; 265: 147-151.

181 Stamataki S, Nikolopoulos TP, Korres S, Felekis D, Tzangaroulakis A and Ferekidis E. Juvenile recurrent respiratory papillomatosis: still a mystery disease with difficult management. Head Neck 2007; 29: 155-162.

182 Campisi G, Giovannelli L, Arico P, Lama A, Di Liberto C, Ammatuna P et al. HPV DNA in clinically different variants of oral leukoplakia and lichen planus. Oral Surg Oral Med Oral Pathol Oral Radiol Endod 2004; 98: 705-711. 
183 Yang SW, Lee YS, Chen TA, Wu CJ and Tsai CN. Human papillomavirus in oral leukoplakia is no prognostic indicator of malignant transformation. Cancer Epidemiol 2009; 33: 118-122.

184 Giuliano AR, Tortolero-Luna G, Ferrer E, Burchell AN, de Sanjose S, Kjaer SK et al. Epidemiology of human papillomavirus infection in men, cancers other than cervical and benign conditions. Vaccine 2008; 26 Suppl 10: K17-28.

185 Bulk S, Berkhof J, Bulkmans NW, Zielinski GD, Rozendaal L, van Kemenade FJ et al. Preferential risk of HPV16 for squamous cell carcinoma and of HPV18 for adenocarcinoma of the cervix compared to women with normal cytology in The Netherlands. Br J Cancer 2006; 94: 171-175.

186 Castellsague X, Diaz M, de Sanjose S, Munoz N, Herrero R, Franceschi S et al. Worldwide human papillomavirus etiology of cervical adenocarcinoma and its cofactors: implications for screening and prevention. J Natl Cancer Inst 2006; 98: 303-315.

187 Severson J, Evans TY, Lee P, Chan T, Arany I and Tyring SK. Human papillomavirus infections: epidemiology, pathogenesis, and therapy. J Cutan Med Surg 2001; 5: 43-60.

188 Ashinoff R, Li JJ, Jacobson M, Friedman-Kien AE and Geronemus RG. Detection of human papillomavirus DNA in squamous cell carcinoma of the nail bed and finger determined by polymerase chain reaction. Arch Dermatol 1991; 127: 1813-1818.

189 Kreuter A, Gambichler T, Pfister H and Wieland U. Diversity of human papillomavirus types in periungual squamous cell carcinoma. Br J Dermatol 2009; 161: 1262-1269.

$190 \mathrm{Li}$ W, Thompson CH, O’Brien CJ, McNeil EB, Scolyer RA, Cossart YE et al. Human papillomavirus positivity predicts favourable outcome for squamous carcinoma of the tonsil. Int J Cancer 2003; 106: 553-558.

191 Mao L, Hong WK and Papadimitrakopoulou VA. Focus on head and neck cancer. Cancer Cell 2004; 5: 311-316.

192 Ritchie JM, Smith EM, Summersgill KF, Hoffman HT, Wang D, Klussmann JP et al. Human papillomavirus infection as a prognostic factor in carcinomas of the oral cavity and oropharynx. Int J Cancer 2003; 104: 336-344 


\title{
Chapter 2
}

\section{Human papillomavirus reduces the prognostic value of nodal involvement in tonsillar squamous cell carcinomas}

\author{
Nadine C. Olthof ${ }^{1,2}$, Jos M.J.A.A. Straetmans ${ }^{1}$, Jeroen J. Mooren ${ }^{1}$, Jos de Jong ${ }^{1,3}$, \\ Ernst-Jan M. Speel ${ }^{2,4}$ and Bernd Kremer ${ }^{1}$ \\ Departments of ${ }^{1}$ Otorhinolaryngology and Head and Neck Surgery, ${ }^{2}$ Molecular Cell Biology, \\ ${ }^{3}$ Radiotherapy and ${ }^{4}$ Pathology, GROW - School for Oncology and Developmental Biology, \\ Maastricht University Medical Centre, Maastricht, the Netherlands
}

Jos M.J.A.A. Straetmans, Nadine C. Olthof, Ernst-Jan M. Speel, and Bernd Kremer contributed equally to this work as first and last authors respectively 


\section{Abstract}

Objectives/Hypothesis: Assessment of the prognostic value of nodal status in relation to human papillomavirus (HPV) status and the various treatment modalities in tonsillar squamous cell carcinomas (TSCC).

Study design: Retrospective 5-year survival analysis.

Methods: A 5-year follow-up of disease-free, disease-specific, and overall survival in a group of 81 patients with TSCC was conducted. The nodal status and integration of HPV-DNA in the genome (detected with fluorescence in situ hybridization) as prognostic indicators were examined while correcting for other clinical parameters (smoking habits, alcohol consumption, treatment modality, differentiation, TNM classification).

Results: Of TSCCs, $41 \%$ were positive for HPV type 16. In these TSCCs, the primary tumor was significantly smaller when compared to HVP-negative TSCCs $(P=0.04)$, whereas the percentage of cases with cervical metastases was identical. In the total population, it was not nodal involvement, but rather HPV manifestation, which was related to patient prognosis. Within the treatment modalities (surgery combined with radiotherapy and radiotherapy alone), neither nodal status nor HPV were prognostic indicators.

Conclusions: Since a substantial percentage of TSCCs are HPV-positive and metastasizes to cervical lymph nodes in less advanced primary tumors, the $\mathrm{N}$ status is an unreliable prognostic indicator in TSCCs. HPV is only prognostically relevant in the total tumor population, but loses its value within patient groups receiving a single treatment modality. The value of HPV for prognosis of patients with TSCC requires further study. 


\section{Introduction}

During the past decades numerous investigations have shown an etiologic relationship between oncogenic or high-risk human papillomavirus (HPV) and squamous cell carcinomas of the tonsil (TSCC) ${ }^{1-4}$. The incidence of HPV in TSCC is increasing, possibly related to changes in sexual behavior, and ranges from $20 \%$ to $80 \%$ in different studies depending on the detection approach used ${ }^{5-8}$. There is increasing evidence that the pathogenesis of HPV-positive tumors is different from their HPV-negative counterparts, which is confirmed by molecular and clinical differences between the two subgroups. Therefore, a different clinical approach may be advisable for both TSCC groups ${ }^{2-4,7,9}$. Weinberger et al. proposed a model for the development of HPV-positive carcinomas, in which three classes are differentiated and divided into two arms. $s^{9}$ In the first arm, tumorigenesis is induced by alcohol consumption and/or smoking tobacco (class I). In this group, HPV superinfection of the tumor site may occur, resulting in an HPV-positive tumor with biological features that resemble alcohol/tobacco-related tumors (class II). In the second arm, the inducer of tumorigenesis is HPV (class III), independent of smoking tobacco and alcohol consumption. Many studies suggest a better prognosis for patients with HPV-associated head and neck carcinomas ${ }^{7}$, as a consequence of an improved response to treatment when compared to HPV-negative tumors ${ }^{10,11}$. Therefore HPV testing has recently been proposed to be included in the standard diagnostic work-up for oropharyngeal carcinomas ${ }^{8-10}$.

Another factor influencing prognosis is tumor spread to cervical lymph nodes. For head and neck tumors in general, a positive $\mathrm{N}$ status is considered the most reliable prognostic marker for an unfavorable prognosis ${ }^{12-14}$. However, TSCC literature is not consistent in confirming the prognostic value of $\mathrm{N}$ status ${ }^{15-17}$. The present study aims to examine the prognostic value of $\mathrm{N}$ status in a series of 81 TSCCs, while also taking into consideration the HPV status, clinicopathological features (age, gender, TNM classification, tumor differentiation grade, smoking tobacco, and alcohol consumption), and treatment of the tumor.

\section{MATERIALS AND MethOdS}

\section{Tumor material and patient data}

The study population consisted of 81 TSCC patients (mean age, 58.9 yrs; range, 39-87 yrs; 73\% male), 2 diagnosed between 1992 and 2001 at the Maastricht University Medical Centre, The Netherlands. The formaldehyde-fixed, paraffin-embedded archival biopsy and resection materials of these patients have been classified by histopathology at the Department of Pathology and analyzed for the presence of oncogenic HPV16 DNA by means of polymerase chain reaction, fluorescence in situ hybridization, and p16 immunostaining. ${ }^{17}$ Data on age, gender, TNM classification, tumor differentiation grade, 
smoking habits, amount of alcohol consumption, treatment modality, and follow-up were collected from the head and neck tumor database of our institute and from reviewing clinical, pathological, radiological, and surgical reports. Tumors of patients treated before 1997 were reclassified according to the 1997 International Union Against Cancer classification. Data on tumor differentiation grade were unavailable for three patients.

Patients were classified as smokers ( $\geq 1$ cigarette, pipe, and/or cigar per day) $(n=69)$ or nonsmokers $(n=12)$. The latter group consisted of patients who had never smoked $(\mathrm{n}=10)$ and former smokers $(\mathrm{n}=2)$, who had stopped smoking more than 10 years before diagnosis of TSCC. Patients were also classified as drinkers (consumption of $>2$ whiskey equivalents of $\geq 10 \mathrm{~g}$ alcohol per day) or nondrinkers ( $0-2$ whiskey equivalents per day). All patients were treated irrespective of their HPV status by multimodal regimens including local resection, combined resection: neck dissection plus local resection, i.e., tonsillectomy or combined mandibular operation (command-procedure), radiotherapy (RT), local resection plus radiotherapy, combined resection plus radiotherapy (CR/RT), chemotherapy, or chemotherapy in combination with previous other treatment modalities.

Patients with tumors feasible for resection without unacceptable compromising organ functionality were treated with radical resection and elective neck dissection and postoperative radiotherapy if indicated. In patients who were primarily treated with radiotherapy, the neck was also treated with radiotherapy. During multidisciplinary counselling, treatment plans were designed dependent on tumor size, neck staging, presence of distant metastases, feasibility of surgery, histopathology of resection specimens, clinical condition and comorbidities. With the exception of microcarcinomas, elective treatment of the neck was performed routinely, including in the N0 neck, because of the high incidence of occult metastases in TSCC ${ }^{14,18-20}$. For patients treated with radiotherapy alone, histopathological data from surgical neck dissection were consequently unavailable. Therefore clinical staging (including panendoscopy, magnetic resonance imaging of the neck, ultrasound with fineneedle aspiration, and $\mathrm{x}$-thorax) was used in this study. In the CR/RT group, there was one patient with a N0 neck according to diagnostic work-up, where a positive lymph node was observed in histopathological analysis after ipsilateral elective neck dissection. This patient was considered as N0 in this study. Follow-up data were collected with a minimum of 5 years after treatment for all patients. The investigation was conducted in accordance with the declaration with the declaration of the World Medical Association in Helsinki in 1964 and the subsequent revisions. The study protocol was approved by the institutional ethical committee. Written consent was obtained from all the patients included in this study.

\section{Statistical analysis}

The association of $\mathrm{N}$ status and HPV status with other factors associated with prognosis, including age at time of diagnosis, gender, TNM status, tumor differentiation grade, smoking habits, and amount of alcohol consumption, were analyzed by cross-tabulations 
using the 2-tailed $\chi 2$ test or 2-tailed Fisher exact test adhering to a significance level of $\mathrm{P} \leq .05$. Survival curves for disease-free survival (DFS), disease-specific survival (DSS), and overall survival (OS) were calculated using the Kaplan-Meier method ${ }^{21}$. Five-year survival was calculated from the date of diagnosis until death or until discharge from follow-up. DFS was calculated from the date of diagnosis until the date of recurrence (local, regional, or distant). Patients without recurrence were censored at the date of the last follow-up or the date of death. Differences between survival times were determined by the log-rank test in univariate analyses (significance level of $\mathrm{P} \leq .05)^{21}$. Four patients initially presented with distant metastases and were excluded from the survival analysis.

Multivariate analyses were performed using the Cox proportional hazards model. Variables included were HPV, smoking tobacco, alcohol consumption, and T classification. The inclusion of treatment modality as a variable depended on the number of patients within each treatment group. Variables remained in the model if their p-values were below $0.10^{17}$. SPSS version 12.0 software (SPSS Inc., Chicago, IL) was used for the statistical analysis.

\section{Results}

\section{N Status and HPV status in relation to patient characteristics}

A positive $\mathrm{N}$ status, as determined in the diagnostic work-up by clinical investigation and radiology, was more frequently observed in non- and former smokers $(p=0.048)$. Other clinicopathological factors (age, alcohol consumption, TNM-stage, and tumor differentiation grade) and HPV status did not appear to be associated with $\mathrm{N}$ status (table 1). HPV status, however, correlated with a poor tumor differentiation grade $(p=0.015)$, as did less or no smoking of tobacco $(p=0.011)$ and alcohol consumption $(p=0.003)$ (table 1$)$. Primary tumor size at time of presentation was found to be significantly smaller in the HPV-positive group than in the HPV-negative group $(p=0.041)$ in spite of comparable frequencies of nodal involvement in both groups. Moreover, in the case of nodal involvement, a swelling in the neck was the main reason for visiting the ENT outpatient department for 15 of the 24 patients with HPV-positive TSCC, compared to only six of the 30 patients with HPV-negative TSCC $(p=0.001)$.

\section{$\mathrm{N}$ status and HPV status in relation to patient treatment}

The different treatment modalities for TSCC are listed in table 2. The two largest patient groups receiving a single treatment modality included 30 patients treated with CR/RT and 30 patients receiving RT. The other treatment modalities were not taken into consideration in this analysis because of the limited number of patients in these groups. 
Table 1. N-status, HPV-status and treatment modality in correlation to patient characteristics.

\begin{tabular}{|c|c|c|c|c|c|c|c|c|c|}
\hline & No & $\mathrm{N}+$ & p-value & $\mathrm{HPV}+$ & HPV- & p-value & $\mathrm{CR} / \mathrm{RT}$ & RT & p-value \\
\hline Male/female & 19 vs. 8 & 38 vs. 16 & NS & 24 vs. 9 & 31 vs. 15 & NS & 20 vs. 10 & 24 vs. 6 & NS \\
\hline Age (mean) & 56.9 & 59.1 & NS & 59.3 & 57.85 & NS & 58.53 & 56.4 & \\
\hline range years & $41-77$ & $39-87$ & & $39-79$ & $41-87$ & & $39-74$ & $44-74$ & \\
\hline \multicolumn{10}{|l|}{ Smoking } \\
\hline $\begin{array}{l}\text { Non-smoker/former smoker } \\
>10 \mathrm{yrs} \text {. }\end{array}$ & 2 & 14 & 0.048 & 11 & 5 & 0.011 & 11 & 1 & 0.001 \\
\hline Smoker & 25 & 40 & & 22 & 43 & & 19 & 29 & \\
\hline \multicolumn{10}{|l|}{ Alcohol } \\
\hline None/social & 12 & 26 & NS & 22 & 16 & 0.003 & 14 & 13 & NS \\
\hline$>2 \mathrm{U} /$ day & 15 & 28 & & 11 & 32 & & 16 & 17 & \\
\hline \multicolumn{10}{|l|}{ TNM } \\
\hline T1,2 vs. T3,4 & 12 vs. 15 & 26 vs. 28 & NS & 20 vs. 13 & 18 vs. 30 & 0.041 & 21 vs. 9 & 8 vs. 22 & 0.001 \\
\hline $\mathrm{T} 1$ & 3 & 6 & & 3 & 6 & & 4 & 2 & \\
\hline $\mathrm{T} 2$ & 9 & 20 & & 17 & 12 & & 17 & 6 & \\
\hline T3 & 12 & 15 & & 9 & 18 & & 8 & 11 & \\
\hline $\mathrm{T} 4$ & 3 & 13 & & 4 & 12 & & 1 & 11 & \\
\hline N0 vs. N+ & I & I & 1 & 9 vs. 24 & 18 vs. 30 & NS & 6 vs. 24 & 11 vs. 19 & NS \\
\hline No & I & I & & 9 & 18 & & 6 & 11 & \\
\hline N1 & I & I & & 6 & 11 & & 7 & 7 & \\
\hline $\mathrm{N} 2$ & l & I & & 16 & 14 & & 17 & 7 & \\
\hline N3 & I & I & & 2 & 5 & & 0 & 5 & \\
\hline $\mathrm{M}+$ & 0 & 4 & NS & 1 & 3 & NS & I & I & I \\
\hline \multicolumn{10}{|l|}{ Tumor differentiation grade } \\
\hline poor & 7 & 22 & NS & 17 & 12 & 0.015 & 11 & 10 & NS \\
\hline moderate/well & 20 & 29 & & 15 & 34 & & 18 & 20 & \\
\hline \multicolumn{10}{|l|}{ HPV16-status } \\
\hline positive & 9 & 24 & NS & l & I & l & 16 & 8 & 0.035 \\
\hline negative & 18 & 30 & & l & I & & 14 & 22 & \\
\hline Local recurrence & 8 & 2 & $0,002^{*}$ & 2 & 8 & NS & 0 & 6 & $0.024^{*}$ \\
\hline Regional recurrence & 3 & 2 & NS & 1 & 4 & NS & 2 & 2 & NS \\
\hline Distant metastasis & 1 & 3 & NS & 2 & 2 & NS & 1 & 3 & NS \\
\hline Total: 81 patients & 27 & 54 & & 33 & 48 & & 30 & 30 & \\
\hline
\end{tabular}

P-values were obtained using 2-tailed $\chi^{2}$-test; asterisks indicate the use of Fisher exact test.

Abbreviations. CR/RT: patients treated with tumor surgery and neck dissection in combination with radiotherapy; RT: patients treated with radiotherapy; NS: no significance detected ( $\mathrm{p}$-value $>0.05$ ).

Functionally resectable tumors were preferably treated with CR/RT, whereas patients with functionally irresectable tumors or other contraindications for surgery were treated with RT alone. T status was significantly lower in the CR/RT group than in the RT group ( $p=0.001$ ), whereas nodal involvement did not differ (table 1). HPV-positive TSCC were more often treated with CR/RT $(p=0.035)$, whereas HPV-negative TSCC were more often treated with RT $(p=0.048)$. In the CR/RT group, all HPV-positive patients had a positive $\mathrm{N}$ status, whereas in HPV-negative patients significantly less nodal involvement was present $(p=0.003)$. 
Table 2. HPV in correlation with treatment.

\begin{tabular}{lccc}
\hline & HPV + & HPV & Total \\
\hline Local resection (LR) & 0 & 1 & 1 \\
Combined resection (CR) & 3 & 3 & 6 \\
LR/RT & 3 & 2 & 5 \\
CR/RT & 16 & 14 & 30 \\
Radiotherapy (RT) & 8 & 22 & 30 \\
Chemotherapy (ChT) & 2 & 1 & 3 \\
CR/RT/ChT & 1 & 0 & 1 \\
RT/ChT & 0 & 3 & 3 \\
None & 0 & 2 & 2 \\
\hline
\end{tabular}

Patients treated with CR/RT (resectable tumors) smoked significantly less than patients treated with RT $(p=0.001)$. Smoking habits observed in both treatment modality groups were HPV-dependent. Nine of the $16 \mathrm{HPV}$-positive patients who were treated with CR/RT were nonsmokers, whereas the eight HPV-positive patients treated with RT (irresectable tumors) all smoked ( $p=0.007)$. In patients with HPV-negative tumors, no significant differences in smoking habits were found between the treatment modality groups. Alcohol consumption did not differ between treatment modality groups. Patients treated with CR/RT had a far more favourable 5-year overall, disease-specific, and disease-free survival compared to patients treated with RT (log-rank $p<0.001)$. This outcome based on patient treatment did not differ between the HPV-positive and HPV-negative patients with TSCC (OS, DSS, log-rank $p<0.001$; DFS, log-rank $p=0.001$ ). Moreover, in both treatment modality groups, there were no differences noted for the development of local and regional recurrence or for development of distant metastasis between HPV-positive and HPV-negative patients with TSCC (Fisher exact test).

\section{$\mathrm{N}$ status and HPV status in relation to outcome}

Nodal involvement did not correlate with survival in either the entire group of TSCC (figure $1 \mathrm{~A}-\mathrm{C}$ ) or in the treatment subgroups $\mathrm{CR} / \mathrm{RT}$ and RT. Remarkably, a trend for a favorable 5-year DFS rate was observed in patients with a lymph node metastasis $(p=0.067)$ (figure 1C). A statistically significant difference between the prognosis of HPV-positive and HPV-negative TSCCs was not found in the univariate analysis. However, there was a trend for a better DSS in the HPV-positive group (logrank $p=0.094$ ) (figure $2 \mathrm{~A}-\mathrm{C}$ ). Also within the treatment subgroups CR/RT and RT, HPV status proved to be an unreliable prognostic indicator. The influence of $\mathrm{N}$ status on prognosis was also analyzed in pa- 
A

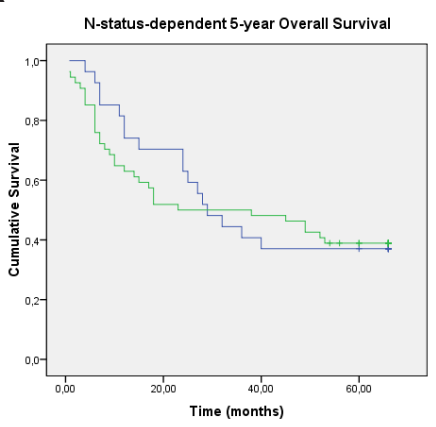

B

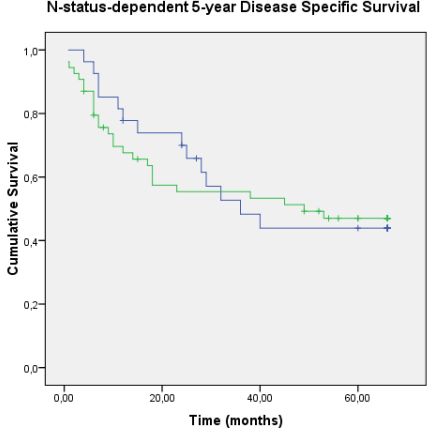

C

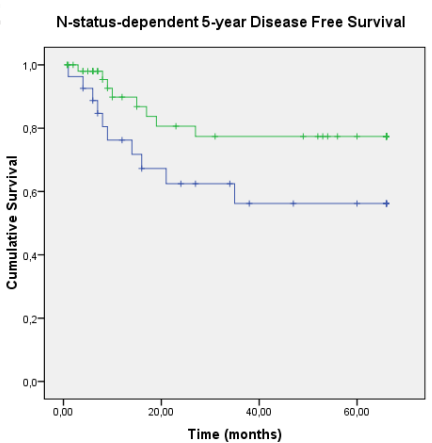

Figure 1

(A) $\mathrm{N}$ status-dependent 5-year overall survival, $\mathrm{p}=\mathrm{NS}$

(B) Five-year disease-specific survival, $p=\theta_{-} \mathrm{NS}$

(C) Five-year disease-free survival, $\mathrm{p}=0.060$

(Kaplan-Meier, log rank)

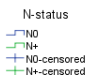

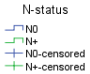

A

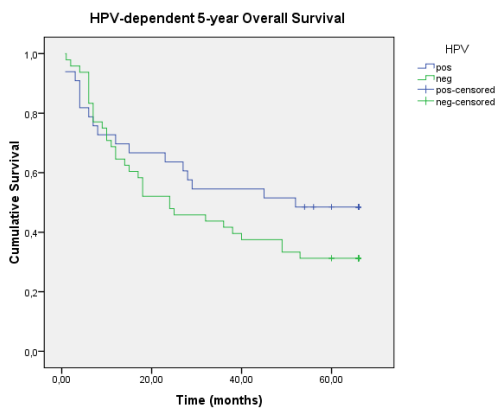

B

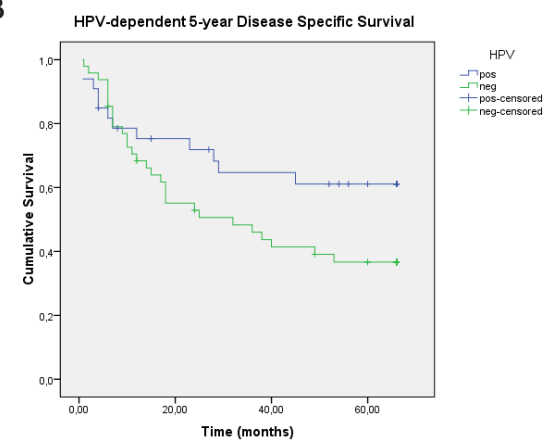

C

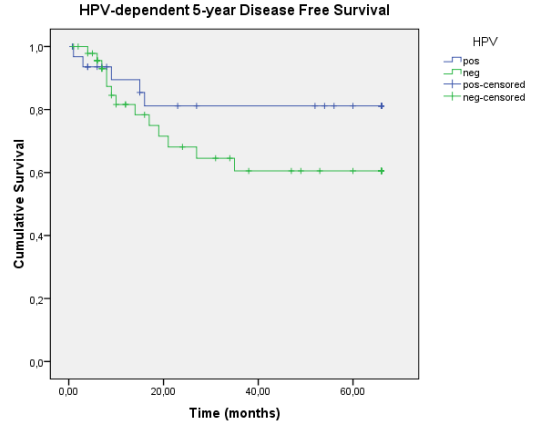

Figure 2.

(A) (HPV)-dependent 5-year overall survival, $\mathrm{p}=\mathrm{NS}$

(B) Five-year disease-specific survival, $\mathrm{p}=0.084$

(C) Five-year disease-free survival, $\mathrm{p}=\mathrm{NS}$

(Kaplan-Meier, log rank) 
tients with HPV-positive and HPV-negative TSCC. In the HPV-negative group, the presence of nodal involvement seemed to be related to an unfavorable 5-year OS, DSS, and DFS rate (figure 3). In the HPV-positive group, however, the presence of nodal involvement seemed to be related to a better OS, DSS, and DFS. In multivariate analysis neither $\mathrm{N}$-status, nor gender, age and tumor differentiation grade appeared to have a statistically significant influence on survival. For HPV-negative TSCCs a 2 times higher risk of cancer death was found (95\% confidence interval [CI ].=0.9-4.2) compared to patients with HPV-positive tumors. Patients with a tumor staged T3 or T4 had a 2.6 times increased risk of cancer death $(95 \% \mathrm{CI}=1.4-4.9)$ compared to patients with tumor staged T1 or T2. However, the strongest prognostic factor was smoking; smokers had a 5.5-fold higher risk (95\% CI $=1.3-23.6)$ of dying from cancer when compared to nonsmokers.17 Multivariate analysis within treatment modality groups $\mathrm{CR} / \mathrm{RT}$ and RT were not performed due to the limited number of patients in each of these groups $(n=30)$.
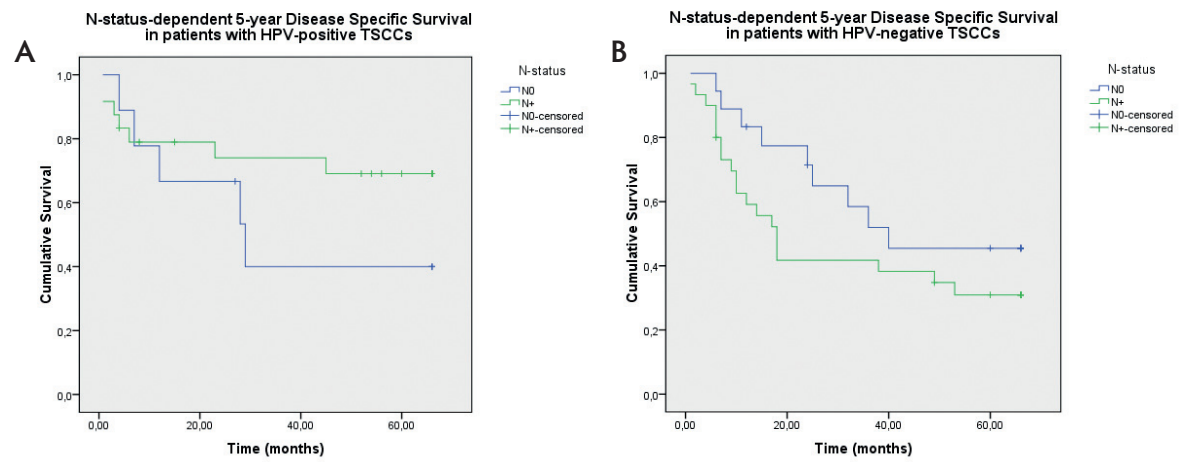

Figure 3

A) N status-dependent 5-year disease-specific survival in patients with human papillomavirus (HPV)-positive tonsillar squamous cell carcinomas (TSCCs).

B) N status-dependent 5-year disease-specific survival in patients with HPV-negative TSCCs

(Kaplan-Meier, log-rank). NS = not significant.

\section{Discussion}

In head and neck squamous cell carcinoma (HNSCC), $\mathrm{N}$ status is known to be an important prognostic factor. Nodal involvement reduces survival by more than $50 \%$ in patients with HNSCCs ${ }^{22-27}$. However, in recent years the prognostic value of nodal involvement in TSCC is becoming increasingly controversial ${ }^{15-17}$. A possible explanation for this finding is the heterogeneity in etiological factors underlying tumorigenesis in different head and neck mucosa areas. For example, HPV appears to play a much more prominent etiologi- 
cal role in TSCC than in other head and neck tumors ${ }^{28,29}$. Moreover, the incidence of HPV in TSCC has increased substantially in the past few decades $s^{5-8}$. Therefore, investigation into whether the presence of HPV underlies the decreased prognostic value of nodal involvement in TSCC is warranted. In our study we noticed that the only clinical parameter associated with a positive neck status in TSCCs was absence of tobacco smoking. This parameter, however, was found to correlate much stronger with the presence of HPV in the tumor ( $41 \%$ of cases). This observation has also been described in other studies ${ }^{7-9}$. Additional parameters correlating to HPV included less or no alcohol consumption, a poor tumor differentiation grade, and a smaller T stage.

The latter finding suggests a different tumor biology for HPV-positive TSCCs with regional spreading occurring at smaller primary tumor sizes. Possibly, HPV-positive tumors were detected in smaller $\mathrm{T}$ stages because of an earlier clinical presentation of a lymph node metastasis in this group. We observed a relationship between a swelling in the neck as presenting symptom and the presence of HPV in the primary tumor. This has also been described in literature ${ }^{17}$. This pattern of regional tumor spreading in smaller primary tumor sizes may contribute to an earlier detection of a so far unknown primary tumor at a smaller size. According to this hypothesis, the tumor biology of HPV-positive tumors would result in the detection of tumors with smaller T stages. In this study patients with tumors feasible for resection with respect to organ functionality were treated with $\mathrm{CR} / \mathrm{RT}$, and (functionally) inoperable tumors were treated with RT. As a consequence, the CR/ RT group showed a significantly better outcome. Because of their smaller primary tumor sizes, HPV-positive TSCCs were more often feasible for resection and subsequently more often created with CR/RT. We would like to stress that conclusions with respect to the efficacy of these treatment modalities should not be extracted from the data presented here. To what extent patient-dependent factors such as life style and comorbidities influence clinical choice and treatment outcome remains to be studied. A favorable performance status appears to be related to HPV-positive tumors ${ }^{11}$. The inverse relation between tobacco smoking, alcohol consumption, and HPV-status suggests also that the difference in life style may result in a decreased prevalence of comorbidities in the HPV-positive tumor population.

$\mathrm{N}$ status was not found to be of prognostic value in TSCC. Patients with HPVnegative TSCC were found to have a 2 times greater risk of cancer death. Separate analysis of the CR/RT and RT groups did not indicate that these two parameters had an effect on prognosis. HPV-positive tumors, thus, show no significant improvement of response to therapy within the different modality groups. Although this could be caused by the relatively limited number of patients in the different treatment groups, a recent study also showed no significantly favorable prognosis of HPV-positive oropharyngeal tumors when treated with combined radio/ chemotherapy ${ }^{11}$. Multiple hypotheses for a better outcome of HPV-positive tumors have been put forward. They are all based on factors related to therapy-outcome: absence of field cancerization as a consequence of the in- 
verse relation of HPV and tobacco smoking and alcohol consumption, an intact apoptotic tumor response to radiation, and an immune surveillance to viral-specific tumor antigens $\mathrm{s}^{30-33}$. However, in most cases multimodal treatment modalities have been used. In our study, the presence of nodal involvement in HPV-negative TSCC seemed to expose a negative influence on the prognosis. However, in HPV-positive TSCC nodal involvement even appeared to ameliorate outcome. This suggests that the tumor biology of HPVpositive TSCC is not only different from the HPV-negative TSCC, but also has a great influence on the clinical presentation and outcome. As mentioned, nodal involvement in HPV-positive TSCCs is often the presenting symptom and seems to indicate the presence of a smaller primary tumor in HPV-positive TSCCs (squealer node in unknown primary tumors). Subsequently, these HPV-positive TSCCs are more feasible for a radical therapeutic approach. This indicates that the outcome of HPV-positive tumors is not only dependent on a better response to different (multimodal) treatment modalities, but more importantly, the presence of HPV in TSCCs seems to determine the choice of treatment as a result of its biology. As a consequence of the controversial prognostic value of nodal involvement, we advise the implementation of testing HPV diagnostically to stratify in TSCC tumor staging.

\section{Conclusions}

HPV-positive tumors, which are associated with less smoking and alcohol, have a different tumor biology. They have smaller primary tumor sizes, although regional lymph node involvement is comparable to HPVnegative tumors. Our data indicate that the relatively favorable prognosis of HPVrelated TSCC is determined by the choice of treatment as a result of its biology. The prognostic value of nodal involvement is reduced by the presence of HPV. HPV testing in the diagnostic work-up is therefore advised in TSCC tumor staging. 


\section{References}

1 Gillison ML, Koch WM, Capone RB, Spafford M, Westra WH, Wu L et al. Evidence for a causal association between human papillomavirus and a subset of head and neck cancers. J Natl Cancer Inst 2000; 92: 709-720.

2 Hafkamp HC, Manni JJ and Speel EJ. Role of human papillomavirus in the development of head and neck squamous cell carcinomas. Acta Otolaryngol 2004; 124: 520-526.

3 Furniss CS, McClean MD, Smith JF, Bryan J, Nelson HH, Peters ES et al. Human papillomavirus 16 and head and neck squamous cell carcinoma. Int J Cancer 2007; 120: 2386-2392.

4 Klussmann JP, Weissenborn SJ, Wieland U, Dries V, Kolligs J, Jungehuelsing M et al. Prevalence, distribution, and viral load of human papillomavirus 16 DNA in tonsillar carcinomas. Cancer 2001; 92: 2875-2884.

5 Klozar J, Kratochvil V, Salakova M, Smahelova J, Vesela E, Hamsikova E et al. HPV status and regional metastasis in the prognosis of oral and oropharyngeal cancer. Eur Arch Otorhinolaryngol 2008; 265 Suppl 1: S75-85.

6 Hafkamp HC, Speel EJ, Haesevoets A, Bot FJ, Dinjens WN, Ramaekers FC et al. A subset of head and neck squamous cell carcinomas exhibits integration of HPV 16/18 DNA and overexpression of $p 16^{I N K 4 A}$ and $p 53$ in the absence of mutations in $p 53$ exons 5-8. Int J Cancer 2003; 107: 394-400.

7 Ragin CC and Taioli E. Survival of squamous cell carcinoma of the head and neck in relation to human papillomavirus infection: review and meta-analysis. Int J Cancer 2007; 121: 1813-1820.

8 Fakhry C and Gillison ML. Clinical implications of human papillomavirus in head and neck cancers. J Clin Oncol 2006; 24: 2606-2611.

9 Weinberger PM, Yu Z, Haffty BG, Kowalski D, Harigopal M, Brandsma J et al. Molecular classification identifies a subset of human papillomavirus--associated oropharyngeal cancers with favorable prognosis. J Clin Oncol 2006; 24: 736-747.

10 National Comprehensive Cancer Network (NCCN). Clinical practice guidelines in oncology - Head and Neck Cancers. v.2.2010, 22-26 (2010).

11 Fakhry C, Westra WH, Li S, Cmelak A, Ridge JA, Pinto H et al. Improved survival of patients with human papillomavirus-positive head and neck squamous cell carcinoma in a prospective clinical trial. J Natl Cancer Inst 2008; 100: 261-269.

12 Mukherji SK, Armao D and Joshi VM. Cervical nodal metastases in squamous cell carcinoma of the head and neck: what to expect. Head Neck 2001; 23: 995-1005.

13 Ferlito A, Rinaldo A, Silver CE, Shah JP, Suarez C, Medina JE et al. Neck dissection: then and now. Auris Nasus Larynx 2006; 33: 365-374.

14 Takes RP. Staging of the neck in patients with head and neck squamous cell cancer: imaging techniques and biomarkers. Oral Oncol 2004; 40: 656-667.

15 Friesland S, Fernberg JO, Lundell G, Munck-Wikland E, Strander H and Lewensohn R. Prognostic impact of complete remission after preoperative irradiation of tonsillar carcinoma: a retrospective analysis of the radiumhemmet data, 1980-1995. Int J Radiat Oncol Biol Phys 1999; 45: 1259-1266.

16 al-Abdulwahed S, Kudryk W, al-Rajhi N, Hanson J, Jenkins H, Gaedke H et al. Carcinoma of the tonsil: prognostic factors. J Otolaryngol 1997; 26: 296-299. 
17 Hafkamp HC, Manni JJ, Haesevoets A, Voogd AC, Schepers M, Bot FJ et al. Marked differences in survival rate between smokers and nonsmokers with HPV 16-associated tonsillar carcinomas. Int $J$ Cancer 2008; 122: 2656-2664.

18 Werning JW, Heard D, Pagano C and Khuder S. Elective management of the clinically negative neck by otolaryngologists in patients with oral tongue cancer. Arch Otolaryngol Head Neck Surg 2003; 129: 83-88.

19 Weiss MH, Harrison LB and Isaacs RS. Use of decision analysis in planning a management strategy for the stage N0 neck. Arch Otolaryngol Head Neck Surg 1994; 120: 699-702.

20 Baatenburg de Jong RJ, Knegt P and Verwoerd CD. Reduction of the number of neck treatments in patients with head and neck cancer. Cancer 1993; 71: 2312-2318.

21 Kaplan EL and Meier P. Nonparametric estimation from incomplete observations. J Am Stat Assoc 1958; 52: 457-481.

22 Kalnins IK, Leonard AG, Sako K, Razack MS and Shedd DP. Correlation between prognosis and degree of lymph node involvement in carcinoma of the oral cavity. Am J Surg 1977; 134: 450-454.

23 Ono I, Ebihara S, Saito H and Yoshizumi T. Correlation between prognosis and degree of lymph node involvement in carcinoma of the head and neck. Auris Nasus Larynx 1985; 12 Suppl 2: S85-89.

24 Jakobsen J, Hansen O, Jorgensen KE and Bastholt L. Lymph node metastases from laryngeal and pharyngeal carcinomas--calculation of burden of metastasis and its impact on prognosis. Acta Oncol 1998; 37: 489-493.

25 Kehrl W, Wenzel S and Niendorf A. Effect of various forms of metastatic lymph node involvement on prognosis of squamous epithelial carcinomas of the upper aerodigestive tract. Laryngorhinootologie 1998; 77: 569-575.

26 Ganzer U, Meyer-Breiting E, Ebbers J and Vosteen KH. Effect of tumor size on lymph node metastasis and type of treatment on the prognosis of hypopharyngeal cancer. Laryngol Rhinol Otol (Stuttg) 1982; 61: $622-628$.

27 Leemans CR, Tiwari RM, van der Waal I, Karim AB, Nauta JJ and Snow GB. Neck lymph node dissection in squamous cell carcinoma originating in the head-and-neck area; the significance for the prognosis. Ned Tijdschr Geneeskd 1992; 136: 221-225.

28 Layland MK, Sessions DG and Lenox J. The influence of lymph node metastasis in the treatment of squamous cell carcinoma of the oral cavity, oropharynx, larynx, and hypopharynx: N0 versus $\mathrm{N}+$. Laryngoscope 2005; 115: 629-639.

29 Sundaram K, Schwartz J, Har-El G and Lucente F. Carcinoma of the oropharynx: factors affecting outcome. Laryngoscope 2005; 115: 1536-1542.

30 Mellin H, Friesland S, Lewensohn R, Dalianis T and Munck-Wikland E. Human papillomavirus (HPV) DNA in tonsillar cancer: clinical correlates, risk of relapse, and survival. Int J Cancer 2000; 89: 300-304.

31 Ferris RL, Martinez I, Sirianni N, Wang J, Lopez-Albaitero A, Gollin SM et al. Human papillomavirus-16 associated squamous cell carcinoma of the head and neck (SCCHN): a natural disease model provides insights into viral carcinogenesis. Eur J Cancer 2005; 41: 807-815.

32 Lindel K, Beer KT, Laissue J, Greiner RH and Aebersold DM. Human papillomavirus positive squamous cell carcinoma of the oropharynx: a radiosensitive subgroup of head and neck carcinoma. Cancer 2001; 92: 805-813. 
33 DeWeese TL, Walsh JC, Dillehay LE, Kessis TD, Hedrick L, Cho KR et al. Human papillomavirus E6 and $E 7$ oncoproteins alter cell cycle progression but not radiosensitivity of carcinoma cells treated with low-dose-rate radiation. Int J Radiat Oncol Biol Phys 1997; 37: 145-154. 


\section{Chapter 3}

Human papillomavirus type 16 integration in oropharyngeal squamous cell carcinomas often occurs in genes involved in tumorigenesis 


\section{Abstract}

Infection with human papillomavirus (HPV) type 16 is an independent risk factor for the development of oropharyngeal squamous cell carcinomas (OPSCC). Although integration of HPV16 DNA into the human genome has been shown to play an important role in anogenital and particularly in uterine cervical carcinogenesis as well as tumor progression, this association is still largely unclear for OPSCC. Integration is mostly determined by PCR-based methods or in situ hybridization. However, reported HPV integration frequencies for OPSCC vary greatly and fluctuate between $0 \%$ and $100 \%$, which might be due to the applied methods.

We have evaluated 75 patients with OPSCC for the physical status of HPV16, i.e. episomal versus integrated, using two independent techniques to detect virus-human fusion sites, i.e. PCR amplification of papillomavirus transcripts (APOT-PCR) and detection of integrated papillomavirus sequences by ligation mediated PCR (DIPS-PCR).

HPV16 integration in the cellular genome was identified in approximately $40 \%$ of OPSCC. HPV integration sites were distributed over the genome, with a preference for gene loci reported to be involved in tumorigenesis and including BCL2, FANCC, TRAF3 and TP63. Integration was detected in both exon and intron sequences, as well as in sense or antisense orientation of the reported genes. Half of the integration sites were found in the proximity of reported fragile sites.

These data indicate that HPV16 integration is not a prerequisite for tumorigenesis of OPSCC, but in case of integration this often occurs in transcribed regions and especially in genes with reported involvement in tumorigenesis. 


\section{Introduction}

Approximately 600.000 new cases of head and neck squamous cell carcinoma (HNSCC) have been estimated to occur worldwide in 2011, ranking them in sixth position of all carcinomas $^{1-3}$. Disappointingly, even with the implementation of multimodal therapies, limited progress has been made in the last decades with respect to disease-free survival or 5 -year survival rates, which are currently 50\% - 60\% for new HNSCC patients ${ }^{3,4}$.

Risk factors for the development of HNSCC include environmental factors, excessive tobacco- and alcohol use, as well as HPV infections. Particularly oropharyngeal squamous cell carcinomas (OPSCC) show high infection rates, with up to $50 \%$ of the tumors being HPV-positive, mainly HPV type 16. HPV-positive tumors tend to show clinicopathological and molecular characteristics that are different from those of patients with tobacco- or alcohol-induced tumors ${ }^{5-7}$. The reported prevalence of HPV-related OPSCC, however, varies broadly amongst several studies due to differences in the study population, combination of histological subsites, type and number of specimens analyzed, and detection methods used.

It has been shown for anogenital carcinomas, in particular uterine cervical carcinomas, that integration of viral DNA into the host genome directly correlates to the progression from dysplastic lesions to carcinomas in most of the cases $^{8,9}$. Integration of HPV DNA appears to be a direct result of chromosomal integrity destabilizing processes mediated by the expression of viral oncogenes E6 and E7 and seems to occur relatively late in the progression of anogenital dysplasia. In the anogenital region, almost 200 integration sites have been mapped, which showed to be unique, and involved all chromosomes although some clusters of integration could be identified, for example in the cytegenetic bands 4q13.3, 8q24.21, 13q22.1 and 17q21 $1^{8,10-12}$. Preferred sites for integration proved to be fragile sites, translocation break points, and transcriptionally active regions. Even though many similarities are seen between uterine cervical carcinomas and HPV-induced HNSCC, the almost exclusive infection with HPV16 in HNSCC may indicate differences in tumorigenic mechanisms. In addition, high variation in integration frequency have been reported in HNSCC, ranging from virus being present only in an episomal form to $100 \%$ integrated, depending to the techniques applied to determine integration status ${ }^{6,13-15}$. This confers the need for a more detailed analysis of integration frequencies and characterization of integration sites. It has already been shown for HNSCC that HPV can integrate ${ }^{16,17}$ but we are the first providing integration data for a cohort of $75 \mathrm{HPV}$-positive OPSCC with two methods that give direct information about the viral-human fusion site, namely APOT-PCR- and DIPS-PCR. In conclusion, our data showed that HPV16 could only be found in episomal state in the majority of OPSCC and integration is therefore not a necessity for carcinogenesis. On the other hand, when integration does occur, transcribed regions and especially gene with known involvement in tumorigenesis were detected. 


\section{Materials and methods}

\section{Subjects and Material}

Clinical samples were collected from patients treated at the the departments of otorhinolaryngology, head and neck surgery of the University hospitals of Cologne and Maastricht between 1994-2009. Written informed consent was obtained from all patients. From a total of 75 patients fresh frozen tumor tissue, preserved in liquid nitrogen, was analyzed. Inclusion criteria were the availability of sufficient fresh frozen tumor tissue containing $\geq 70 \%$ tumor cells, with sufficient and high quality tumor DNA and RNA as well as active infection with HPV16, as shown by the presence of HPV DNA ${ }^{18}$ and overexpression of the surrogate marker p16 ${ }^{\mathrm{INK} 4 \mathrm{~A}}$, as previously reported ${ }^{19,20}$.

Patient age ranged from 44-83 years (median 62.7 years). Fifty-seven (76.0\%) patients were male and eightteen $(24.0 \%$ ) patients were female.

\section{Immunohistochemistry for p16 INK4A}

Immunohistochemical staining was performed on corresponding $5 \mu \mathrm{m}$-thick formaldehyde-fixed, paraffin-embedded tissue sections. Sections were stained as previously described by Wittekindt et al. ${ }^{21}$. Briefly, monoclonal mouse anti human p16 ${ }^{\mathrm{INK} 4 \mathrm{~A}}$ antibody, clone E6H4, CINtec Histology Kit (MTM Laboratories AG, Heidelberg, Germany) was used as the primary antibody. Immunohistochemical detection was performed by the avidin-biotinylated peroxidase complex $(\mathrm{ABC})$ procedure (Vectastain-EliteABC kit; Vector) or PowerVision (Leica Biosystems Newcastel Ltd, Newcastle, UK). Peroxidase activity was detected using diaminobenzidine $/ \mathrm{H}_{2} \mathrm{O}_{2}$ (BD Biosciences, Heidelberg, Germany). Sections were counterstained with hematoxylin and mounted in mounting medium. Each analysis included negative and positive controls.

\section{PCR}

DNA was isolated from fresh frozen tumor material using QIAGEN Gentra Puregene Tissue Kit (Cologne) or QIAgen DNA Blood Mini Kit (Maastricht), as per the manufacturers instruction (Qiagen, Hilden, Germany). The presence of HPV DNA was detected using a higly sensitive group-specific nested PCR with degenerate primers A5/A10 and A6/A8 $(268 \mathrm{bp} \text { product })^{18}$. Five $\mu \mathrm{l}$ of PCR product were separated on a $1.5 \%$ agarose gel and visualized using ethidium bromide staining. When HPV DNA was detected, HPV typing was performed, either by direct sequencing (Cologne) or by type-specific PCR (Maastricht).

In addition, $\beta$-globin gene PCR served as a positive control for sufficient DNA of adequate quality and to show that sample were free of PCR inhibitory substances (268 bp PC04/GH20 PCR product) ${ }^{22}$. 


\section{Amplification of Papillomavirus Oncogene Transcripts PCR (APOT-PCR)}

Total RNA was extracted from five $10 \mu \mathrm{m}$-thick snap frozen tissue sections, using the RNeasy mini kit (Qiagen, Hilden, Germany) according to the manufacturer's instructions, including DNase treatment. RNA concentration and quality were determined by RNA standard sense chips on a BioRad Experion system (BioRad, Munich, Germany). HPV oncogene transcripts were amplifed as described before ${ }^{23}$. Briefly, reverse transcription was performed using $25 \mu \mathrm{M}$ oligo- $(\mathrm{dT})_{17}$ primer coupled to a linker sequence $(\mathrm{dT})_{17}-\mathrm{p} 3,10 \mathrm{mM}$ dNTPs each, $0.1 \mathrm{M} \mathrm{DTT}, 5 \mathrm{x}$ RT-buffer and SuperScript reverse transcriptase (Invitrogen, Karlsruhe, Germany) ${ }^{24}$. Quality of cellular DNA was determined by a standard GAPDH gene PCR (441 bp product). Firststrand cDNAs containing viral oncogene sequences were subsequently amplified with semi-nested PCR using HPV-E7 specific 5'primers and oligo(dT) and adaptor primers ( $\left.3^{\prime}\right)$. PCR products were separated on a $1.2 \%$ agarose gel. Bands typical for integration were cut out, purified (QIAGEN Gel extraction kit, QIAGEN, Hilden, Germany) and sequenced (GATC Biotech, Konstanz, Germany). Sequence results were analyzed using the BLASTN program and further mapped using map viewer, both provided by the NCBI.

\section{Detection of Integrated Papillomavirus Sequences PCR (DIPS-PCR)}

Integrated papillomavirus sequences were detected using the Detection of Integrated Papillomavirus Sequences-PCR (DIPS-PCR) assay, as described earlier ${ }^{11}$. Shortly, genomic DNA was digested using the Sau3AI restriction enzyme and an enzyme-specific adapter was ligated to the restriction-digested DNA using T4 DNA ligase (Roche Diagnostics, Mannheim, Germany). Linear PCR was performed using 5 HPV16 specific forward primers in independent setups, all using the same specific adapter primer 1 (AP1). All independent PCRs were followed by individual exponential PCRs using further virus-specific forward primers and the AP1 reverse primer. PCR products were separated on a $1.2 \%$ agarose gel and products of interest were excised and subsequently sequenced (GATC Biotech). Sequence results were analyzed using the BLASTN program and further mapped using map viewer, both provided by the NCBI.

\section{Results}

The integration status of the viral genome was analyzed using both an mRNA based 3'-RACE PCR based on Klaes et al..$^{23}$ (APOT-PCR, Amplification of Papilloma Virus Oncogene Transcripts) as well as with a ligation-mediated Detection of Integrated Papillomavirus Sequences (DIPS-PCR) based on Luft et al. ${ }^{11}$. A preselected group of 75 patients 
with OPSCC, known to harbour active HPV16 infection, was analyzed. PCR-products suspected to be derived from integrated HPV16 genomes were sequenced and compared with the human genome database using the BLASTN-program and further mapped using the Map Viewer, provided by the National Cancer Institute, USA. When viral-cellular fusion products were detected, HPV16 was considered to be integrated.

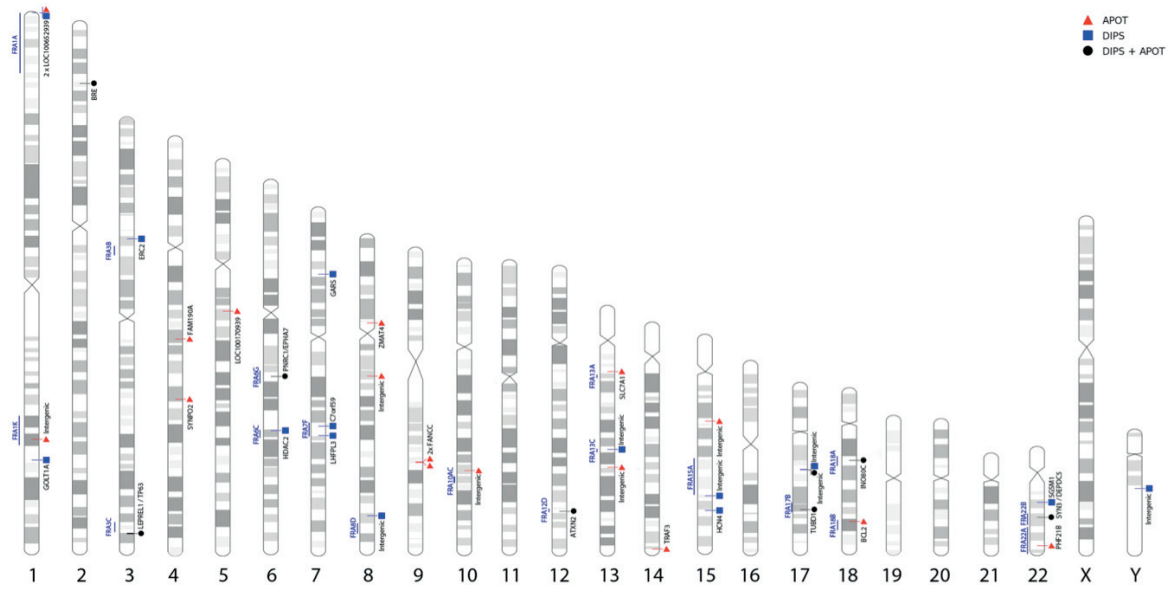

Figure 1. Chromosomal distribution of viral integration sites. Integration sites were found all over the genome, except for chromosomes 11, 16, 19, 20, 21 and X. Integration sites are indicated on the right side of each chromosome and fragile sites that are located within $5 \mathrm{MB}$ of the nearest integration site are indicated on the left side of the chromosome. Integration sites detected by APOT-PCR are indicated by red triangles, sites detected by DIPS-PCR are indicated by blue squares and sites detected by both methods are indicated by black filled circles.

A total of 29 OPSCC (38.7\%) showed integration with either DIPS-PCR and/ or APOT-PCR, whereas 46 samples only showed episomal PCR products (61.3\%). Integration sites were found to be distributed throughout the genome, targeting most chromosomes except chromosomes 11, 16, 19, 20, 21 and X (see figure 1), which supports previous findings in anogenital lesions that there is no preferred integration site for HPV in the human genome $\mathrm{e}^{12,25}$.

Analysis of the genomic integration locus using DIPS-PCR detected a total of 21 viral-cellular fusion products from 19 samples. As shown for anogenital lesions, we also found 3'disruption sites of the HPV genome to be different in all samples, ranging from nucleotide 1124 in the HPV16 E1 gene up to nucleotide 3351 in the HPV16 E2 gene. A total of 13 disruption sites were found in the $E 1$ gene and 8 were found in the E2/E4 gene. Integration events occurred in transcribed genomic regions in 14/21 cases (66.7\%), whereas $7 / 21(33.3 \%)$ integration products were mapped to intergenic regions 
without known reported genes. We found both integration into exons (5/14) as well as into introns (9/14) and integration occurred in sense (7/14) as well as in antisense (7/14) orientation of the genes.

HPV oncogene transcripts could be amplified from 23 OPSCC samples, showing 26 fusion transcripts. A total of 21 transcripts showed direct splicing from viral nucleotide 880 into the cellular flanking sequence (Type A splicing as described by Klaes et al. ${ }^{23}$, figure 2). One transcript was spliced using the E4 splice acceptor site before splicing into the cellular flanking sequence (Type B splicing, figure 2). Four transcripts, however, showed so far undescribed splicing from viral nucleotide 880 to viral nucleotide 409 (in the viral E6 gene) and subsequently to the human sequence (Type D splicing, figure 2). One additional episomal sample showed similar splicing, from viral nucleotide 880 to viral nucleotide 409, without evidence for integration. Most episomal viral transcripts are spliced regularly from nucleotide 880 to 3358, however, two cases of episomal HPV showed splicing from 880 to 2702 and 880 to 2707 .

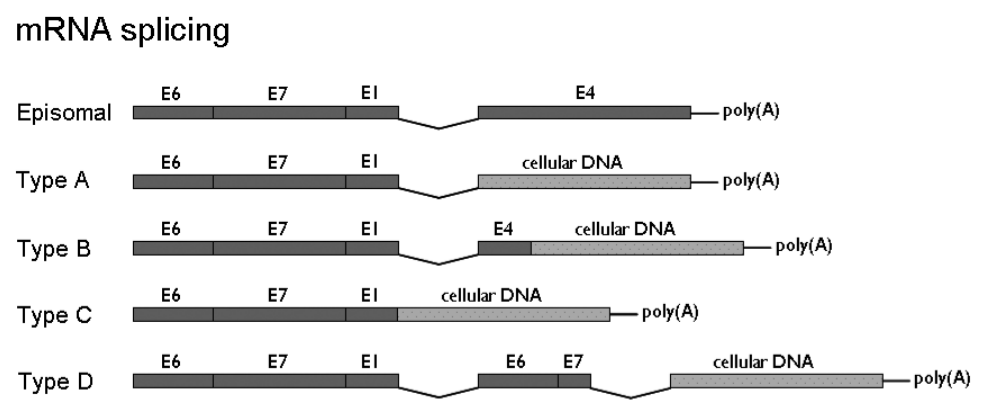

Figure 2. Episomal and integration derived mRNA splicing types. Type A shows splicing from HPV E1 (nucleotide 880) to the cellular sequence. Type B shows HPV E1 spliced to HPV E4 and subsequently to the cellular DNA. Type C transcripts are not spliced (not observed in this study). Type D shows so far undescribed splicing from viral E1 to viral nucleotide 409 and subsequently from viral E7 to the cellular sequence. Viral DNA is indicated as such, since it has not been sequenced. Adapted from Wentzensen et al. ${ }^{12}$ and Lace et al. ${ }^{16}$.

Although most patients only show one integration site, using either APOT- and/ or DIPS-PCR, there are three patients that show more than one integration site. The highest number of integration sites found was 4 , with 3 of them detected by DIPS-PCR. In addition, APOT-PCR was able to detect two fusion transcripts in this tumor, which were located in the same cytogenetic band with a distance of $43.2 \mathrm{kB}$ (patient no. 1). However, the fusion transcript detected by APOT-PCR did not correlate to the DIPS-PCR integration sites. Two additional sample showed two independent splice products using APOTPCR, which proved to be in different chromosomes. 
The presence of fragile sites was analyzed for all integration loci, and eightteen integration sites (48.6\%) proved to be located within $5 \mathrm{Mb}$ of the nearest fragile site.

Of the cellular sequences that were found using either DIPS- and/or APOTPCR, 27 fusion products corresponded to a known or predicted gene (73\%), whereas the remaining 10 sequences were located in intergenic regions (27\%). For the (predicted) genes, 9 fusion sequences corresponded to introns and 5 to exons using DIPS-PCR and 11 fusion transcripts corresponded to introns and 7 to exons using APOT-PCR. Furthermore, the viral sequences proved to be in sense orientation with the cellular sequences for only half of these genes.

Of the 27 viral-human fusion products that were found to correspond to transcribed regions, 12 fusion products matched known tumor-related genes (BCL2, BRE, EPHA7, FANCC (2x), HDAC2, INO80C, LEPREL1, SYNPO2, TP63, TRAF3, TUBD1) whereas an additional 5 fusion products matched genes involved in pathways that are reported to be compromised in tumors (ERC2, GARS, SLC7A1, SYN3, ZMAT4), as verified using the ATLAS of genetics and cytogenetics in oncogoly and hematology database ${ }^{26}$. The remaining 10 fusion products were not associated with any known or suspected tumor-related gene. Lastly, 3 integration events occurred into pseudo-genes.

In 9 cases, the fusion products detected with DIPS- and APOT-PCR showed correlation. In one additional case, the sequence obtained by APOT-PCR was located $20 \mathrm{MB}$ downstream of the sequence detected by DIPS-PCR. In three cases the splice products used the natural splice acceptor sites for the human genome, whereas 7 products were spliced to a cryptic splice acceptor site.

In 17 cases (16 carcinomas) the fusion products could only be detected by either APOT-PCR (11) or DIPS-PCR (6). Of the 11 cases (10 carcinomas) where APOT-PCR could detect a fusion transcript, DIPS-PCR showed no detectable band in 6 cases and only an episomal band in 4 cases. Vice versa, in the 6 cases where DIPS-PCR could detect a viral-human fusion product, APOT-PCR showed no detectable band in 2 cases and detected 4 episomal bands.

Finally, in five cases the results from APOT-PCR and DIPS-PCR did not correlate, as the fusion products originated from different chromosomes.

\section{Discussion}

DNA based PCR methods, including DIPS- and APOT-PCR, can be used to determine the exact chromosomal location of viral integration sites. So far these methods have mainly been applied to determine HPV integration in anogenital lesions, reporting high integration frequencies ${ }^{8,9,12}$. In these studies it has been reported that HPV integration often leads to deregulated and enhanced oncogene expression, which suggests a major role for HPV integration in neoplastic transformation ${ }^{27,28}$. 
For HNSCC there is much controversy in reported integration frequencies. Depending on the detection methods used to assess the viral physical status, both literature in favour of integration (FISH and PCR $)^{6,14,15}$ as well as episomal cellular appearance $(\mathrm{PCR})^{13}$ have been published.

This study is the first reporting the exact chromosomal location of viral integration on a large cohort of HPV16-positive OPSCC tumors using DIPS- and APOT-PCR. We were able to identify a viral-cellular fusion product in $38.7 \%$ of the tumors indicating that HPV is maintained in an episomal state in the remaining tumors. 


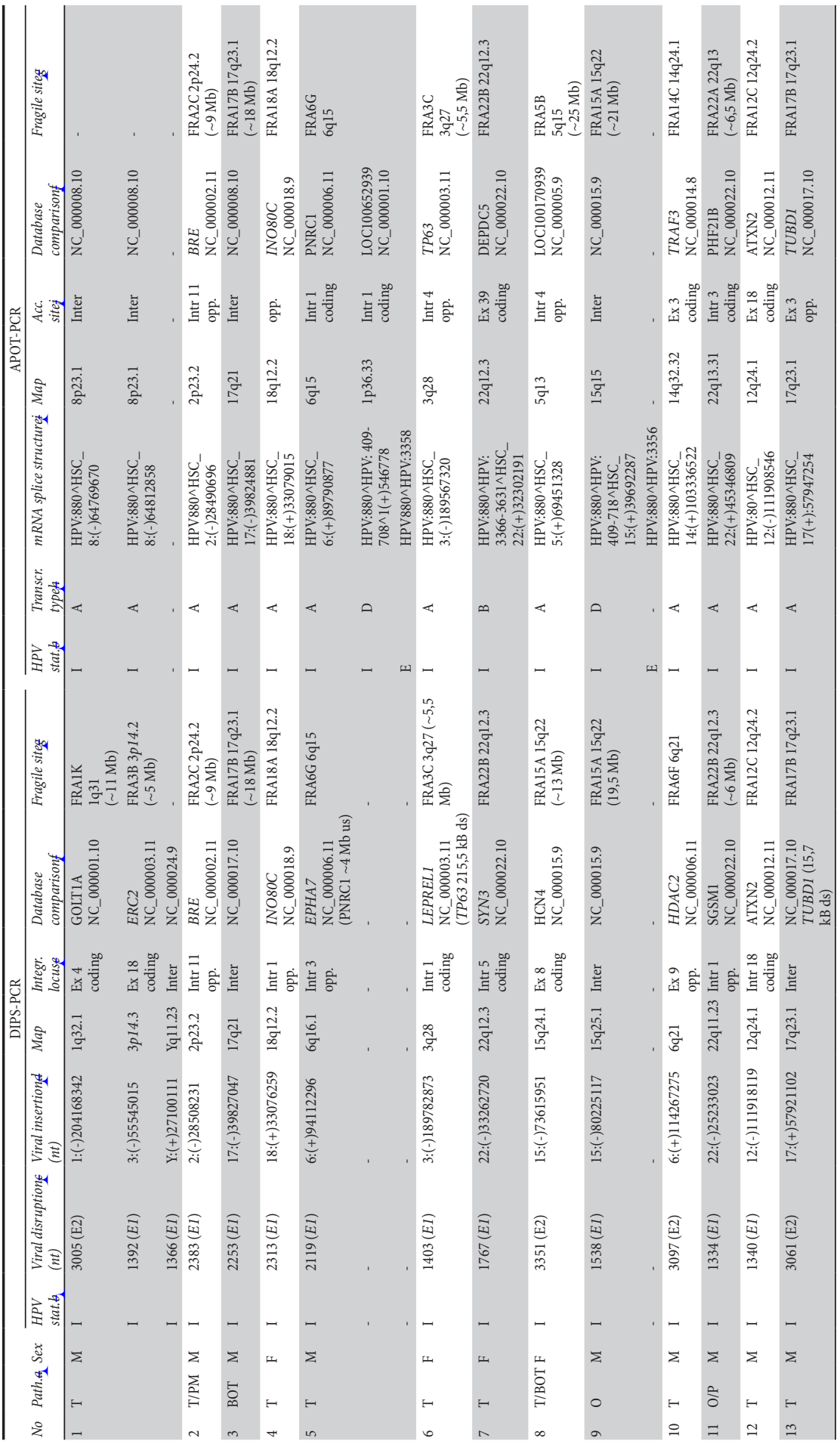




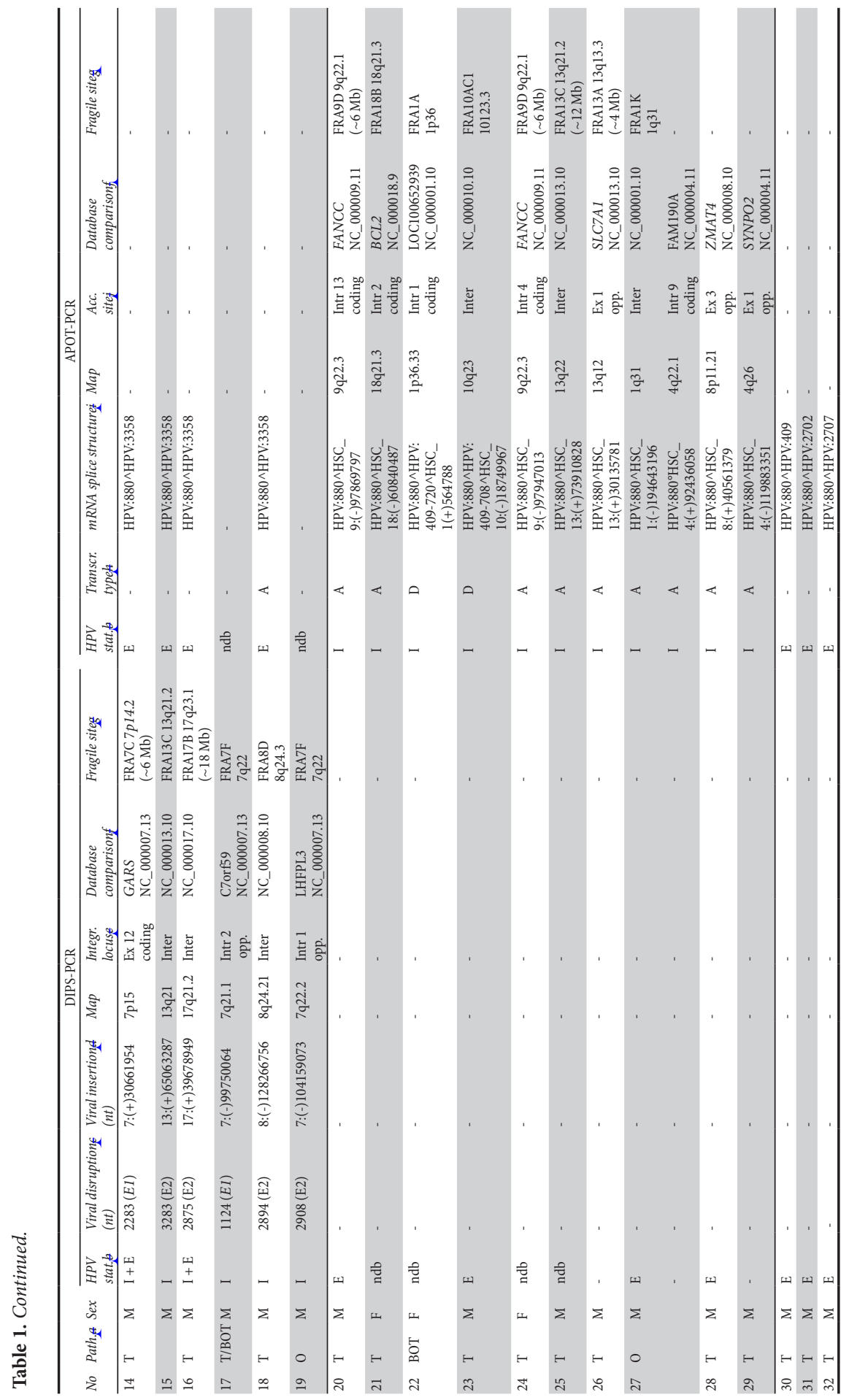




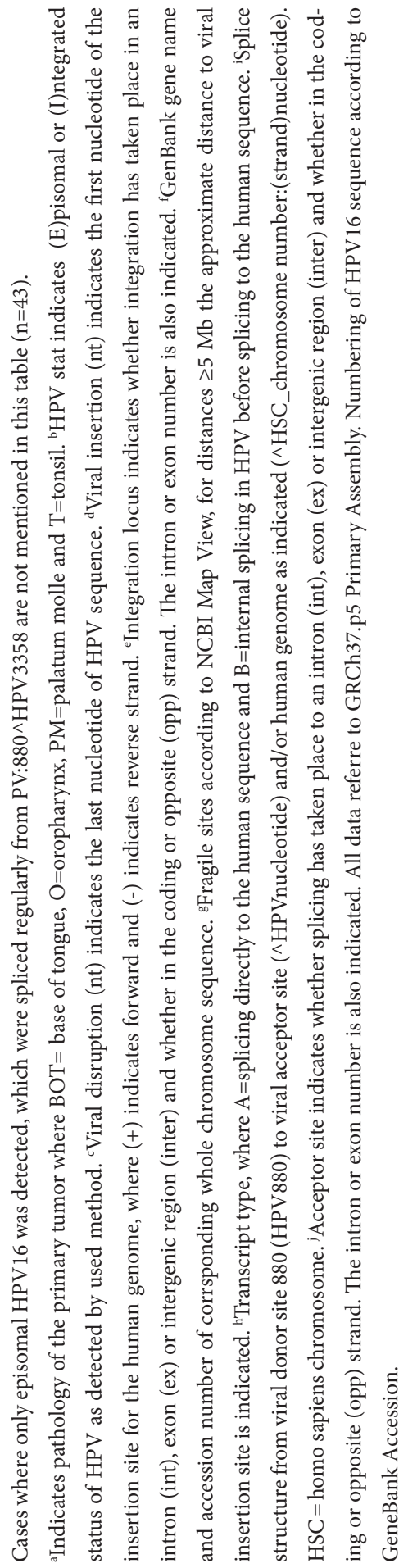


Although initial reports showed integration percentages of up to $88 \%$ by APOT$\mathrm{PCR}^{23}$, more recent studies analyzing integrated viral sequences using DIPS- or APOTPCR are in line with our findings as they showed integration percentages ranging from $7.4 \%{ }^{29}$ using DIPS-PCR up to 55\% using APOT-PCR ${ }^{9,30}$. Analysis of HNSCC using APOT-PCR showed integration ranging from $17 \%^{17}$ up to $66 \%^{16}$ of the HPV-positive samples. However, these studies analyzed only a small number of tumor-derived samples (12 and 9 respectively).

In line with these previous reports, we have also found integration sites distributed all over the human genome, without obvious preferences for any cytogenetic region. However, for anogenital carcinomas some integration sites tended to cluster to defined cytogenetic bands. Based on the results of our study, we cannot confirm this pattern for OPSCC, although the total number of integration sites found in our cohort might not be sufficient to observe possible clustering. However, it is interesting to note that we have found integration loci on chromosomes $8 \mathrm{q} 24.21,13 \mathrm{q} 22.1$ and $17 \mathrm{q} 21$, which were reported to harbour HPV integration clusters ${ }^{8}$. Furthermore, we found integration at $3 \mathrm{q} 28$ containing the LEPREL1 gene, which was spliced to TP63. Kraus et al. also reported two integration loci in this same region. This might point to an additional site for HPV integration clustering, which could indicate direct influence of HPV integration on the TP63 tumor suppressor gene. In addition, two independent integration events occurred in the FANCC gene located on $9 \mathrm{q} 22.3$. Alteration in this region have recently been reported to an early and frequent event in head and neck cancer development ${ }^{31 .}$

In our study, a total of $73 \%$ of integrated samples was found to be located in transcribed regions, which is in agreement with previous studies ${ }^{8-11,23,25,32}$. It is well established that only $2 \%$ of the total human genome codes for transcribed sequences, and we agree with Kraus et al. ${ }^{8}$ that integration is therefore not an entirely random event, even though the found integration sequences are distributed all over the genome. This hypothesis is further underlined by the high percentage of integration in sequences that code for tumor related genes.

From the total of 75 samples, 21 (26.3\%) integration sites were found using DIPSPCR and 26 (34.2\%) were found using APOT-PCR. However, only 11 sites (14.5\%) were found by both methods. Inconsistencies between DIPS- and APOT-PCR indicate that detection of integration-derived sequences might be influenced by the cellular environment and therefore could have missed integration events. These may include very long viral-cellular fusion products, high viral load, high viral gene expression, alterations of the HPV promotor, transcriptional silencing driven by cellular sequences and integration in head-to-tail tandem repeats. A combination of independant methods is therefore recommended for further studies to maximize the detection of viral integration.

The so far undescribed splicing from viral E1 to E6 gene and subsequently from from viral E7 gene to human cellular DNA (figure 2) suggests that HPV is integrated in head-to-tail tandem repeats in these cases. 
In two cases we have found integration sequences for both DIPS- and APOTPCR, however, the viral-cellular fusion transcript as detected by APOT-PCR turned out to be in opposite direction as compared to DIPS-PCR. In a third case the integration sequences found by DIPS- and APOT-PCR were derived from the same chromosome, although the found loci were $20 \mathrm{MB}$ apart. It has been shown that HPV DNA integration can lead to complex genomic rearrangements. Both rearrangement changing the orientation of the 5'-and 3' cellular sequences flanking the viral integration site, as well as deletions of larger genomic regions starting at the viral integration site have been reported ${ }^{33,34}$.

Taken together, the relatively high number of integration sites in either genes or predicted genes suggests that the disruption or deregulation of specific genes through HPV integration could contribute to the process of transformation and carcinogenesis. However, since we have only detected fusion products in 39.5\% of OPSCC, it is not likely that HPV16 integration is a necessary cause for tumorigenesis.

In conclusion, we report integration in specific or predicted genes. This may have a direct effect on the gene itself but could also have effect on other cellular genes and pathways due to complex genomic alterations at the site of integration ${ }^{35}$. The (tumor-specific) effects of these alterations on the process of transformation and tumorigenesis should be systematically evaluated in ongoing or future studies.

\section{Acknowledgements}

The following authors are acknowledged for their contribution to this chapter: Christian U. Hübbers and Jutta Kolligs from the Jean-Uhrmacher-Institute for Otorhinolaryngological Research, University of Cologne, Cologne, Germany; Jens-Peter Klussmann from the Department of Otorhinolaryngology and Head and Neck Surgery, School of Medicine, University Hospital Giessen, Giessen, Germany; Simon F. Preuss from Department of Otorhinolaryngology, Head and Neck Surgery, University Hospital of Cologne, Cologne, Germany; Uta Drebber from the Institute for Pathology, University Hospital of Cologne, Cologne, Germany; Frans C.S. Ramaekers from the Department of Molecular Cell Biology, GROW - School for Oncology and Developmental Biology, Maastricht University Medical Centre, Maastricht, the Netherlands; Bernd Kremer from the department of Otorhinolaryngology and Head and Neck Surgery, GROW - School for Oncology and Developmental Biology, Maastricht University Medical Centre, Maastricht, the Netherlands; Ernst-Jan M. Speel from the Depratment of Pathology, GROW School for Oncology and Developmental Biology, Maastricht University Medical Centre, Maastricht, the Netherlands. 


\section{References}

1 Parkin DM, Bray F, Ferlay J and Pisani P. Global cancer statistics, 2002. CA Cancer J Clin 2005; 55: 74-108.

2 Kamangar F, Dores GM and Anderson WF. Patterns of cancer incidence, mortality, and prevalence across five continents: defining priorities to reduce cancer disparities in different geographic regions of the world. J Clin Oncol 2006; 24: 2137-2150.

3 Jemal A, Bray F, Center MM, Ferlay J, Ward E and Forman D. Global cancer statistics. CA Cancer J Clin 2011; 61: 69-90.

4 Hafkamp HC, Manni JJ and Speel EJ. Role of human papillomavirus in the development of head and neck squamous cell carcinomas. Acta Otolaryngol 2004; 124: 520-526.

5 Klussmann JP, Weissenborn S and Fuchs PG. Human papillomavirus infection as a risk factor for squamous-cell carcinoma of the head and neck. N Engl J Med 2001; 345: 376; author reply 377.

6 Hafkamp HC, Manni JJ, Haesevoets A, Voogd AC, Schepers M, Bot FJ et al. Marked differences in survival rate between smokers and nonsmokers with HPV 16-associated tonsillar carcinomas. Int J Cancer 2008; 122: 2656-2664.

7 Olthof NC, Straetmans JM, Snoeck R, Ramaekers FC, Kremer B and Speel EJ. Next-generation treatment strategies for human papillomavirus-related head and neck squamous cell carcinoma: where do we go? Rev Med Virol 2012; 22: 88-105.

8 Kraus I, Driesch C, Vinokurova S, Hovig E, Schneider A, von Knebel Doeberitz M et al. The majority of viral-cellular fusion transcripts in cervical carcinomas cotranscribe cellular sequences of known or predicted genes. Cancer Res 2008; 68: 2514-2522.

9 Vinokurova S, Wentzensen N, Kraus I, Klaes R, Driesch C, Melsheimer P et al. Type-dependent integration frequency of human papillomavirus genomes in cervical lesions. Cancer Res 2008; 68: $307-$ 313.

10 Ziegert C, Wentzensen N, Vinokurova S, Kisseljov F, Einenkel J, Hoeckel M et al. A comprehensive analysis of HPV integration loci in anogenital lesions combining transcript and genome-based amplification techniques. Oncogene 2003; 22: 3977-3984.

11 Luft F, Klaes R, Nees M, Durst M, Heilmann V, Melsheimer P et al. Detection of integrated papillomavirus sequences by ligation-mediated PCR (DIPS-PCR) and molecular characterization in cervical cancer cells. Int J Cancer 2001; 92: 9-17.

12 Wentzensen N, Ridder R, Klaes R, Vinokurova S, Schaefer U and Doeberitz MK. Characterization of viral-cellular fusion transcripts in a large series of HPV16 and 18 positive anogenital lesions. Oncogene 2002; 21 : 419-426.

13 Mellin H, Dahlgren L, Munck-Wikland E, Lindholm J, Rabbani H, Kalantari M et al. Human papillomavirus type 16 is episomal and a high viral load may be correlated to better prognosis in tonsillar cancer. Int J Cancer 2002; 102: 152-158.

14 Koskinen WJ, Chen RW, Leivo I, Makitie A, Back L, Kontio R et al. Prevalence and physical status of human papillomavirus in squamous cell carcinomas of the head and neck. Int J Cancer 2003; 107: 401-406. 
15 Begum S, Cao D, Gillison M, Zahurak M and Westra WH. Tissue distribution of human papillomavirus 16 DNA integration in patients with tonsillar carcinoma. Clin Cancer Res 2005; 11: 5694-5699.

16 Lace MJ, Anson JR, Klussmann JP, Wang DH, Smith EM, Haugen TH et al. Human papillomavirus type 16 (HPV-16) genomes integrated in head and neck cancers and in HPV-16-immortalized human keratinocyte clones express chimeric virus-cell mRNAs similar to those found in cervical cancers. J Virol 2011; 85: 1645-1654.

17 Wiest T, Schwarz E, Enders C, Flechtenmacher C and Bosch FX. Involvement of intact HPV16 E6/ E7 gene expression in head and neck cancers with unaltered $p 53$ status and perturbed $p R b$ cell cycle control. Oncogene 2002; 21: 1510-1517.

18 Wieland U, Ritzkowsky A, Stoltidis M, Weissenborn S, Stark S, Ploner M et al. Communication: papillomavirus DNA in basal cell carcinomas of immunocompetent patients: an accidental association? J Invest Dermatol 2000; 115: 124-128.

19 Hafkamp HC, Speel EJ, Haesevoets A, Bot FJ, Dinjens WN, Ramaekers FC et al. A subset of head and neck squamous cell carcinomas exhibits integration of HPV 16/18 DNA and overexpression of $p 16^{I N K 4 A}$ and $p 53$ in the absence of mutations in $p 53$ exons 5-8. Int J Cancer 2003; 107: 394-400.

20 Klussmann JP, Gultekin E, Weissenborn SJ, Wieland U, Dries V, Dienes HP et al. Expression of p16 protein identifies a distinct entity of tonsillar carcinomas associated with human papillomavirus. Am J Pathol 2003; 162: 747-753.

21 Wittekindt C, Gultekin E, Weissenborn SJ, Dienes HP, Pfister HJ and Klussmann JP. Expression of p16 protein is associated with human papillomavirus status in tonsillar carcinomas and has implications on survival. Adv Otorhinolaryngol 2005; 62: 72-80.

22 Klussmann JP, Weissenborn SJ, Wieland U, Dries V, Kolligs J, Jungehuelsing M et al. Prevalence, distribution, and viral load of human papillomavirus 16 DNA in tonsillar carcinomas. Cancer 2001; 92: 2875-2884.

23 Klaes R, Woerner SM, Ridder R, Wentzensen N, Duerst M, Schneider A et al. Detection of high-risk cervical intraepithelial neoplasia and cervical cancer by amplification of transcripts derived from integrated papillomavirus oncogenes. Cancer Res 1999; 59: 6132-6136.

24 Vinokurova S, Wentzensen N, Einenkel J, Klaes R, Ziegert C, Melsheimer P et al. Clonal history of papillomavirus-induced dysplasia in the female lower genital tract. J Natl Cancer Inst 2005; 97: 18161821.

25 Wentzensen N, Vinokurova S and von Knebel Doeberitz M. Systematic review of genomic integration sites of human papillomavirus genomes in epithelial dysplasia and invasive cancer of the female lower genital tract. Cancer Res 2004; 64: 3878-3884.

26 Iavazzo C, Pitsouni E, Athanasiou S and Falagas ME. Imiquimod for treatment of vulvar and vaginal intraepithelial neoplasia. Int J Gynaecol Obstet 2008; 101: 3-10.

27 von Knebel Doeberitz M, Bauknecht T, Bartsch D and zur Hausen H. Influence of chromosomal integration on glucocorticoid-regulated transcription of growth-stimulating papillomavirus genes E6 and E7 in cervical carcinoma cells. Proc Natl Acad Sci U S A 1991; 88: 1411-1415. 
28 Jeon S and Lambert PF. Integration of human papillomavirus type 16 DNA into the human genome leads to increased stability of E6 and E7 mRNAs: implications for cervical carcinogenesis. Proc Natl Acad Sci U S A 1995; 92: 1654-1658.

29 Matovina M, Sabol I, Grubisic G, Gasperov NM and Grce M. Identification of human papillomavirus type 16 integration sites in high-grade precancerous cervical lesions. Gynecol Oncol 2009; 113: 120127.

30 Hillemanns P and Wang X. Integration of HPV-16 and HPV-18 DNA in vulvar intraepithelial neoplasia. Gynecol Oncol 2006; 100: 276-282.

31 Ghosh A, Ghosh S, Maiti GP, Mukherjee S, Mukherjee N, Chakraborty J et al. Association of FANCC and PTCH1 with the development of early dysplastic lesions of the head and neck. Ann Surg Oncol 2011;

32 Klimov E, Vinokourova S, Moisjak E, Rakhmanaliev E, Kobseva V, Laimins L et al. Human papilloma viruses and cervical tumours: mapping of integration sites and analysis of adjacent cellular sequences. BMC Cancer 2002; 2: 24.

33 Gallego MI, Schoenmakers EF, Van de Ven WJ and Lazo PA. Complex genomic rearrangement within the $12 \mathrm{q} 15$ multiple aberration region induced by integrated human papillomavirus 18 in a cervical carcinoma cell line. Mol Carcinog 1997; 19: 114-121.

34 Peter M, Stransky N, Couturier J, Hupe P, Barillot E, de Cremoux P et al. Frequent genomic structural alterations at HPV insertion sites in cervical carcinoma. J Pathol 2010; 221: 320-330.

35 Lockwood WW, Coe BP, Williams AC, MacAulay C and Lam WL. Whole genome tiling path array CGH analysis of segmental copy number alterations in cervical cancer cell lines. Int J Cancer 2007; 120: $436-443$ 



\section{Chapter 4}

\section{Comprehensive analysis of HPV16 integration in oropharyngeal squamous cell carcinomas reveals}

no significant impact of physical status on viral oncogene and virally disrupted human gene expression

Nadine C. Olthof ${ }^{1,2}$, Ernst-Jan M. Speel ${ }^{2,3}$, Jutta Kolligs ${ }^{4}$, Annick Haesevoets ${ }^{2}$, Mieke Henfling ${ }^{2}$, Frans C.S. Ramaekers ${ }^{2}$, Simon F. Preuss ${ }^{5}$, Uta Drebber 6 , Ulrike Wieland ${ }^{7}$, Steffi Silling ${ }^{7}$, Wan L. Lam ${ }^{8}$, Emily A. Vucic ${ }^{8}$, Bernd Kremer ${ }^{1}$, Jens-P. Klussmann ${ }^{9}$ and Christian U. Huebbers ${ }^{4}$

Departments of ${ }^{1}$ Otorhinolaryngology and Head and Neck Surgery, ${ }^{2}$ Molecular Cell Biology and

${ }^{3}$ Pathology, GROW - School for Oncology and Developmental Biology, Maastricht University Medical Centre, Maastricht, the Netherlands. ${ }^{4}$ Jean-Uhrmacher-Institute for Otorhinolaryngological Research, University of Cologne, Cologne, Germany. ${ }^{5}$ Department of Otorhinolaryngology, Head and Neck Surgery, ${ }^{6}$ Institute for Pathology ${ }_{1}{ }^{7}$ Institute of Virology, National Reference Centre for Papilloma- and Polyomaviruses, University Hospital of Cologne, Cologne, Germany. ${ }^{8}$ Department of Integrative Oncology, British Columbia Cancer Research Centre, Vancouver, Canada.

${ }^{9}$ Department of Otorhinolaryngology, Head and Neck Surgery, University Hospital of Giessen, Giessen, Germany.

Nadine C. Olthof, Ernst-Jan M. Speel, Jens Peter Klussmann and Christian U. Huebbers contributed equally to this work as first and last authors respectively 


\section{Abstract}

Infection with high-risk human papillomavirus (HPV) type 16 is an independent risk factor for the development of oropharyngeal squamous cell carcinomas (OPSCC). However, it is unclear whether viral integration is an essential hallmark in the carcinogenic process of OPSCC and whether HPV integration correlates with the level of viral gene transcription and influences the expression of disrupted host genes.

We analyzed 75 patients with OSCC. HPV16-positivity was proven by $p 16^{I N K A A}$ immunohistochemistry, PCR and FISH. Viral integration was examined using DIPS- as well as APOT-PCR. Viral E2, E6 and E7 gene expression levels were quantified by real time (RT)-PCR. Expression levels of 7 human genes disrupted by the virus were extracted from mRNA expression profiling data of 32 OSCC. Viral copy numbers were assessed by quantitative RTPCR in 73 tumors. We identified 37 HPV16-human fusion products indicating viral integration in $29(39 \%)$ OPSCC. In the remaining tumors (61\%) only episome-derived PCR products were detected. When comparing OPSCC with or without an integration-derived fusion product, we did not find significant differences in the mean expression of viral genes $E 2, E 6$ and $E$ 7, nuclear FISH staining patterns or the viral copy numbers per cell, nor did the expression of the HPV-invaded genes differ from either group of OPSCC. In conclusion, our data do not support the hypothesis that integration affects the levels of viral and/or HPV-disrupted human gene transcripts. Thus constitutive, rather than a high level, of expression of oncogene transcripts appears to be required in HPV-related OPSCC. 


\section{Introduction}

Approximately 600.000 new cases of head and neck squamous cell carcinoma (HNSCC) have been estimated to occur worldwide in 2011, ranking them in sixth position of all carcinomas $^{1-3}$. Risk factors for the development of HNSCC include environmental factors, excessive tobacco and alcohol use, as well as human papillomavirus (HPV) infections. Particularly oropharyngeal squamous cell carcinomas (OPSCC) are associated with HPV164. This group of carcinomas shows clinicopathological and molecular characteristics that differ from alcohol- and tobacco-induced carcinomas ${ }^{4-6}$. Studies that have assessed the prevalence of HPV-induced OPSCC report frequencies ranging from $20 \%$ to up to $90 \%{ }^{5,7-9}$.

Although integration of the viral DNA into the host genome is not part of the normal viral life cycle, studies in anogenital carcinomas have shown a significant correlation between integration and progression of dysplastic lesions to invasive carcinomas ${ }^{10,11}$. For example in uterine cervical carcinomas, it has been shown that oncogene transcripts indicating viral integration can be identified in $55 \%$ of HPV 16 positive cases and $92 \%$ of the HPV 18 positive cases, and that particularly for HPV 16 the integration events have been found to occur already in cervical intraepithelial neoplasia (CIN $)^{11}$. We recently also detected viral integration in head and neck oropharyngeal dysplasia adjacent to squamous cell carcinoma by FISH, however these dysplasia are a rare finding in the oropharynx ${ }^{12}$.

Using Amplification of Papillomavirus Oncogene Transcripts PCR (APOT-PCR), so far only two studies report HPV16 integration in 2 out of 4 and 6 out of 9 tumors in HPV-DNA positive OPSCC ${ }^{13,14}$.

However, there is controversy with respect to the relation between viral integration and viral gene expression. Integration of HPV DNA in uterine cervical squamous cell carcinomas (UCSCC) has been correlated to disruption of the viral regulatory gene $E 2^{15,16}$. Studies in cell lines have shown that E2 represses the viral E6 and E7 expression ${ }^{17}$. In the uterine cervical cell line W12, integration of HPV was shown to result in higher levels of the oncogenes E6/E7 and a selective growth advantage over cells harboring extrachromosomal HPV DNA ${ }^{18}$. This had led to the hypothesis that the levels of viral E6 and $E 7$ transcripts are higher in lesions in which viral integration resulted in E2 disruption, which is thought to lead to deregulation of cell cycle control ${ }^{19-21}$.

On the other hand, a study in primary keratinocytes immortalized with HPV16 genomes has shown that disruption of the $E 2$ gene sequence upon viral integration does not result in increased expression of the viral E6 and $E 7$ oncogenes ${ }^{13}$. In addition, a publication by Häfner et al. using APOT-PCR has shown no correlation between the integration state of the viral genome and the expression of the viral gene E6 in a collection of 55 HPV16-positive cervical carcinoma samples ${ }^{22}$. It would be interesting to examine viral physical status and E2, E6 and E7 gene expression in primary OPSCC since this information is lacking. 
Here we present the HPV16 integration status for a collection of 75 HPV16-DNAand $\mathrm{p} 16^{\mathrm{INK} 4 \mathrm{~A}}$ positive OPSCC using APOT- and Detection of Integrated Papillomavirus Sequences PCR (DIPS-PCR), and its relation to the level of gene expression for the viral genes E2, E6 and E7, a number of human genes disrupted by viral integration and viral DNA-load.

\section{Materials and methods}

\section{Subjects and Material}

Fresh frozen clinical OPSCC samples from 75 patients treated at the Departments of Otorhinolaryngology and Head and Neck Surgery of the University Hospitals of Cologne and Maastricht between 1994 and 2009 were collected from the archives of the Departments of Pathology of both hospitals. Patient material was used according to the code for proper secondary use of human tissue. Inclusion criteria were the availability of sufficient fresh frozen tumor tissue containing $\geq 70 \%$ tumor cells, high quality tumor DNA and RNA and HPV16 infection, as detected by HPV-specific DNA analysis ${ }^{4,5,23,24}$ and overexpression of the surrogate marker $\mathrm{p} 16^{\mathrm{INK} 4 \mathrm{~A}}$ as detected by immunohistochemistry ${ }^{25,26}$.

Patient age ranged from $44-83$ years (median 62.7 years). Fifty-seven $(76.0 \%)$ patients were male and eighteen $(24.0 \%)$ were female.

\section{Amplification of Papillomavirus Oncogene Transcripts PCR (APOT-PCR)}

Total RNA was extracted from five $10 \mu \mathrm{m}$-thick snap frozen tissue sections using the RNeasy mini kit (Qiagen, Hilden, Germany) and DNase treatment. RNA concentration and quality were determined by RNA StdSens Chips on a BioRad Experion system (BioRad, Munich, Germany). HPV oncogene transcripts were amplified as described before ${ }^{27}$. Briefly, reverse transcription was performed using $25 \mu \mathrm{M}$ oligo- $(\mathrm{dT})_{17}$ primer coupled to a linker sequence (dT) ${ }_{17}$-p3, $10 \mathrm{mM}$ dNTPs each, 0.1 M DTT, 5x RT-buffer and SuperScript reverse transcriptase (Invitrogen, Karlsruhe, Germany) ${ }^{28}$. Quality of transcribed cDNA was determined by a standard GAPDH gene PCR (441 bp product). First-strand cDNAs containing viral oncogene sequences were subsequently amplified with semi-nested PCR using HPV-E7 specific 5'primers and oligo(dT) and adaptor primers (3'). PCR products were separated on a 1.2\% agarose gel. Both bands typical for episomal and integration status were cut out, purified using the QIAGEN Gel extraction kit (QIAGEN, Hilden, Germany) and sequenced (GATC Biotech, Konstanz, Germany). Sequence results were analyzed using the BLASTN program and further mapped using map viewer (both NCBI) ${ }^{29,30}$. 


\section{Detection of Integrated Papillomavirus Sequences PCR (DIPS-PCR)}

Integrated papillomavirus sequences were detected using the Detection of Integrated Papillomavirus Sequences-PCR (DIPS-PCR) assay, as described earlier ${ }^{31}$. Briefly, genomic DNA was digested using the Sau3AI restriction enzyme and an enzyme-specific adapter was ligated to the restriction-digested DNA using T4 DNA ligase (Roche Diagnostics, Mannheim, Germany). Linear PCR was performed using 5 HPV16 specific forward primers in independent setups, all using the same specific adapter primer 1 (AP1). All independent PCRs were followed by individual exponential PCRs using further virusspecific forward primers and the AP1 reverse primer. PCR products were separated on a $1.2 \%$ agarose gel and products of interest were excised, purified, sequenced and analyzed as described before.

\section{Gene expression analysis}

\section{mRNA Expression Profiling}

Total RNA was collected from a subset of 32 samples, randomly selected from the 75 patients in this study. Samples were analysed using Agilent Whole Human Genome $4 \times 44 \mathrm{~K}$ Microarrays, which represent more than 41,000 unique human transcripts. Labelling and hybridizations were performed according to the manufacturer's instructions (Agilent Technologies). Hybridized arrays were scanned using an Axon GenePix 4000B or 4200A scanner. Microarray analysis was performed using GenePix Pro 6.0.1.25. For normalization processing, the median array intensity was calculated based on the background-subtracted intensity value for all spots excluding control type spots on the array. The background-subtracted intensity value of each spot was then divided by the median array intensity of each microarray.

In the 32 tumor samples, 6 samples showed fusion products that were located within 7 genes. Normalized expression data for these genes were collected for all $32 \mathrm{sam}$ ples. Per gene the expression in the sample with integration in that gene was compared to samples with or without an identified fusion product. Graphs were made using Graph Pad Prism 5.

\section{HPV16 oncogene expression by RT-PCR}

RNA isolated from 61 samples of which sufficient RNA was available after APOT analysis, was reverse transcribed using the iScript cDNA Synthesis Kit (BioRad Laboratories, Hercules, CA, USA). RT-PCR reactions were performed using SensiMix SYBR \& Fluorescein (GC Biotech, Alphen a/d Rijn, the Netherlands). The following HPV-specific primers were used (see figure 1): E2 (87 bp product) forward primer 5'- TGATAG- 
TACAGACCTACGTGACCATATAGA-3' (Primer Express v2.0 (Applied Biosystems, Carlsbad, USA)) and reverse primer 5'- ATTACAAGGCCAGAGAAATGGG-3' (Primer Express); E6 (106 bp product) forward primer 5'-CAGTTATGCACAGAGCTGCAA- $3^{\prime 32}$ and reverse primer 5' - ATGACTTTGCTTTCGGGATT-3'32; E7 (86 bp product) forward primer 5'AGAGGAGGAGGATGAAATAGATGGT-3'and reverse primer 5'-CAATATTGTAACCTTTTGTTGCAAGTG-3' (designed using Primer-BLAST (National Center for Biotechnology Information (NCBI) $)^{33}$. Because of limited material, E7 expression analysis was performed on 45 samples. The detection of the housekeeping gene Hypoxanthine Phosphoribosyltransferase (HPRT) was used for normalization of mRNA levels: forward primer 5'CACTGGCAAAACAATGCAGACT -3' and reverse primer 5'GTCTGGCTTATATCCAACACTTCGT -3. Cell lines SiHa and CaSki were used as positive controls, and the HPV18-positive cell line HeLa was used as a control for HPV16 specificity.

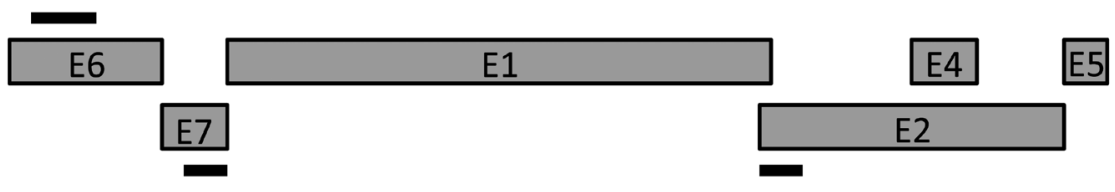

Figure 1. HPV16 genome showing the localization of the RT-PCR-products obtained for E2, E6 and E7 viral oncogenes.

\section{Fluorescence In Situ Hybridisation (FISH) for HPV16}

FISH was performed as described previously, on $4 \mu \mathrm{m}$ thick paraffin embedded tissue sections of 61/75 samples for which formalin-fixed, paraffin-embedded tumor blocks were available ${ }^{5,25,34}$. Briefly, sections were deparaffinised, pretreated with $85 \%$ formic acid $/ 0.3 \%$ $\mathrm{H}_{2} \mathrm{O}_{2}, 1 \mathrm{M} \mathrm{NaSCN}$ and $4 \mathrm{mg} / \mathrm{ml}$ pepsin, postfixed in $4 \%$ formaldehyde in PBS and dehydrated in an ascending ethanol series. For the co-localization experiments, we used biotin-labelled HPV16 probes (PanPath, Amsterdam, the Netherlands) together with digoxigenin-labelled BAC-clones containing human DNA sequences also identified in the viral-human fusion PCR products obtained by APOT/DIPS PCR. These BAC clones were grown according to the manufacturer's instructions (BACPAC Resources Centre, Childrens Hospital Oakland Research Institute, Oakland, USA). DNA was isolated using the Nucleobond BAC-100 kit (BioKé, Leiden, the Netherlands). Both probes were applied under a coverslip in a hybridization mixture containing $2 \mathrm{ng} / \mu \mathrm{l} \mathrm{HPV} 16$ probe, $10 \mathrm{ng} / \mu \mathrm{l} \mathrm{BAC}$ probe, $50 \%$ formamide, $2 \times$ SSC $\mathrm{pH} 7.0$, 50x excess salmon sperm DNA (Sigma) and 10x excess human CoT DNA. 
Probes and tissue DNA were denatured simultaneously for 5 minutes at $80^{\circ} \mathrm{C}$ prior to hybridization overnight at $37^{\circ} \mathrm{C}$ in a humid chamber. After hybridization the preparations were washed stringently in $2 \times \mathrm{SSC}+0.05 \%$ tween- 20 at $42^{\circ} \mathrm{C}(2$ times $5 \mathrm{~min}), 0.1 \times \mathrm{SSC}$ at $61^{\circ} \mathrm{C}$ ( 2 times $\left.5 \mathrm{~min}\right)$ and $4 \times \mathrm{SSC}+0.05 \%$ tween- 20 at RT. Biotin-labelled probe was detected using peroxidase-conjugated-avidine (Dako, Glostrup, Denmark; 1:200 diluted in 4x SSC containing $5 \%$ non-fat dry milk; 30 minutes at $37^{\circ} \mathrm{C}$ ) and biotin-conjugated goat-antiavidine (Vector laboratories, Burlingame, CA; 1:100 diluted in $4 \times \mathrm{SSC}$ containing 5\% nonfat dry milk; 30 minutes at $37^{\circ} \mathrm{C}$ ). Thereafter, a tyramide signal amplification reaction was performed under a coverslip by applying $50 \mu \mathrm{C}$ Cy-labelled tyramide in PBS containing $0.1 \mathrm{M}$ imidazole, $\mathrm{pH} 7.6$ and $0.001 \% \mathrm{H}_{2} \mathrm{O}_{2}$ for 10 minutes at $37^{\circ} \mathrm{C}$. The digoxigenin-labelled probe was detected using mouse-anti-digoxigenin (Dako; 1:200), followed by TRITC-conjugated rabbit-anti-mouse (Dako;1:1000) and finally TRITC-conjugated swine-anti-rabbit (Dako; 1:100); incubated for 30 minutes at $37^{\circ} \mathrm{C}$. Finally, slides were washed and dehydrated in an ascending ethanol series and mounted in Vectashield (Vector laboratories, Burlingame, CA) containing 4',6-diamidino-2-phenylindole (DAPI; Sigma; $0.2 \mu \mathrm{g} / \mu \mathrm{l}$ ).

\section{Viral load}

Viral load of HPV16 was determined using real-time fluorescence PCR with type-specific primers and probes as described earlier ${ }^{26}$. Briefly, viral load was expressed as the number of HPV16 DNA copies per $\beta$-globin-gene copy. Gene copy numbers of $\beta$-globin were determined using the LightCycler-Control Kit DNA (Roche Molecular Biochemicals) according to the manufacturer's instructions as previously described ${ }^{37}$. Calculation of initial copy numbers in samples was performed by the LightCycler 480 software (Version 1.5) using a standard curve generated with exactly quantified HPV DNA standards (ten-fold dilution series of full length HPV16 plasmid) that were amplified in the same PCR run ${ }^{35-37}$. The analytical sensitivity of the assay was ten copies of HPV16 standard DNA. A negative control (water or DNA extracted from RTS3B cells that are negative for HPV) was included in each run and never yielded fluorescence signals above the background ${ }^{36}$.

\section{Statistics}

Differences in viral and human gene expression levels were analyzed using a 2-tailed Fisher's exact test after testing for equality of variances. A significance level of $p \leq 0.05$ was chosen for all analyses. To test whether a single sample deviated from a group of samples, SPSS was used to identify outliers. This was defined as any value that lays more than 1.5 times the interquartile range below the first quartile in a Box-and-Whisker Plot from all samples, or more than 1.5 times the interquartile range above the third quartile. All calculations were performed using IBM SPSS Statistics 19. 


\section{Results}

\section{Detection of viral integration by DIPS- and APOT-PCR}

Table 1 in chapter 3 and figure 1 in chapter 3 summarize the integration sites of HPV16 into the genome of 29 of the 75 HPV16 DNA- and p16 ${ }^{\mathrm{INK} 4 \mathrm{~A}}$-positive OPSCC (39\%) as identified by DIPS- and APOT-PCR. Exclusively episomal PCR products were detected in the remaining 46 tumors (61\%).

In the 29 tumors with viral integration a total of 37 fusion products were identified, of which 10 harbored cellular sequences corresponding to intergenic regions and 27 to known or predicted genes, including 12 tumor-related genes (BCL2, BRE, EPHA7, FANCC (2x), HDAC2, INO80C, LEPREL1, SYNPO2, TP63, TRAF3, TUBD1), 5 genes involved in deregulated tumor-related pathways (ERC2, GARS, SLC7A1, SYN3, ZMAT4), and 10 genes with no known role in tumorigenesis. All genes were verified using the ATLAS of genetics and cytogenetics in oncology and hematology Database ${ }^{38}$ and the UniProtKB Database ${ }^{39}$.

\section{Detection of gene expression}

Subsequently, we analyzed whether HPV16 integration as detected by PCR, correlated with the level of expression of the invaded gene. In addition, we determined whether integration correlated with the expression of the viral genes E2, E6 and E7.

\section{Expression of genes disrupted by HPV}

We extracted the level of expression of HPV-invaded genes from expression profiling data of a subset of 32 OPSCC, in which HPV16 integrated within a gene in 6 out of 32 OPSCC, one of which contained two different integration sites (sample 10, table 1 in chapter 3). For each gene, its expression was compared between the single sample with HPV integration in the affected gene, the group of samples showing exclusively episomal PCR products $(n=20)$ and the group of samples with fusion products harboring sequences derived from other chromosomal loci $(n=11)$ (figure 2). In all cases there was no significant change in the mean mRNA expression levels of the HPV-invaded genes between the subgroups with or without a fusion product. In the tumor with the HPV integration in the particular gene, the expression did not surpass the 1.5 interquartile range (IQR) of the group of samples with integration-derived fusion products, as calculated using SPSS, in 6 of the 7 genes. In the tumor with integration in the FANCC gene, the expression of the gene fell between 1.5 and 3 times the IQR and was considered a mild outlier. However, one additional sample without a fusion product surpassed the IQR more than 3 times and was considered an extreme outlier. 

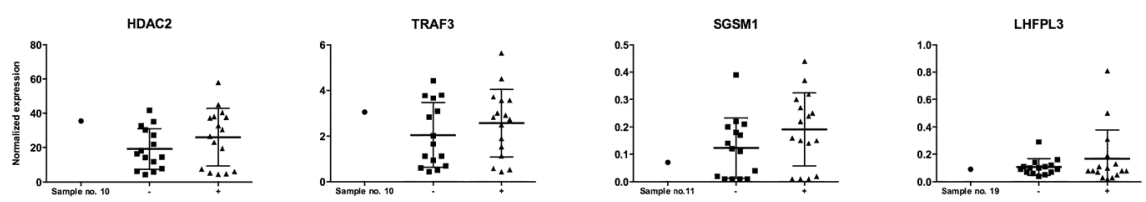

Sample without $(-)$ or with $(+)$ fusion product
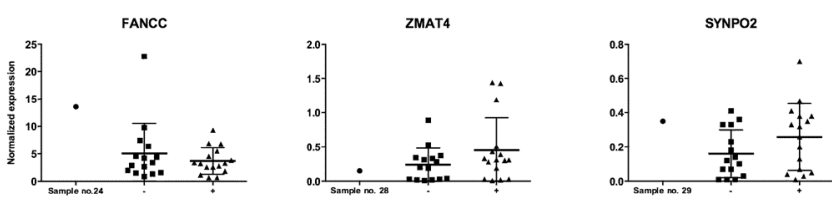

Sample without (-) or with (+) fusion product

Figure 2. Expression intensities for genes affected by HPV integration. The expression of a gene, affected by HPV integration in one sample, is compared to the expression of that gene in samples where exclusively episomal PCR products could be detected using APOT- and/or DIPS-PCR, and to the expression in samples where fusion products could be identified. Bars: Mean with standard deviation.

In conclusion, our data suggest that the mRNA expression of a gene invaded by HPV16 does not differ from the expression of that gene in samples where it has not been disrupted by the virus.

\section{Viral gene expression}

Viral gene expression could be assessed in 63 cases. APOT-PCR was able to detect a PCR product in 59 of these cases, however, the expression levels of E2, E6 and E7 as detected using qRT-PCR, varied widely. The viral gene expression of the 4 cases without detectable APOT-PCR product was nearly zero, indicating that the viral genome is not transcribed.

When comparing cases in which a fusion transcript was detected using APOTPCR (i.e. actively transcribed fusion product) with the remaining cases, no significant differences were seen in the mean $\log 2$ expression levels of either E2 (1717 vs. 97; $p=0.308$ ), E6 (1859 vs. $195, p=0.344$ ) or $E 7$ (1724 vs. $8, p=0.2943$ ) (see figure 3 ). Rather, a large variation in expression levels of these viral E2, E6 and E7 genes was observed, independent of HPV integration status.

\section{Viral load}

To determine whether viral load correlated with the integration status as determined using APOT- and/or DIPS-PCR and FISH, we have performed RT-DNA-PCR in 73 OPSCC samples.

Viral load ranged from $6.8^{\star} 10^{-6}$ up to 194 HPV DNA copies per $\beta$-globin gene copy. When comparing the average viral load in cases in which a fusion product was de- 
tected using APOT- and/or DIPS-PCR with the remaining cases, no significant differences were seen ( 14 vs. 17 HPV DNA copies / $\beta$-globin; $p=0.683$ ). No correlation was seen between the mean $\log 2$ expression levels of the viral genes E2, E6 or E7 and the viral load.

\section{Discussion}

In this study we have comprehensively analyzed a large collection of 75 HPV16 positive OPSCC for their HPV16 physical status (episomal vs. integrated) and its relation to viral oncogene expression and virally disrupted human genes. In particular we were interested to see if cases with proven integration would show higher $E 6 / E 7$ viral oncogene expression than E2 expression as suggested by studies with cervical cancer cell lines ${ }^{17,19-21}$. By detecting viral-human fusion products with APOT- and/or DIPS-PCR in 39\% of these cases we provided direct evidence for viral integration. The so-called episomal products obtained by DIPS- and/or APOT-PCR in the remaining cases are indicative for the presence of episomal HPV DNA, although they by themselves provide no proof for this assumption, because they could eventually also arise from integrated head to tail repeats of the viral genome. In this respect, two recently publisched studies have shown that

A

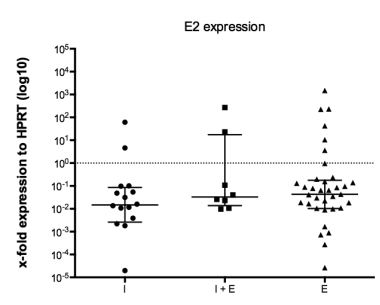

C

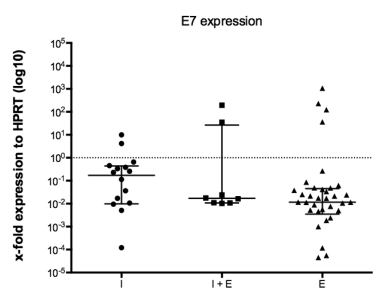

B

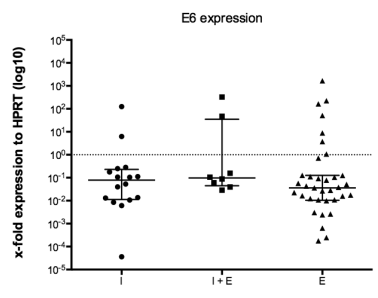

D

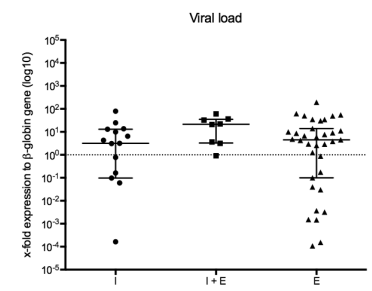

Figure 3. Expression of the viral genes E2, $E 6$ and $E 7$ and viral load. (A-C) Expression of the viral genes has been normalized to HPRT expression. (D) Viral load has been normalized to $\beta$-globin. $\mathrm{E}=$ episomal, $\mathrm{E}+\mathrm{I}=$ episomal and integrated, $\mathrm{I}=$ integrated. Bars: Median with interquartile range. 
using -DIPS-PCR with other primer combinations or multiplex PCR followed by massive parallel sequencing may detect additional sites of HPV integration which is in agreement with our findings comparing DIPS- and APOT-PCR ${ }^{40,41}$. The expression of HPV16 interrupted genes as well as viral genes E2, E6 and E7 in these tumors, however, did not differ significantly from cases where no fusion product was detected. Furthermore, the cases with integration showed no notable differences in viral load in comparison with the remaining tumors. These data indicate that HPV16 integration in these tumors does not necessarily affect the levels of HPV-disrupted human gene transcripts and/or viral gene transcripts. Thus constitutive rather than a high level of expression of oncogene transcripts appears to be required in HPV-related OPSCC.

We identified integration sites by APOT- and/or DIPS-PCR in 27 out of 75 OPSCC, of which 21 showed one, 5 showed two and 1 case showed four integration sites. In addition, 8 of these 27 tumors also harbored episomal viral DNA. Exclusively viral HPV16 DNA or RNA sequences indicating the presence of episomal virus were identified in the remaining 48 OPSCC. This finding is in agreement with results on a series of HPV 16 positive cervical squamous cell carcinomas in which $55 \%$ showed viral integration by APOT-PCR ${ }^{11}$. In the OPSCC, integration sites showed to be distributed all over the human genome with half of them near fragile sites and some of them in previously detected clusters of viral integration (3q28, 8q24.21, 13q22.1 and 17q21) ${ }^{42}$. Interestingly, in 27 out of 37 detected sequences HPV16 directly interrupted known or predicted genes. Taken together, these data suggest that HPV16 integration is not simply a random event, but rather has a preference for less protected and more accessible chromosomal regions like transcribed tumor-genes and fragile sites. It can be speculated that integration takes place in genes which are highly expressed during carcinogenesis rather than that the integration itself affecting the genomic sites is the driving force.

We had access to mRNA expression profiling data of a subset of the OPSCC used in this study including 6 cases with proven integration ( 7 sites in total). In these cases integration of HPV16 occurred within gene sequences, including the known tumor related genes FANCC, HDAC2, SYNPO2 and TRAF3. Indeed, expression of FANCC and HDAC2 genes has been reported to play a role in $\mathrm{HNSCC}^{43-46}$. Viral integration, however, did not lead to significantly different expression of the interrupted gene in comparison to OPSCC having integration in another DNA sequence or showing solely episomal virus. This is in contrast to a recent study of our group showing that integration of low-risk HPV6 in the $A K R 1 C 3$ gene resulted in loss of gene expression in a laryngeal carcinoma ${ }^{47}$. In this case, however, the other gene copy was lost in the tumor as shown by array CGH analyses. In the 6 OPSCC studied here, no loss of the chromosomal regions containing the virally interrupted genes has been detected by array CGH (Olthof, Lam, unpublished results). This indicates that one or more expressed gene copies are still present in these tumors, which can mask a possible effect of the integration on gene expression. On the other hand, this might also point to the fact that viral integration is not per se meant to deregulate the 
interrupted gene in the cell, as also can be concluded by the finding of HPV16 integrated in intergenic sequences of 10 OPSCC in this study. In conclusion, these data suggest that if there is an effect of viral integration on carcinogenesis, affecting the genomic site is unlikely to be the driving force in OPSCC. Nevertheless, this has to be confirmed on the protein level in further studies.

Alternatively, integration might have an effect on viral oncogene E6 and/or E7 expression. In this respect it has been hypothesized that integration leads to disruption of the viral E2 gene, which as a consequence cannot regulate E6 and E7 gene expression anymore from the LCR promoter region. Our DIPS-PCR data show that integration always affected the $E 2$ gene, either by disrupting the viral $E 2$ gene itself ( $38 \%)$ or by disrupting the upstream E1 gene (62\%), also leading to E2 loss. Nevertheless, in most of these tumors E2 mRNA transcripts were detectable at different levels of expression and these transcript levels did not differ significantly from those detected in OPSCC with episomal virus. This is in contrast to the results of Häfner et al., which showed a decrease in E5 transcript levels (downstream of E2) in uterine cervical lesions with integrated HPV16 ${ }^{22}$. Nevertheless, a rather constant transcription level of E6 oncogene transcripts was detected independent of the physical status of the virus in these lesions. In OPSCC, we also observed a broad distribution for E6 and E7 transcript levels independent of a detected viral integration event. This points to the fact that a constitutive expression of viral transcripts seems to be required within tumors. Only in a few cases very high levels of viral gene transcripts (E2 as well as E6 and E7) were detected, indicating that mechanisms other than E2 binding to the viral LCR promoter region might influence transcription levels such as methylation of the LCR region ${ }^{48,49}$.

In conclusion our data indicate that HPV physical status (extrachromosomal episomes or host DNA integrated) does not affect the levels of viral and/or HPV-disrupted human gene transcripts. Therefore constitutive and not a high level of expression of oncogene transcripts appears to be required in HPV-related OPSCC.

\section{Acknowledgements}

We would like to thank Oliver Siefer, Dirk Vellinga and Zlatan Mujagic for technical assistance. Primer sequences for HPRT were kindly provided by Prof. Dr. L. Hofland from Erasmus Medical Centre, Rotterdam, the Netherlands. The sponsors had no role in the study design, data collection, analysis and interpretation of the data, writing the article, and decision to submit the article for publication. This study was supported by the Koeln Fortune Program, Faculty of Medicine, University of Cologne, Cologne, Germany (Grant number 40/2010 to CUH) and the Jean Uhrmacher Foundation, Cologne, Germany. 


\section{References}

1 Jemal A, Bray F, Center MM, Ferlay J, Ward E and Forman D. Global cancer statistics. CA Cancer J Clin 2011; 61: 69-90.

2 Kamangar F, Dores GM and Anderson WF. Patterns of cancer incidence, mortality, and prevalence across five continents: defining priorities to reduce cancer disparities in different geographic regions of the world. J Clin Oncol 2006; 24: 2137-2150.

3 Parkin DM, Bray F, Ferlay J and Pisani P. Global cancer statistics, 2002. CA Cancer J Clin 2005; 55: 74-108.

4 Olthof NC, Straetmans JM, Snoeck R, Ramaekers FC, Kremer B and Speel EJ. Next-generation treatment strategies for human papillomavirus-related head and neck squamous cell carcinoma: where do we go? Rev Med Virol 2012; 22: 88-105.

5 Hafkamp HC, Manni JJ, Haesevoets A, Voogd AC, Schepers M, Bot FJ et al. Marked differences in survival rate between smokers and nonsmokers with HPV 16-associated tonsillar carcinomas. Int J Cancer 2008; 122: 2656-2664.

6 Klussmann JP, Mooren JJ, Lehnen M, Claessen SM, Stenner M, Huebbers CU et al. Genetic signatures of HPV-related and unrelated oropharyngeal carcinoma and their prognostic implications. Clin Cancer Res 2009; 15: 1779-1786.

7 Begum S, Cao D, Gillison M, Zahurak M and Westra WH. Tissue distribution of human papillomavirus 16 DNA integration in patients with tonsillar carcinoma. Clin Cancer Res 2005; 11: 5694-5699.

8 Koskinen WJ, Chen RW, Leivo I, Mäkitie A, Bäck L, Kontio R et al. Prevalence and physical status of human papillomavirus in squamous cell carcinomas of the head and neck. Int J Cancer 2003; 107: 401-406.

9 Mellin H, Dahlgren L, Munck-Wikland E, Lindholm J, Rabbani H, Kalantari M et al. Human papillomavirus type 16 is episomal and a high viral load may be correlated to better prognosis in tonsillar cancer. Int J Cancer 2002; 102: 152-158.

10 Kraus I, Driesch C, Vinokurova S, Hovig E, Schneider A, von Knebel Doeberitz M et al. The majority of viral-cellular fusion transcripts in cervical carcinomas cotranscribe cellular sequences of known or predicted genes. Cancer Res 2008; 68: 2514-2522.

11 Vinokurova S, Wentzensen N, Kraus I, Klaes R, Driesch C, Melsheimer P et al. Type-dependent integration frequency of human papillomavirus genomes in cervical lesions. Cancer Res 2008; 68: 307-313.

12 Mooren JJ, Kremer B, Claessen SM, Voogd AC, Bot FJ, Peter Klussmann J et al. Chromosome stability in tonsillar squamous cell carcinoma is associated with HPV16 integration and indicates a favorable prognosis. Int J Cancer 2013; 132: 1781-1789.

13 Lace MJ, Anson JR, Klussmann JP, Wang DH, Smith EM, Haugen TH et al. Human papillomavirus type 16 (HPV-16) genomes integrated in head and neck cancers and in HPV-16-immortalized human keratinocyte clones express chimeric virus-cell mRNAs similar to those found in cervical cancers. J Virol 2011; 85: 1645-1654. 
Comprehensive analysis of HPV16 integration in OPSCC reveals no significant impact of physical status on viral oncogene and virally disrupted human gene expression

14 Wiest T, Schwarz E, Enders C, Flechtenmacher C and Bosch FX. Involvement of intact HPV16 E6/ E7 gene expression in head and neck cancers with unaltered $p 53$ status and perturbed $p R b$ cell cycle control. Oncogene 2002; 21: 1510-1517.

15 Arias-Pulido H, Peyton CL, Joste NE, Vargas H and Wheeler CM. Human papillomavirus type 16 integration in cervical carcinoma in situ and in invasive cervical cancer. J Clin Microbiol 2006; 44: 1755-1762.

16 Ziegert C, Wentzensen N, Vinokurova S, Kisseljov F, Einenkel J, Hoeckel M et al. A comprehensive analysis of HPV integration loci in anogenital lesions combining transcript and genome-based amplification techniques. Oncogene 2003; 22: 3977-3984.

17 Rampias T, Sasaki C, Weinberger P and Psyrri A. E6 and E7 gene silencing and transformed phenotype of human papillomavirus 16-positive oropharyngeal cancer cells. J Natl Cancer Inst 2009; 101: 412-423.

18 Jeon S, Allen-Hoffmann BL and Lambert PF. Integration of human papillomavirus type 16 into the human genome correlates with a selective growth advantage of cells. J Virol 1995; 69: 2989-2997.

19 Gammoh N, Grm HS, Massimi P and Banks L. Regulation of human papillomavirus type 16 E7 activity through direct protein interaction with the E2 transcriptional activator. J Virol 2006; 80: 1787-1797.

20 Ganguly N and Parihar SP. Human papillomavirus E6 and E7 oncoproteins as risk factors for tumorigenesis. J Biosci 2009; 34: 113-123.

21 Narisawa-Saito M and Kiyono T. Basic mechanisms of high-risk human papillomavirus-induced carcinogenesis: roles of E6 and E7 proteins. Cancer Sci 2007; 98: 1505-1511.

22 Hafner N, Driesch C, Gajda M, Jansen L, Kirchmayr R, Runnebaum IB et al. Integration of the HPV16 genome does not invariably result in high levels of viral oncogene transcripts. Oncogene 2008; 27: 1610-1617.

23 Klussmann JP, Weissenborn S and Fuchs PG. Human papillomavirus infection as a risk factor for squamous-cell carcinoma of the head and neck. N Engl J Med 2001; 345: 376; author reply 377.

24 Klussmann JP, Weissenborn SJ, Wieland U, Dries V, Kolligs J, Jungehuelsing M et al. Prevalence, distribution, and viral load of human papillomavirus 16 DNA in tonsillar carcinomas. Cancer 2001; 92: 2875-2884.

25 Hafkamp HC, Speel EJ, Haesevoets A, Bot FJ, Dinjens WN, Ramaekers FC et al. A subset of head and neck squamous cell carcinomas exhibits integration of HPV 16/18 DNA and overexpression of $p 16^{I N K 4 A}$ and $p 53$ in the absence of mutations in $p 53$ exons 5-8. Int J Cancer 2003; 107: 394-400.

26 Klussmann JP, Gultekin E, Weissenborn SJ, Wieland U, Dries V, Dienes HP et al. Expression of p16 protein identifies a distinct entity of tonsillar carcinomas associated with human papillomavirus. Am J Pathol 2003; 162: 747-753.

27 Klaes R, Woerner SM, Ridder R, Wentzensen N, Duerst M, Schneider A et al. Detection of high-risk cervical intraepithelial neoplasia and cervical cancer by amplification of transcripts derived from integrated papillomavirus oncogenes. Cancer Res 1999; 59: 6132-6136.

28 Vinokurova S, Wentzensen N, Einenkel J, Klaes R, Ziegert C, Melsheimer P et al. Clonal history of papillomavirus-induced dysplasia in the female lower genital tract. J Natl Cancer Inst 2005; 97: 1816-1821.

29 Basic Logical Alignment Search Tool (BLAST). National Center for Biotechnology Information (NCBI). 2011; http://blast.ncbi.nlm.nih.gov/. 
30 Map Viewer. National Center for Biotechnology Information (NCBI). 2011; http://www.ncbi.nlm.nih. gov/mapview/.

31 Luft F, Klaes R, Nees M, Durst M, Heilmann V, Melsheimer P et al. Detection of integrated papillomavirus sequences by ligation-mediated PCR (DIPS-PCR) and molecular characterization in cervical cancer cells. Int J Cancer 2001; 92: 9-17.

32 Chow LT and Broker TR. In vitro experimental systems for HPV: epithelial raft cultures for investigations of viral reproduction and pathogenesis and for genetic analyses of viral proteins and regulatory sequences. Clin Dermatol 1997; 15: 217-227.

33 Primer-BLAST. National Center for Biotechnology Information (NCBI). http://www.ncbi.nlm.nih. gov/tools/primer-blast.

34 Hopman AH, Kamps MA, Smedts F, Speel EJ, Herrington CS and Ramaekers FC. HPV in situ hybridization: impact of different protocols on the detection of integrated HPV. Int J Cancer 2005; 115: 419-428.

35 Weissenborn SJ, Funke AM, Hellmich M, Mallmann P, Fuchs PG, Pfister HJ et al. Oncogenic human papillomavirus DNA loads in human immunodeficiency virus-positive women with high-grade cervical lesions are strongly elevated. J Clin Microbiol 2003; 41: 2763-2767.

36 Weissenborn SJ, Wieland U, Junk M and Pfister H. Quantification of beta-human papillomavirus DNA by real-time PCR. Nat Protoc 2010; 5: 1-13.

37 Seedorf K, Krammer G, Durst M, Suhai S and Rowekamp WG. Human papillomavirus type 16 DNA sequence. Virology 1985; 145: 181-185.

38 Atlas of genetics and cytogenetics in oncogoly and haematology. http://AtlasGeneticsOncology.org.

39 UniProt Knowledgebase: a hub of integrated protein data. Margrane M and and the Uniprot Consortium. 2011; http://www.uniprot.org.

40 Li H, Yang Y, Zhang R, Cai Y, Yang X, Wang Z et al. Preferential sites for the integration and disruption of human papillomavirus 16 in cervical lesions. J Clin Virol 2013; 56: 342-347

$41 \mathrm{Xu}$ B, Chotewutmontri S, Wolf S, Klos U, Schmitz M, Durst M et al. Multiplex Identification of Human Papillomavirus 16 DNA Integration Sites in Cervical Carcinomas. PLoS ONE 2013; 8: e66693.

42 Schmitz M, Driesch C, Jansen L, Runnebaum IB and Durst M. Non-random integration of the HPV genome in cervical cancer. PLoS ONE 2012; 7: e39632.

43 Ghosh A, Ghosh S, Maiti GP, Mukherjee S, Mukherjee N, Chakraborty J et al. Association of FANCC and PTCH1 with the development of early dysplastic lesions of the head and neck. Ann Surg Oncol 2012; 19 suppl 3: S528-538.

44 Wreesmann VB, Estilo C, Eisele DW, Singh B and Wang SJ. Downregulation of Fanconi anemia genes in sporadic head and neck squamous cell carcinoma. ORL J Otorhinolaryngol Relat Spec 2007; 69: $218-225$.

45 Chang HH, Chiang CP, Hung HC, Lin CY, Deng YT and Kuo MY. Histone deacetylase 2 expression predicts poorer prognosis in oral cancer patients. Oral Oncol 2009; 45: 610-614.

46 Chang CC, Lin BR, Chen ST, Hsieh TH, Li YJ and Kuo MY. HDAC2 promotes cell migration/invasion abilities through HIF-1alpha stabilization in human oral squamous cell carcinoma. J Oral Pathol Med 2011; 40: 567-575. 
47 Huebbers CU, Preuss SF, Kolligs J, Vent J, Stenner M, Wieland U et al. Integration of HPV6 and downregulation of AKR1C3 expression mark malignant transformation in a patient with juvenile-onset laryngeal papillomatosis. PLoS ONE 2013; 8: e57207.

48 Chaiwongkot A, Vinokurova S, Pientong C, Ekalaksananan T, Kongyingyoes B, Kleebkaow P et al. Differential methylation of E2 binding sites in episomal and integrated HPV 16 genomes in preinvasive and invasive cervical lesions. Int J Cancer 2013; 132: 2087-2094.

49 Park IS, Chang X, Loyo M, Wu G, Chuang A, Kim MS et al. Characterization of the methylation patterns in human papillomavirus type 16 viral DNA in head and neck cancers. Cancer Prev Res (Phila) 2011; 4: 207-217. 




\title{
Chapter 5
}

\section{Viral load, gene expression and mapping of viral integration sites in HPV16-associated head and neck squamous cell carcinoma cell lines}

\author{
Nadine C. Olthof ${ }^{1,2}$, Christian U. Huebbers ${ }^{3}$, Jutta Kolligs ${ }^{3}$, Mieke Henfling', \\ Frans C.S. Ramaekers ${ }^{1}$, Josefa A. van Lent, Sander P.A. Stegmann ${ }^{5}$, \\ Steffi Silling ${ }^{6}$, Ulrike Wieland ${ }^{6}$, Thomas E. Carey ${ }^{7}$, Heather M. Walline',
} Susanne M. Gollin ${ }^{8}$, Thomas K. Hoffmann', Johan de Winter ${ }^{10}$, Bernd Kremer', JensPeter Klussmann ${ }^{11}$ and Ernst-Jan M. Spee ${ }^{2,12}$

Departments of ${ }^{1}$ Otorhinolaryngology and Head and Neck Surgery, ${ }^{2}$ Molecular Cell Biology,

${ }^{5}$ Clinical Genetics and ${ }^{12}$ Pathology, GROW - School for Oncology and Developmental

Biology, Maastricht University Medical Centre, Maastricht; ${ }^{3}$ Jean-Uhrmacher-Institute for Otorhinolaryngological Research, University of Cologne, Cologne, Germany; ${ }^{\circ}$ nstitute of Virology, National Reference Centre for Papilloma- and Polyomaviruses, University Hospital of Cologne, Cologne, Germany; ${ }^{7}$ Department of Otolaryngology, University of Michigan, Ann Arbor, USA; ${ }^{8}$ Department of Human Genetics, University of Pittsburgh Graduate School of Public Health and the University of Pittsburgh Cancer Institute, PA, USA; ${ }^{9}$ Department of Otorhinolaryngology and Head and Neck surgery, Ulm, Germany; ${ }^{10}$ Department of Clinical Genetics, VU University Medical

Center, Amsterdam, The Netherlands; ${ }^{11}$ Department of Otorhinolaryngology, Head and Neck

Surgery, School of Medicine, University Hospital of Giessen, Giessen, Germany.

Nadine Olthof, Christian Huebbers, Jens Peter Klussmann and Ernst-Jan M. Speel contributed equally to this work as first and last authors respectively 


\section{Abstract}

Introduction. Although patients with HPV-related HNSCC generally have a better prognosis when compared to patients with non-HPV-associated HNSCC, a subgroup of HPV-positive patients with poor prognosis has been recognized, particularly related to smoking, EGFR overexpression and chromosomal instability. In addition, viral integration into the host genome might contribute to carcinogenesis, as is shown for cervical carcinomas. For HNSCC, the reported integration frequencies vary widely, and have so far not been correlated to prognosis or response to therapy. Therefore, all seven reported HPV16-positive HNSCC cell lines have been carefully analysed for viral and host genome parameters.

Methods. The viral integration status, viral load, viral gene expression and the presence of aneusomies was evaluated in the cell lines: UD-SCC-2, UM-SCC-047, UM-SCC-104, UPCI:SCC090, UPCI:SCC152, UPCI:SCC154 and 93VU147T. HPV integration was examined using FISH, APOT- and DIPS-PCR. Viral load and the expression of the viral genes E2, E6 and E7 was determined via quantitative PCR.

Results. All cell lines showed integration-specific staining patterns using FISH. APOTand DIPS-PCR revealed integration-derived fusion productsin six cell lines, and only episomal PCR products for UM-SCC-104. Viral load ranged from 1 up to 739 copies per cell and all but one (UPCI:SCC154) cell lines showed aneusomy.

Conclusions. All HPV16-positive HNSCC cell lines available have been meticulously analysed for HPV-related parameters. These cell lines were shown to contain both episomal and integrated DNA as well as parameters associated with a poor prognosis, making them very suitable model systems for the development of new antiviral therapies, specifically directed towards this subtype of HPV-related HNSCC. 


\section{Introduction}

Infection with high-risk human papillomavirus (HPV) is a causative factor for the development of several types of neoplasms, including cervical, anogenital and a subset of head and neck cancers. Although most head and neck squamous cell carcinomas (HNSCC) can be attributed to the exposure to environmental factors, such as excessive tobacco- and alcohol use, approximately $20-25 \%$ of these cancers are caused by infection with HPV16. Notably, HPV-induced tumors are preferentially found in the oropharynx, where up to $90 \%$ of the malignancies are associated with $\mathrm{HPV}^{1-5}$.

Patients with HPV-induced carcinomas display clinical and molecular characteristics that are distinct from those in patients with tobacco- and alcohol-induced tumors. It is now well accepted that patients with HPV-derived tumors have a favourable prognosis, independent of the chosen treatment strategy ${ }^{6-12}$.

As a result, as first described by Ang et al. ${ }^{6}$, HNSCC can be divided into three risk groups, depending on HPV status, the number of pack-years of tobacco smoking and nodal stage: 1) Patients with HPV-positive HNSCC that had $<10$ pack-years, or patients with HPV-positive HNSCC that had >10 pack-years and had N0-N2a carcinomas were considered to be at low risk for disease-related death; 2) Patients with HPV-positive tumors, $>10$ pack-years and a nodal status of N2b-N3 or patients with HPV-negative T2-T3 tumors that had $<10$ pack-years were considered to be at intermediate risk; 3) Patients with HPV-negative tumors and $>10$ pack-years, or patients with HPV-negative $\mathrm{T} 4$ tumors and $<10$ pack years were considered to be high risk. In addition, it was shown that EGFR overexpression negatively affects overall survival both in HPV-positive as well as in HPV-negative tumors. Chromosomal instability was also reported to have a negative influence on prognosis, especially in $\mathrm{HPV}$-positive tumors ${ }^{13}$. These data indicate that smoking, advanced nodal stage, EGFR overexpression and chromosomal instability are risk parameters for poor prognosis in HPV-associated HNSCC ${ }^{6,13}$.

From uterine cervical (pre)malignancy models it is hypothesized that integration of HPV into the host genome plays an important role in the carcinogenic process. It correlates with the severity and progression of these lesions ${ }^{14,15}$ and is considered a risk factor for the development of uterine cervical squamous cell carcinoma ${ }^{15}$. In addition, a higher viral load is associated with higher grade lesions. It is, however, not possible to predict tumor progression based on the integration status of HPV or the viral load ${ }^{16}$.

HNSCC, in particular oropharyngeal squamous cell carcinomas, are mostly discovered as metastatic disease and data on premalignant lesions are scarce. Therefore limited information is available on the role of viral integration in the development of these tumors. It is hypothesized, however, that viral integration also promotes carcinogenesis in HNSCC, but this is not substantiated by clinical studies on premalignant lesions, as is the case for cervical lesions. 
Furthermore, the reported integration percentages in HNSCC vary considerably, ranging from $0 \%$ to almost $100 \%$ in different publications ${ }^{17-20}$. This extreme variation might be explained by the different patient populations studied, the different methods applied to study viral integration and a lack of correlation between these methods.

However, the integration status of the virus can be of significance in relation to treatment. Chang et al. ${ }^{21}$ and Herdman et al. ${ }^{22}$ have shown a clear difference in the response of keratinocytes with episomal versus integrated HPV. Using these cell line models it could be shown that interferon therapy can eradicate episomal HPV infection, but leads to a growth advantage for cells containing integrated HPV. This indicates that antiviral therapies might be influenced by the viral integration status. Thus, it is imperative to have a well-characterized model for HPV-associated HNSCC, for which the physical status of the virus is known.

This study presents a detailed analysis of the integration status in 7 HPV-positive HNSCC cell lines is presented, which have been established from HPV-induced tumors. The integration status has been assessed using a set of independent techniques, i.e. FISH, APOT- and DIPS-PCR. In addition, the expression levels of the viral genes E2, E6 and E7 and the expression levels of EGFR, as well as the viral load were analyzed.

\section{Materials and methods}

\section{Cell lines}

Human HPV16-positive HNSCC cell lines were obtained from different sources. Cell lines UPCI:SCC090, UPCI:SCC152 and UPCI:SCC154 were kindly provided by Dr.Susanne Gollin from the University of Pittsburgh, Pittsburgh, USA. The UPCI:SCC152 cell line was established from a recurrence in the patient from which the cell line UPCI:SCC090 was derived ${ }^{23}$. Cell line UD-SCC-2 was a kind gift from Dr. Thomas Hoffmann; present address University of Ulm, Ulm, Germany ${ }^{24}$. The cell lines UM-SCC-047 and UMSCC-104 were a kind gift from Dr. Thomas Carey, University of Michigan, Michigan, USA $^{25,26}$. The cell line 93VU147T was provided by Dr. J.P. de Winter, Free University Medical Centre, Amsterdam, the Netherlands ${ }^{27}$. Clinicopathological data of the patients and tumors from which the cell lines were derived are given in table 1. 
Table 1. Characteristics of patients from which the cell lines have been derived.

\begin{tabular}{|c|c|c|c|c|c|c|c|}
\hline Cell line & UD-SCC-2 & UM-SCC-47 & $\begin{array}{c}\text { UM- } \\
\text { SCC-104 }\end{array}$ & $\begin{array}{c}\text { UPCI: } \\
\text { SCC090 }\end{array}$ & $\begin{array}{c}\text { UPCI: } \\
\text { SCC152 }\end{array}$ & $\begin{array}{c}\text { UPCI: } \\
\text { SCC154 }\end{array}$ & 93VU147T \\
\hline $\mathrm{M} / \mathrm{F}$ & M & M & M & M & M & M & M \\
\hline $\begin{array}{l}\text { Age at } \\
\text { diagnosis }\end{array}$ & 58 & 53 & 56 & 46 & 47 & 54 & 58 \\
\hline Smoking & $\mathrm{y}$ & $\mathrm{y}$ & y & y & $\mathrm{y}$ & y & $\mathrm{y}$ \\
\hline Alcohol & $\mathrm{y}$ & n.a. & y & $\mathrm{y}$ & $\mathrm{y}$ & $\mathrm{y}$ & $\mathrm{y}$ \\
\hline $\begin{array}{l}\text { Primary tumor } \\
\text { site }\end{array}$ & $\begin{array}{l}\text { hypo- } \\
\text { pharynx }\end{array}$ & $\begin{array}{l}\text { lateral } \\
\text { tongue }\end{array}$ & $\begin{array}{l}\text { floor of } \\
\text { mouth }\end{array}$ & $\begin{array}{l}\text { base of } \\
\text { tongue }\end{array}$ & $\begin{array}{l}\text { hypo- } \\
\text { pharynx }\end{array}$ & tongue & $\begin{array}{l}\text { floor of } \\
\text { mouth }\end{array}$ \\
\hline TNM & T1N3 & T3N1M0 & T4N2bM0 & T2N0 & recurrence & $\mathrm{T} 4 \mathrm{~N} 2$ & $\mathrm{~T} 4 \mathrm{~N} 2$ \\
\hline Differentiation & n.a. & $\mathrm{M} / \mathrm{W}$ & $\mathrm{P} / \mathrm{M}$ & $\mathrm{P}$ & M & n.a. & M \\
\hline
\end{tabular}

Abbreviations: M: Male; F: Female; n.a.: not available; W: well differentiated; M: medium differentiated; P: poorly differentiated.

Cell lines UD-SCC-2 and 93VU147T were cultured in MEM (Invitrogen, Carlsbad, CA, USA) containing 10\% FCS (Sigma, St Louis, MO, USA), 2 mM glutamine (Invitrogen), $0.1 \mathrm{mM}$ MEM non-essential amino acids (Invitrogen) and 0.005\% gentamycin (Eurovet Animal Health BV, Bladel, the Netherlands). The remaining cell lines were cultured in DMEM (Invitrogen) containing the same additives as described above. Cell lines UM-SCC-047, UPCI:SCC090 and UD-SCC-2 were received in 2008 and UM-SCC-104, UPCI:SCC152, UPCI:SCC154 and 93VU147T in 2011 and were frozen immediately upon arrival. All cell lines were confirmed to have unique genotypes, as tested using the ProfilerPlus assay, except the cell lines UPCI:SCC090 and UPCI:SCC152, which shared the same genotype as they are derived from the same patient (see supplementary table 1). Cell lines in culture were regularly tested for infection with mycoplasma.

The uterine cervical cancer cell lines SiHa and CaSki were used as HPV16- and p16 ${ }^{\mathrm{INK} 4 \mathrm{~A}}$ positive controls in p16 $6^{\mathrm{INK} 4 \mathrm{~A}}$ immunostainings and HPV16-specific PCR analysis. The uterine cervical cancer cell line HeLa, the HPV-negative HNSCC cell lines UPCI:SCC003, and the osteosarcoma cell line U2OS containing the empty pJ $4 \Omega$-vector ${ }^{28}$ were used as negative controls in these assays. The latter cell line harbouring HPV16-E2containing pJ $4 \Omega$-vector was used as a positive control for HPV16-E2 RT-PCR. 


\section{DNA/RNA extraction}

DNA was isolated from cultured cells using QIAamp DNA Blood Mini Kit (Qiagen, Hilden, Germany) as per the manufacturers' instruction. Total RNA was extracted using the RNeasy mini kit (Qiagen) according to the manufacturer's instructions, including DNase treatment. RNA concentration and quality were determined by RNA standard sense chips on a BioRad Experion system (BioRad, Munich, Germany).

\section{HPV DNA PCR}

The presence of HPV DNA was detected by PCR using the consensus primer set GP5 $+/ 6+{ }^{29}$, followed by type-specific primers for HPV16 and HPV18. The following primers were used:

\begin{tabular}{lll}
\hline Target & Primer & Sequence \\
\hline HPV16 & Forward & 5' ACAGGAGCGACCCAGAAAGTTAC-3' \\
& Reverse & 5' GCATAAATCCCGAAAAGCAAAGT-3' \\
HPV18 & Forward & 5'CACATTGGAAAAACTAACTAACACACTGG-3' \\
& Reverse & 5'CAGCTATGTTGTGAAATCGTCGTT-3' \\
\hline
\end{tabular}

Primers were synthesized by Biolegio BV, Nijmegen, the Netherlands.

Five $\mu \mathrm{l}$ of PCR product were separated on a $1.5 \%$ agarose gel and visualized GelStar Nucleic Acid Gel Stain (Cambrex Bio Science Rockland Inc., Rockland, USA).

\section{Viral load}

Viral load of HPV16 was determined using real-time fluorescence PCR with type-specific primers and probes as described earlier ${ }^{30}$. Briefly, viral load was expressed as the number of HPV16 DNA copies per $\beta$-globin-gene copy. Gene copy numbers of $\beta$-globin were determined using the LightCycler-Control Kit DNA (Roche Molecular Biochemicals) according to the manufacturer's instructions as previously described ${ }^{31}$. Calculation of initial copy numbers in samples was performed by the LightCycler 480 software (Version 1.5) using a standard curve generated with exactly quantified HPV DNA standards (ten-fold dilution series of full length HPV16 plasmid) that were amplified in the same PCR run ${ }^{30-32}$. The analytical sensitivity of the assay was ten copies of HPV16 standard DNA. A negative control (water or DNA extracted from RTS3B cells that are negative for HPV) was included in each run and never yielded fluorescence signals above the background ${ }^{31}$. 


\section{Viral integration analysis}

The detection of viral integration can be studied by various methods. Most commonly used are methods based on the DNA-ratio of the oncoproteins E2 and E6, based on reports in uterine cervical carcinomas showing that integration of HPV often leads to disruption of parts of the E2 gene region, while retaining intact E6 and E7 oncogenes ${ }^{33}$. However, for HNSCC it has been shown that HPV is able integrate in tandem head- totail arrays of complete but linearized HPV DNA genomes ${ }^{34}$, which implies that methods based on the E2/E6 DNA-ratio might underestimate the percentage of integration.

In situ hybridisation (ISH), either fluorescent (F) or chromogenic (C), can be used to visually determine the integration status of the virus. This method differentiates between episomal and integrated virus based on the signal pattern in the nucleus of the infected host cell, whereby a punctate pattern indicates integration and a diffuse signal indicates episomal virus ${ }^{35}$. Sensitive (F)ISH assays have been described that are able to detect a single copy of HPV per cell ${ }^{36}$. However, this also implies that a single or few episomal copies of HPV could display a punctate pattern, and subsequently be interpreted as integration, thus resulting in overestimation of the viral integration frequency.

The physical status of HPV can also be assessed by identifying viral-human fusion products. The two most commonly used methods are Detection of Integrated Papillomavirus Sequences (DIPS-PCR), which amplifies the genomic fusion region between viral and cellular DNA downstream the integration locus, and 3'-RACE-PCR (Amplification of Papillomavirus Oncogene Transcripts; APOT-PCR), which detects integrationderived mRNA transcripts. Subsequent sequencing of the obtained PCR products can be used to identify the integration locus.

While methods based on E2/E6 DNA- ratios can only detect integration status (integrated versus episomal), APOT- and DIPS-PCR as well as (F)ISH can also provide information on the number of integration events.

However, determining viral integration frequency is hindered due to disconcordance between different methods. Therefore, the effect of viral integration on response to therapy and therefore prognosis is hard to estimate.

\section{Fluorescence in situ Hybridisation}

HPV16-specific probes were purchased from PanPath, Amsterdam, the Netherlands. BACclones, used for colocalization experiments, were grown according to the manufacturer's instructions (BACPAC Resources Centre, Childrens Hospital Oakland Research Institute, Oakland, USA). DNA was isolated using the the Nucleobond BAC-100 kit (BioKé, Leiden, the Netherlands). Probes for centromeres (CEPs) 1, 3 and 9 were available in our lab, previ- 
ously described in Hopman et al. ${ }^{37}$. Probes and clones were labelled using either the Dignick translation kit or the Biotin-nick translation kit (Roche, Basel, Switzerland), according to the manufacturer's instructions. Labelled CEP probes for CEP17 and CEPX were kindly provided by the Department of Clinical Genetics, Maastricht University Medical Centre, Maastricht, the Netherlands. To exclude possible hybridization to RNA transcripts cells were treated with $10 \mathrm{ng} / \mathrm{ml}$ ribonuclease A (Qiagen) in a control experiment.

Fluorescence in situ hybridisation (FISH) was performed as described earlier ${ }^{3,38,39}$. Briefly, cells were fixed in 70\% ethanol, spotted on glass slides, airdried for 15 minutes and subsequently baked for 30 minutes at $80^{\circ} \mathrm{C}$. After cooling, slides were incubated with $0.01 \%$ pepsin (800-1200 U/mg protein from porcine stomach mucosa; Sigma) in $0.01 \mathrm{~N} \mathrm{HCl}$ for 20 minutes at $37^{\circ} \mathrm{C}$, washed and postfixed in $1 \%$ formaldehyde in PBS for 10 minutes at RT. Slides were then dehydrated in an ascending ethanol series and airdried. Probes were applied under a coverslip according to the manufacturer's instructions. Probe and target DNA were denatured simultaneously for 3 minutes at $80^{\circ} \mathrm{C}$ prior to hybridization overnight at $37^{\circ} \mathrm{C}$ in a humid chamber. After hybridization the preparations were washed stringently in $2 \times \mathrm{SSC} / 0.05 \%$ tween-20 at $42^{\circ} \mathrm{C}, 0.1 \times \mathrm{SSC}$ at $61^{\circ} \mathrm{C}$ and $4 \times \mathrm{SSC} / 0.05 \%$ tween-20 at RT for $2 \times 5$ minutes each. Biotinlabelled probe was detected using FITC-conjugated-avidine (Dako, Glostrup, Denmark; 1:500) followed by biotin-conjugated goat-anti-avidine (Vector laboratories, Burlingame, CA; 1:100) and finally FITC-conjugated-avidine (Dako; 1:500); incubated for 30 minutes at $37^{\circ} \mathrm{C}$. In cases where two hybridisation probes were used simultaneously, biotin-labelled probes was detected as described above. The digoxigenin-labelled probe was detected using mouse-anti-digoxigenin (Dako; 1:200), followed by TRITC-conjugated rabbit-anti-mouse (Dako; 1:1000) and finally TRITC-conjugated swine-anti-rabbit (Dako; 1:100); incubated for 30 minutes at $37^{\circ} \mathrm{C}$. Finally, slides were washed and dehydrated in an ascending ethanol series and mounted in Vectashield (Vector laboratories) containing 4',6-diamidino-2-phenylindole (DAPI; Sigma; $0.2 \mu \mathrm{g} / \mu \mathrm{l}$ ).

Images were acquired using a Leica DMRXA microscope (Leica, Wetzlar, Germany) equipped with optical filters for DAPI, fluorescein and TRITC and a 63× Plan Apo (NA 1.32) objective. The microscope was connected to a digital black and white CCD camera (Metasystems Image Pro System, Sandhausen, Germany) for image recording. Staining patterns were scored according to the criteria first described by Cooper et al. ${ }^{35}$, where a punctate signal indicates integrated virus, and a diffuse pattern indicates extrachromosal viral copies.

\section{Metaphase spreads}

Metaphase spreads were made as described in ${ }^{40}$, with minor adjustments. Briefly, cells were cultured until approximately $50 \%$ confluency. Medium was then replaced by medium containing $0.1-0.5 \mu \mathrm{g} / \mathrm{ml}$ colcemid (Sigma) and $0-0.01 \mu \mathrm{g} / \mathrm{ml}$ ethidium bromide and incubated for $2-4$ hours at $37^{\circ} \mathrm{C}$. Optimal conditions varied per cell line. After incubation, cells were trypsynized and subsequently treated with $0.075 \mathrm{M} \mathrm{KCl}$ for 10 minutes at $37^{\circ} \mathrm{C}$. Cells 
were washed twice and fixed in methanol/acetic acid (3:1, v/v). FISH probes were used for hybridisation as outlined above, with minor adjustments. Slides were only incubated for 8 minutes with $0.01 \%$ pepsin $(800-1200 \mathrm{U} / \mathrm{mg}$ protein from porcine stomach mucosa; Sigma) in $0.01 \mathrm{~N} \mathrm{HCl}$ at $37^{\circ} \mathrm{C}$. After washing, slides were dehydrated in an ascending ethanol series, and airdried. Slides were then baked for 10 minutes at $56^{\circ} \mathrm{C}$. Postfixation was performed in $4 \%$ formaldehyde in PBS for 10 minutes at RT. After postfixation, the protocol was followed as described above.

\section{Amplification of Papillomavirus Oncogene Transcripts (APOT-PCR)}

HPV oncogene transcripts were amplified as described before ${ }^{15}$ (and chapter 4). Briefly, reverse transcription was performed using $25 \mu \mathrm{M}$ oligo- $(\mathrm{dT})_{17}$ primer coupled to a linker sequence $(\mathrm{dT})_{17}$-p3, $10 \mathrm{mM}$ dNTPs each, 0.1 M DTT, 5x RT-buffer and SuperScript reverse transcriptase (Invitrogen, Karlsruhe, Germany) ${ }^{41}$. Quality of cDNA was determined by a standard GAPDH gene PCR. First-strand cDNAs containing viral oncogene sequences were subsequently amplified with semi-nested PCR using HPV-E7 specific 5'primers and oligo(dT) and adaptor primers (3'). PCR products were separated on a $1.2 \%$ agarose gel. Bands typical for integration were cut out, purified (QIAGEN Gel extraction kit, QIAGEN, Hilden, Germany) and sequenced (GATC Biotech, Konstanz, Germany). Sequence results were analyzed using the BLASTN program ${ }^{42}$ and further mapped using map viewer, both provided by the National Center for Biotechnology Information (NCBI ${ }^{43}$.

\section{Detection of Integrated Papillomavirus Sequences (DIPS-PCR)}

Integrated papillomavirus sequences were detected using the Detection of Integrated Papillomavirus Sequences-PCR (DIPS-PCR) assay, as described earlier ${ }^{44}$ (and chapter 4). Shortly, genomic DNA was digested using the Sau3AI restriction enzyme and an enzymespecific adapter was ligated to the restriction-digested DNA using T4 DNA ligase (Roche Diagnostics, Mannheim, Germany). Linear PCR was performed using 5 HPV16 specific forward primers in independent setups. All independent PCRs were followed by individual exponential PCRs using further virus-specific forward primers and the AP1 reverse primer. PCR products were separated on a 1.2\% agarose gel and products of interest were excised and subsequently sequenced (GATC Biotech). Sequence results were analyzed using the BLASTN program ${ }^{42}$ and further mapped using map viewer, both provided by the $\mathrm{NCBI}^{43}$.

\section{mRNA expression of HPV16 E2, E6 and E7 and human EGFR}

RNA was reverse transcribed using the iScript cDNA Synthesis Kit (BioRad Laboratories, Hercules, CA, USA). Real-time PCR reactions were performed using SensiMix SYBR \& Fluorescein (GC Biotech, Alphen a/d Rijn, the Netherlands). The detection of the house- 
keeping gene hypoxanthine phosphoribosyltransferase (HPRT) was used for normalization of mRNA levels. Primer sequences for HPRT were kindly provided by prof. dr. L. Hofland from Erasmus Medical Centre, Rotterdam, the Netherlands. The following primers, synthesized by Biolegio BV, were used:

\begin{tabular}{llll}
\hline Target & Primer & Sequence & Ref \\
\hline HPV16 E2 & Forward & 5 TGATAGTACAGACCTACGTGACCATATAGA-3' & \\
& Reverse & 5'-ATTACAAGGCCAGAGAAATGGG-3' & \\
HPV16 E6 & Forward & 5'-CAGTTATGCACAGAGCTGCAA-3' & 45 \\
& Reverse & 5'-ATGACTTTGCTTTTCGGGATT-3' & \\
HPV16 E7 & Forward & 5'-AGAGGAGGAGGATGAAATAGATGGT-3' & 46 \\
& Reverse & 5'-CAATATTGTAACCTTTTGTTGCAAGTG-3' & \\
EGFR & Forward & 5'-CCAAGGGAGTTTGTGGAGAA-3' & \\
& Reverse & 5' CTTCCAGACCAGGGTGTTGT 3' & \\
HPRT & Forward & 5' CACTGGCAAAACAATGCAGACT -3' & \\
& Reverse & 5' GTCTGGCTTATATCCAACACTTCGT -3' & \\
\hline
\end{tabular}

\section{Results}

Active HPV16 infection is present in all cell lines

All cell lines have been tested for active HPV16 infection, using the algorithm suggested previously ${ }^{48}$. The cell lines showed overexpression of CDK-inhibitor p16 $6^{\mathrm{INK} 4 \mathrm{~A}}$ using immunocytochemistry on AgarCyto blocks, which is routinely used as a surrogate marker for HPV infection (see figure 1A). Furthermore, the presence of HPV16 DNA has been shown by PCR, first using the consensus primers GP5+/6+ and subsequently by using type-specific primers for HPV16- and -18 (see figure 1B). RT-PCR analysis of the viral oncogenes E6 and E7 showed viral gene expression in all cell lines (see below).

\section{Viral load}

HPV16 load in all cell lines was estimated using PCR, and was expressed as the number of HPV16 copies per $\beta$-globin copy. Viral load varied from 1 (UM-SCC-104) up to 739 (UPCI:SCC090) HPV16 copies per $\beta$-globin gene copy (see table 2 ). 


\section{FISH integration analysis}

All cell lines were tested for the presence of HPV16 DNA using FISH and they all showed a reproducible punctate nuclear signal, which indicates viral integration. Each cell line showed a specific number of FISH signals per nucleus, ranging from 2 (UD-SCC-2 and UPCI:SCC154) to 7 (93VU147T) (figure 1C). UPCI:SCC090 and -152, derived from the same patient, showed identical spot numbers. UM-SCC-104, however, showed a variable number of signals per nucleus, ranging from 1 to 4 (table 2). Notably, cell lines with a high viral load exhibited a higher number and/or more intense FISH signals (see figure $1 \mathrm{C}$ and table 2) and also showed stronger HPV16-specific PCR bands on agarose gel (see figure 1B). Possible hybridization to RNA transcripts was excluded by treating the cells with RNAse in a control experiment.

\section{Identification of HPV16 integration sites by PCR}

APOT-PCR, a PCR-based method that can amplify both viral-human fusion transcripts as well as episome-derived viral transcript, was used to identify the site of viral integration in the cellular genome. A single integration site was identified in 5 cell lines (UMSCC-047, UPCI:SCC090, UPCI:SCC152, UPCI:SCC154 and 93VU147T)(see table 3). Sequencing analysis of the obtained viral-human fusion transcripts revealed viral integration in 3 genes and in 2 intergenic regions. The protein-coding regions identified were DIAPH2, exon 21 (UD-SCC-2), TP63 exon 7 (3q28, UM-SCC-047) and NAP1 exon 4 (9q22.33, UPCISCC:090 and UPCI:SCC152; both derived from two subsequently diagnosed recurrent tumors from the same patient). The intergenic regions identified were located on chromosomes 17q12 (93VU147T) and 21q11.2 (UPCI:SCC154).

All fusion transcripts detected by APOT-PCR showed type A splicing as described by Klaes et al. ${ }^{49}$ from viral nucleotide 880 directly into the human sequence in sense orientation with the identified gene (see also chapter 3 ). Interestingly, only episomal transcripts could be identified in the UM-SCC-104 cell line, suggesting the presence of complete episomes, either integrated or extrachromosomal.DIPS-PCR was performed to verify the identified integration sites and to search for possible viral-human fusion products in the cell line where no fusion transcript could be identified using APOT-PCR (UM-SCC-104). No fusion product could be amplified in this cell line, although the presence of episomal viral copies was confirmed. In the remaining cell lines the integration sequences identified using APOT-PCR were confirmed by DIPS-PCR. DIPS-PCR identified the integration site in the UPCI:SCC154 cell line to be located within the NRIP1 gene. Identified integration sites are portrayed in figure 2 and summarized in table 3.

To confirm that the identified human sequences were localized adjacent to the viral genome, double-target FISH analysis was performed using both the HPV16 probe and $\mathrm{BAC}$-probes complementary to the putative integration sequence (see figure $3 \mathrm{~A}$ ). BAC- 


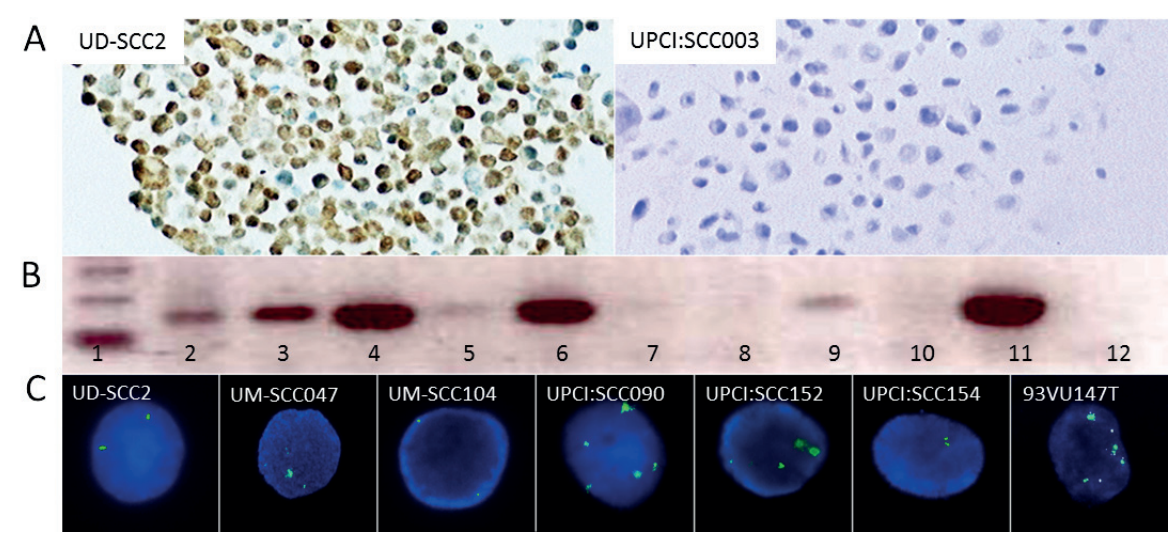

Figure 1.

A) Representative examples of $16^{\text {INK4A }}$ staining in cell lines UD-SCC-2 (HPV16 positive) and UPCI:SCC003 (HPV-negative)

B) HPV16-specific PCR. Lane 1 shows the 100 bp, 200 bp and 300 bp fragments of a 100 bp ladder for fragment size determination, lane 2-12 show the results of the HPV16 specific PCR. Lane 2: UD-SCC-2; lane 3: UM-SCC-047; lane 4: UPCI:SCC090; lane 5: UM-SCC-104; lane 6: UPCI:SCC152; lane 7: UPCI:SCC154; lane 8: U2OS cell line with the empty pJ4 $\Omega$-vector as negative control; lane 9: 93VU147T; lane 10: HeLa (HPV18 cervix carcinoma cell line); lane 11: CaSki (HPV16 positive cervix carcinoma cell line); lane 12: water.

C) HPV16 FISH staining pattern in the seven cell lines. HPV16 was detected using a FITC-labelled probe (green) and cell nuclei are stained with DAPI (blue).

probes were shown to colocalize with all HPV16 signals in two cell lines (UM-SCC-047 and UPCI:SCC154). In three additional cell lines, HPV16 signals were also detected without colocalization with the BAC-probe (UPCI:SCC090, UPCI:SCC152 and 93VU147T).

\section{HPV mapping on metaphase preparations}

For the cell lines in which the integration loci did not colocalize to a BAC-probe (UM-SCC-104, UPCI:SCC090 and 93VU147T), HPV16 FISH analysis in combination with karyotyping based on inverted DAPI staining was performed on metaphase preparations. All data are summarized in table 2. In the UPCI:SCC090 cell line additional integration events were mapped to chromosomes 3 and 6, which is in agreement with data from Ragin et al. ${ }^{50}$. Interestingly, in the metaphase preparations of the UM-SCC-104 cell line, metaphase chromosomes did not show HPV16 FISH signals, whereas interphase cells, also present in the preparation, did show a nuclear FISH staining pattern similar to the staining on $70 \%$ ethanol suspensions (see figure 1C). This was shown in repeated experiments with different observers (JvL, E-JS, NO). Al- 
though this might be a sensitivity issue, another explanation might be that the virus is extrachromosomal, which is supported by the detection of only episomal transcripts by APOT- and DIPS-PCR (see above).

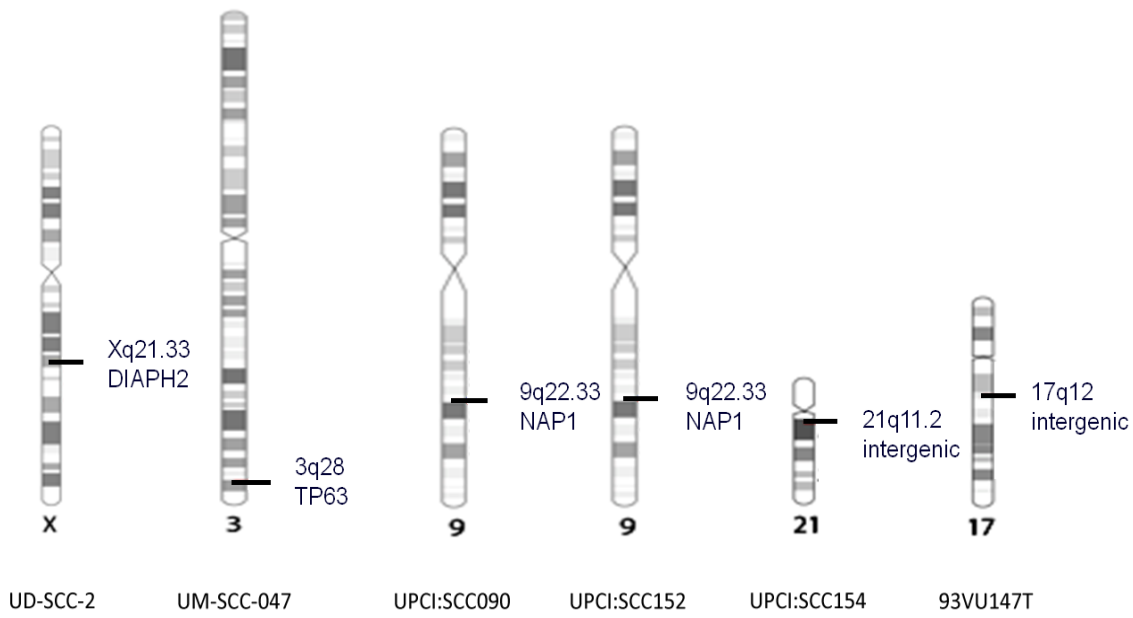

Figure 2. HPV integration sites for the individual cell lines as detected by APOT- or DIPS-PCR. For each cell line the corresponding chromosome is displayed, portraying the identified integration site.

\section{Integration events and ploidy status}

To determine whether multiple colocalizing FISH-signals indicated duplication or translocation of the involved chromosome, double-target FISH was performed on metaphase preparations of the cell lines, using both a CEP-probe as well as an HPV probe. This showed that integration can be followed by deletion of the sister chromosome and duplication (UD-SCC-2) or multiplication (UM-SCC-047) of the chromosome containing HPV integration, with all respective chromosomes showing signals for both the CEPprobe as well as the HPV16 probe. Duplication of chromosomes with concurrent duplication of the sister chromosome was also seen (UPCI:SCC090, UPCI:SCC152), shown by the presence of chromosomes containing only a signal for the CEP-probe as well as chromosomes containing signals for both CEP- and HPV16 probes. Lastly, duplication could also be accompanied by translocation of a small portion of the involved chromosome to a different chromosome (UM-SCC-047). 
The detected multiplication of chromosomes is in line with the ploidy status of the different cell lines, which in 6 of the 7 cell lines showed copy number variations for chromosomes 1 and 7, a hallmark for chromosomal instability and aneusomy ${ }^{13}$ (table 2).

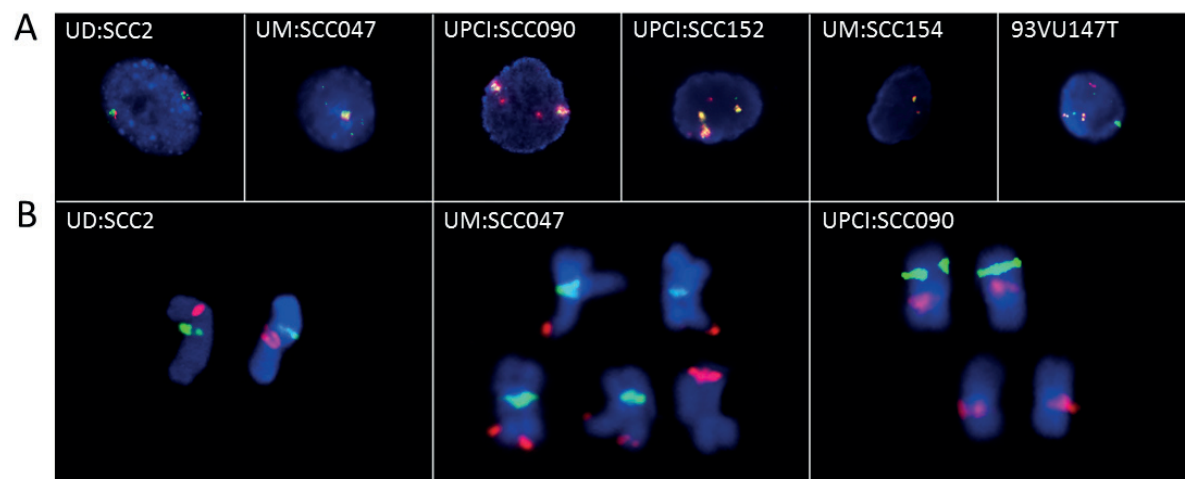

Figure 3.

A) Colocalisation of FITC-labelled HPV16 probes (green) with TRITC-labelled BAC clones (red) on interphase nuclei of UD-SCC-2 (BAC clone RP11-212B22), UM-SCC-047 (BAC clone RP11-373I6), UPCI:SCC090 and UPCI:SCC152 (BAC clone RP11-23B15 for both), UPCI:SCC154 (BAC clone RP11-10J13) and 93VU147T (BAC clones RP111331M22 and RP11-365D23, respectively).

B) Colocalisation of HPV16 probes with probes for CEPX (green), CEP3 (green) or CEP9 (red) on metaphase spreads of UD-SCC-2, UM-SCC-047 and UPCI:SCC090, respectively. 


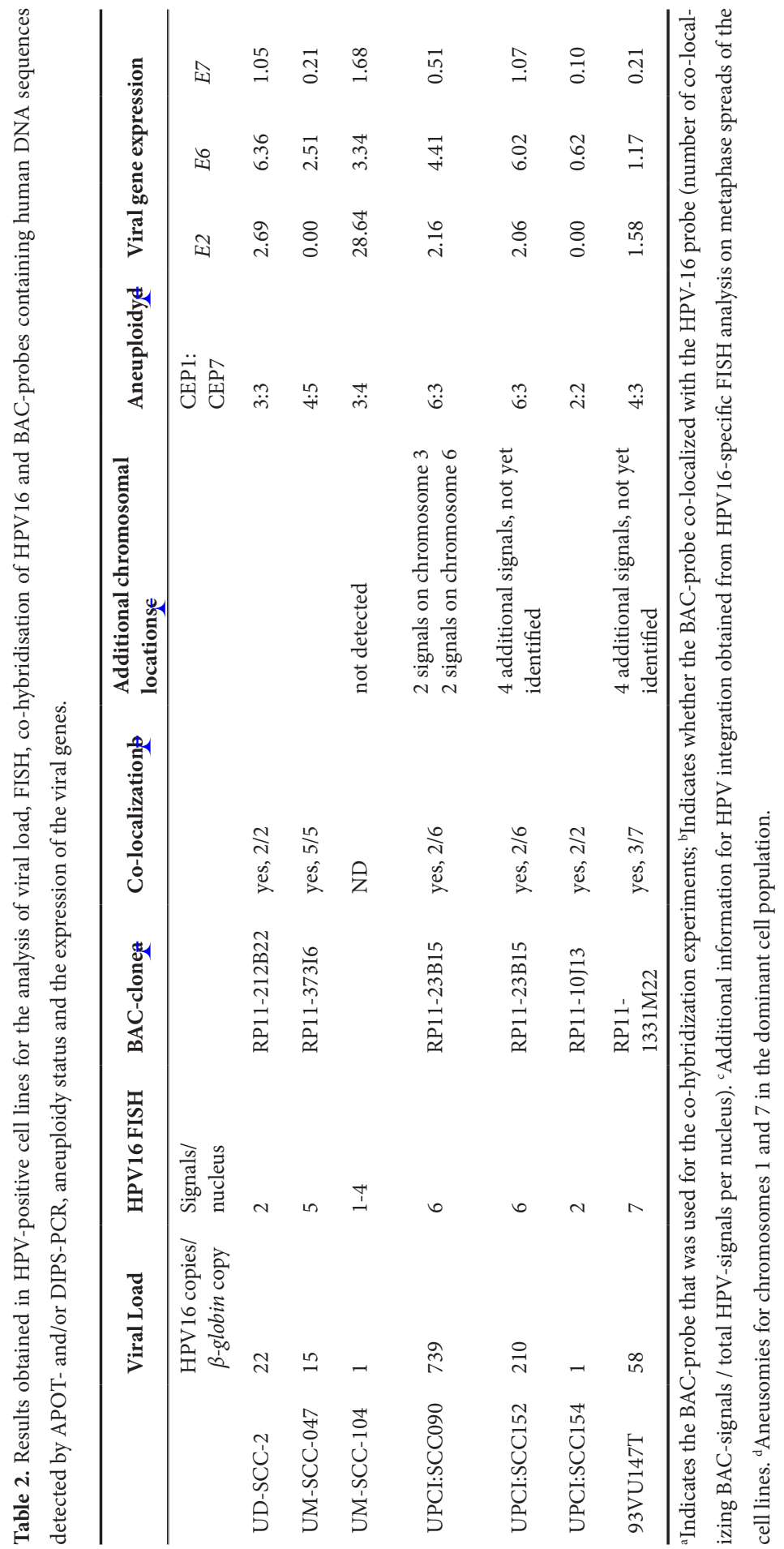




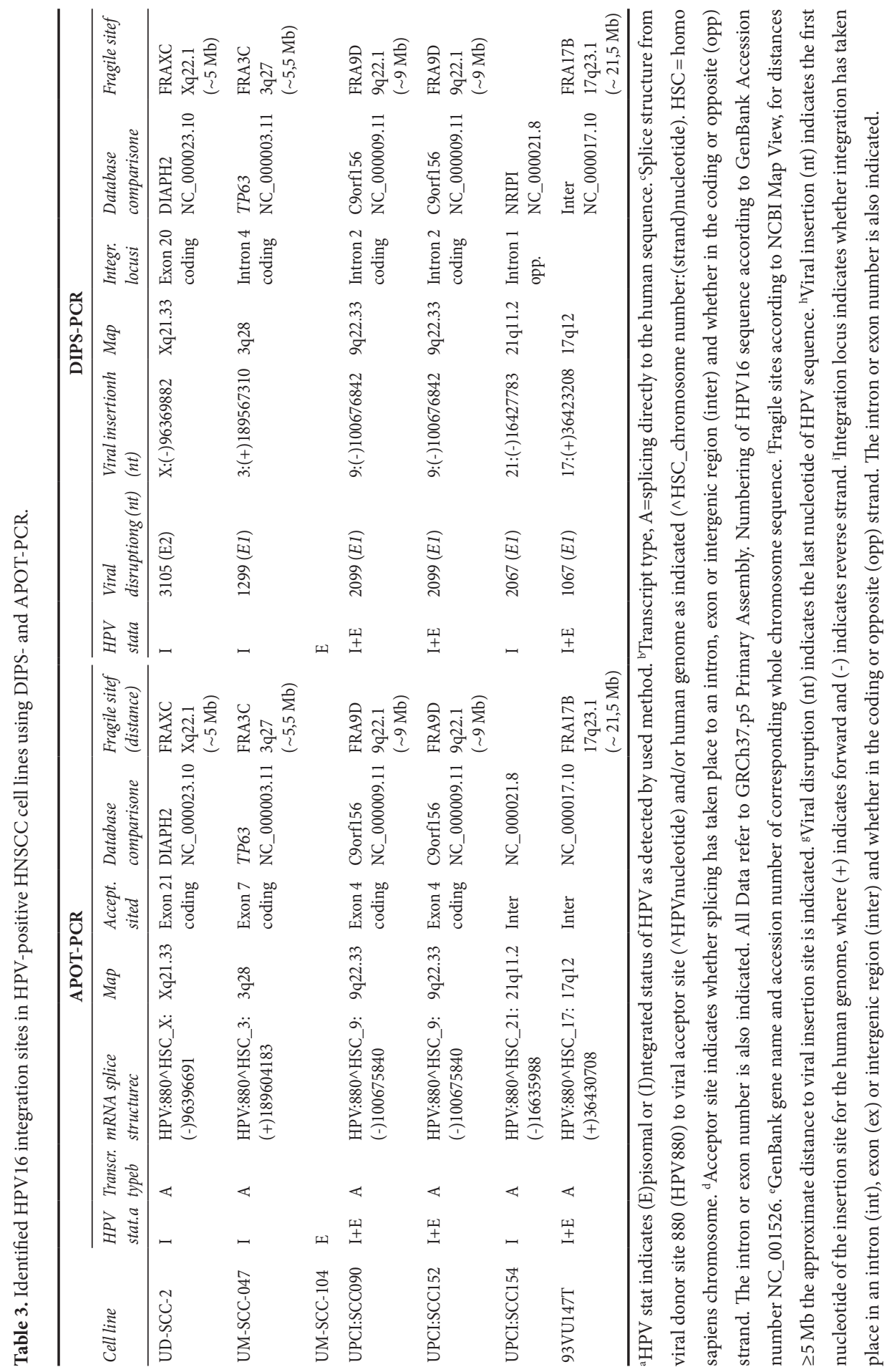




\section{Gene expression of HPV16 E2, E6 and E7 and human EGFR}

To determine whether integration affects the expression of the viral genes, the expression levels of the viral genes E2, E6 and E7 were determined using RT-PCR (see figure 4). Expression of the viral gene E2, which is known to regulate gene transcription of the oncogenes E6 and E7, was present at variable levels in six of the seven cell lines. Expression of the viral oncogenes E6 and E7 could be detected in all cell lines at variable levels, but no correlation could be found with the levels of E2 expression. Furthermore, no correlation was found between the number of FISH HPV16 signals, viral load and viral gene expression.

In addition, the level of EGFR expression was examined for each of the seven cell lines. This showed a variable expression of 0.4 (UPCI:SCC090) up to 5.6-fold (UMSCC-104) expression to HPRT. As the median EGFR expression in 61 primary HPVassociated HNSCC is 0.3 fold to HPRT (range 0.001-18.6-fold to HPRT, unpublished results), this indicates an increased expression of EGFR in all cell lines.
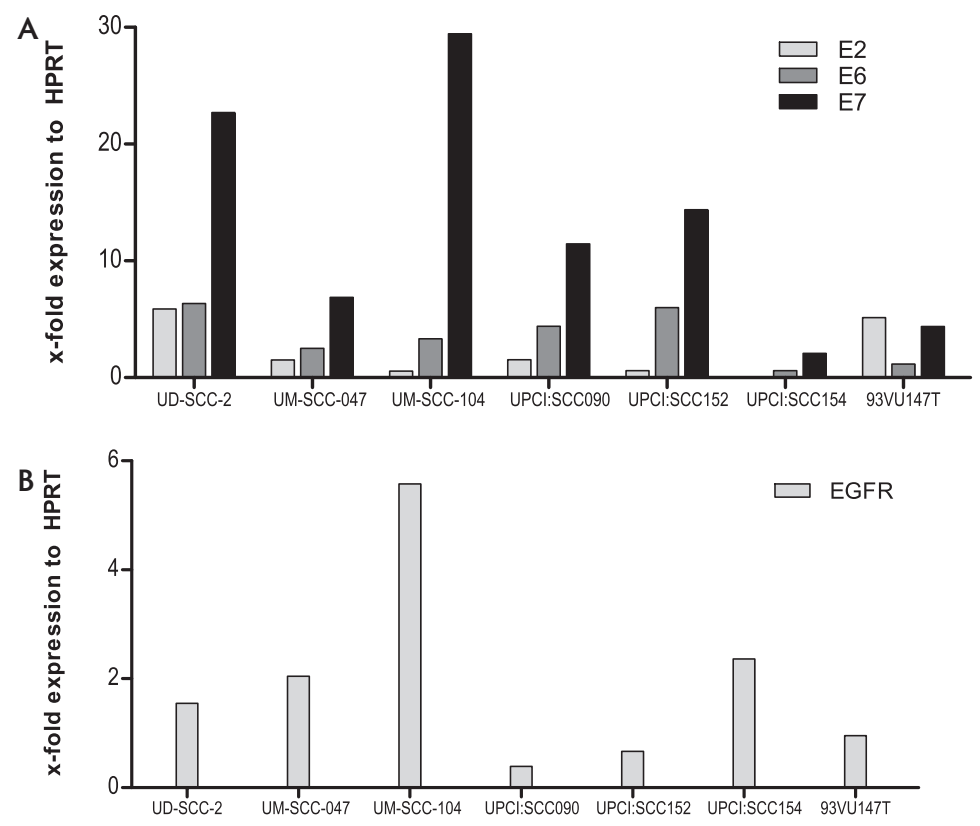

Figure 4.

A) Expression of viral genes E2, E6 and $E 7$ for each of the seven cell lines. Expression levels are displayed as $\mathrm{x}$-fold change as compared to the expression of the housekeeping gene HPRT.

B) Expression of EGFR for each of the seven cell lines. Expression levels are displayed as $\mathrm{x}$-fold change as compared to the expression of the housekeeping gene HPRT. 


\section{Discussion}

HR-HPV infection is a well-established risk factor contributing to the development of HNSCC, particularly OPSCC. In recent years it has been shown that HPV-positive tumors have different clinical and patho-biological characteristics, including a better prognosis as compared to HPV-negative tumors ${ }^{48}$. It is still under debate which factors, in addition to the presence of HPV DNA and the resulting viral gene expression in the host cell, are contributing to tumor development and progression. For example, integration of the viral DNA into the host genome, and the resulting disruption of invaded genes might play an important role in the process of HPV carcinogenesis, as seen in HPV-associated cervical cancer ${ }^{51,52}$. In the case of HNSCC, not many studies have addressed this highly relevant issue ${ }^{53-55}$ (and chapter 4 ).

Since in vitro testing is still an important step in the development of new therapeutic options, it is imperative to be able to study well-established cell line models for HPV-positive HNSCC. In the underlying study, HPV16-associated parameters, such as viral load and integration, have been assessed in seven established HNSCC cell lines, shown to be HPV-induced by $16^{\mathrm{INK} 4 \mathrm{~A}}$ immunostaining and HPV-type-specific PCR.

Integration of HPV DNA was detected in 6 of the 7 cell lines using three independent methods, i.e. APOT- and DIPS-PCR and FISH, which all gave concurrent results with respect to the integration locus. Furthermore, for one of the cell lines (UPCI:SCC090) our results confirmed a previously reported integration site on $9 \mathrm{q} 31^{50}$. Two cell lines that were derived from the same patient (UPCI:SCC090 and UPCI:SCC152), showed identi$\mathrm{cal}$ integration sites despite the fact that they were established from biopsies taken from different locations and at different time points, indicating clonal expansion of the tumor. One cell line (UM-SCC-104) did not show integration, but rather the presence of extrachromosomal HPV DNA, as assessed by APOT- and DIPS-PCR.

We detected viral loads varying from 1 up to 739 HPV 16 copies per $\beta$-globin gene copy. In contrast to results obtained from cervical malignancies ${ }^{56}$, viral load did not seem to be correlated to integration status. This can be concluded from the two cell lines showing a viral load of 1 HPV DNA copy per $\beta$-globin copy, one of which showed HPV DNA integration and the other showed only episomal HPV.

Cell lines with a higher viral load did exhibit strong punctate FISH signals, indicating that the HPV genome may be present in integrated tandem repeats. This assumption is supported by the finding that these strong signals are not derived from RNA transcripts, present at these loci, as shown by RNAse treatment before the FISH analysis (data not shown). Moreover, the cell lines showed 2 up to 7 HPV integration sites as detected with the FISH procedure, whereas in primary tumors generally only 1 signal per nucleus is detected ${ }^{13}$. To determine whether this is due to either multiplication of the integration locus, or a result of multiple independent integration events, co-hybridization of HPV16 probes with a BAC-probe complementary to the identified integration 
sequences was performed. In the cell lines UD-SCC-2, UM-SCC-047 and UPCI:SCC154 all HPV16 signals were shown to colocalize with the BAC-probe, while in UPCI:SCC090, UPCI:SCC152 and 93VU147T the BAC-probe colocalized with part of the HPV16 FISH signals. The presence of more than one colocalizing signal indicates multiplication of the integration locus. Multiplication of an existing integration site was furthermore shown by co-hybridization of the HPV-probe with CEP-probes for the corresponding chromosome. For the UD-SCC-2 cell line, derived from a male patient, the two HPV16 FISH signals were located on two different CEPX-containing chromosomes, indicating that a duplication event has occurred. In the UPCI:SCC090 four chromosome copies containing CEP9 were detected, of which two harboured HPV16 signals, indicating duplication of both copies of chromosome 9. In the UM-SCC-047 cell line five HPV16 signals were detected on five separate chromosomes, of which four also containing CEP3, indicating multiplication of the initial integration site. The fifth chromosome contained very strong HPV- and BAC-signals but no CEP3 signal (see figure 3B), which might indicate that this chromosome evolved by a different mechanism, for example involving both translocation of part of chromosome 3 and amplification of the integration site. Figure 5 provides a schematic representation of the multiplication and translocation events identified in the HNSCC cell lines indicated.

Besides HPV16 signals colocalizing with the BAC-probe in UPCI:SCC090, UPCI:SCC152 and 93VU147T cell lines, additional HPV16 signals were detected. The non-colocalizing HPV signals might indicate multiple independent integration events, which were not detected by APOT- or DIPS-PCR. A possible explanation for the fact that the APOT-PCR assay is unable to detect all the different integration sequences may be that (several of) these sequences are not actively transcribed and therefore not clinically relevant. On the other hand, the inability of the DIPS-PCR assay to detect these integrated sequences may come from an alternative integration mechanism that is not detected by our PCR, which is based on E1 and E2 HPV sequences. Using DIPS-PCR with additional primers covering the entire HPV genome, Li et al. ${ }^{57}$ described a mechanism for HPV16 integration in exfoliated cervical cells based on disruption of the $L 1$ or L2 gene. These authors indicated that integration at these viral sites would normally not result in progression to (pre)malignant lesions. It is therefore likely that such integration events have occurred in our cell lines, before or after the clinically relevant integration event took place.

From studies in cervical cancer it is known that viral load does not necessarily correlate to expression levels of $E 6$ and $E 7^{58}$. Similarly, in the HNSCC cell lines, as well as in primary HNSCC (see chapter 4), the variation in viral load was not reflected in the expression of the viral genes E2, E6 and E7. Furthermore, the current concept of cervical carcinogenesis suggests that HPV integration leads to disruption of the viral genome in the $E 1$ or $E 2$ open reading frame (ORF), followed by loss of the $E 2$ inhibitory gene function on $E 6$ and $E 7$ expression ${ }^{59,60}$. Subsequently expression of both oncogenes is thought to be 


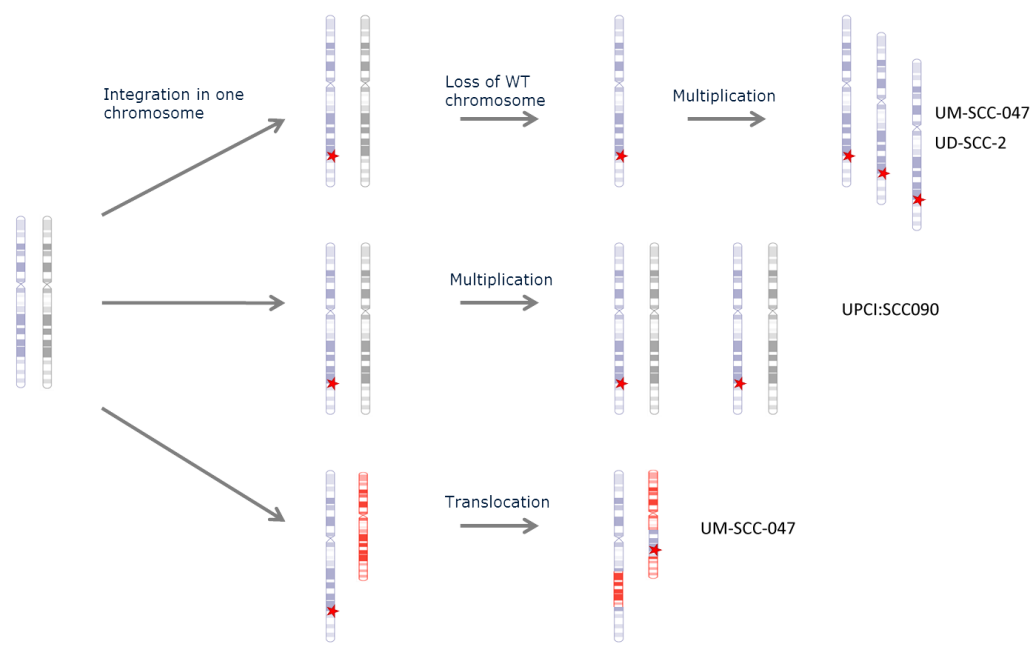

Figure 5. Schematic representation of the possible multiplication and translocation events in the cell lines.

enhanced ${ }^{61-63}$. However, in the different HNSCC cell lines, such a correlation could not be found. E2 mRNA levels were highly variable in UD-SCC-2, UM-SCC-47, UPCI:SCC090, UPCI:SCC152 and 93VU147T, even though integration was identified. A recent publication suggests that HPV integration without concurrent loss of the E2 gene can also occur in HNSCC resulting in viral concatenates in the human genome ${ }^{53}$. The high viral load in combination with a limited number of strong FISH signals indicates that integration of such stretches of multiple HPV-copies could have occurred in our cell lines as well. E6 and $E 7 \mathrm{mRNA}$ levels were equally variable in all cell lines, and no correlation was seen with the expression levels of $E 2$. This is in agreement with the results obtained in primary HNSCC (chapter 4), in which the expression levels of E2, E6 and E7 mRNA transcripts were highly variable and did not show correlation to the physical status of the virus.

In conclusion, we have characterized seven established HPV16-positive HNSCC cell lines, which shows viral integration in six cases and variable viral load and expression of early viral genes E2, E6 and E7. Furthermore they exhibit characteristics associated with a poor prognosis, such as EGFR overexpression and aneusomy ${ }^{13,48}$. Since these cell lines reflect tumors with a poor prognosis, results obtained in studies testing new treatment options using these cell lines might be especially beneficial for the group of HPVpositive HNSCC patients that respond poorly to currently used treatment modalities. 


\section{References}

1 Doorbar J. Molecular biology of human papillomavirus infection and cervical cancer. Clin Sci 2006; 110: $525-541$.

2 Fakhry C and Gillison ML. Clinical implications of human papillomavirus in head and neck cancers. J Clin Oncol 2006; 24: 2606-2611.

3 Hafkamp HC, Speel EJ, Haesevoets A, Bot FJ, Dinjens WN, Ramaekers FC et al. A subset of head and neck squamous cell carcinomas exhibits integration of HPV 16/18 DNA and overexpression of $p 16^{I N K 4 A}$ and $p 53$ in the absence of mutations in $p 53$ exons 5-8. Int J Cancer 2003; 107: 394-400.

4 Nasman A, Attner P, Hammarstedt L, Du J, Eriksson M, Giraud G et al. Incidence of human papillomavirus (HPV) positive tonsillar carcinoma in Stockholm, Sweden: an epidemic of viral-induced carcinoma? Int J Cancer 2009; 125: 362-366.

5 Ragin CC and Taioli E. Survival of squamous cell carcinoma of the head and neck in relation to human papillomavirus infection: review and meta-analysis. Int J Cancer 2007; 121: 1813-1820.

6 Ang KK, Harris J, Wheeler R, Weber R, Rosenthal DI, Nguyen-Tan PF et al. Human papillomavirus and survival of patients with oropharyngeal cancer. N Engl J Med 2010; 363: 24-35.

7 Fakhry C, Westra WH, Li S, Cmelak A, Ridge JA, Pinto H et al. Improved survival of patients with human papillomavirus-positive head and neck squamous cell carcinoma in a prospective clinical trial. J Natl Cancer Inst 2008; 100: 261-269.

8 Fallai C, Perrone F, Licitra L, Pilotti S, Locati L, Bossi P et al. Oropharyngeal squamous cell carcinoma treated with radiotherapy or radiochemotherapy: prognostic role of TP53 and HPV status. Int J Radiat Oncol Biol Phys 2009; 75: 1053-1059.

9 Fischer CA, Zlobec I, Green E, Probst S, Storck C, Lugli A et al. Is the improved prognosis of p16 positive oropharyngeal squamous cell carcinoma dependent of the treatment modality? Int J Cancer 2010; 126: 1256-1262.

10 Lassen $\mathrm{P}$. The role of human papillomavirus in head and neck cancer and the impact on radiotherapy outcome. Radiother Oncol 2010; 95: 371-380.

11 Lassen P, Eriksen JG, Hamilton-Dutoit S, Tramm T, Alsner J and Overgaard J. Effect of HPV-associated $p 16^{I N K 4 A}$ expression on response to radiotherapy and survival in squamous cell carcinoma of the head and neck. J Clin Oncol 2009; 27: 1992-1998.

12 Maxwell JH, Kumar B, Feng FY, Worden FP, Lee JS, Eisbruch A et al. Tobacco use in human papillomavirus-positive advanced oropharynx cancer patients related to increased risk of distant metastases and tumor recurrence. Clin Cancer Res 2010; 16: 1226-1235.

13 Mooren JJ, Kremer B, Claessen SM, Voogd AC, Bot FJ, Peter Klussmann J et al. Chromosome stability in tonsillar squamous cell carcinoma is associated with HPV16 integration and indicates a favorable prognosis. Int J Cancer 2013; 132: 1781-1789.

14 Theelen W, Speel EJ, Herfs M, Reijans M, Simons G, Meulemans EV et al. Increase in viral load, viral integration, and gain of telomerase genes during uterine cervical carcinogenesis can be simultaneously assessed by the HPV 16/18 MLPA-assay. Am J Pathol 2010; 177: 2022-2033. 
15 Klaes R, Woerner SM, Ridder R, Wentzensen N, Duerst M, Schneider A et al. Detection of high-risk cervical intraepithelial neoplasia and cervical cancer by amplification of transcripts derived from integrated papillomavirus oncogenes. Cancer Res 1999; 59: 6132-6136.

16 Saunier M, Monnier-Benoit S, Mauny F, Dalstein V, Briolat J, Riethmuller D et al. Analysis of human papillomavirus type 16 (HPV16) DNA load and physical state for identification of HPV16-infected women with high-grade lesions or cervical carcinoma. J Clin Microbiol 2008; 46: 3678-3685.

17 Mellin H, Dahlgren L, Munck-Wikland E, Lindholm J, Rabbani H, Kalantari M et al. Human papillomavirus type 16 is episomal and a high viral load may be correlated to better prognosis in tonsillar cancer. Int J Cancer 2002; 102: 152-158.

18 Koskinen WJ, Chen RW, Leivo I, Makitie A, Back L, Kontio R et al. Prevalence and physical status of human papillomavirus in squamous cell carcinomas of the head and neck. Int J Cancer 2003; 107: 401-406.

19 Begum S, Cao D, Gillison M, Zahurak M and Westra WH. Tissue distribution of human papillomavirus 16 DNA integration in patients with tonsillar carcinoma. Clin Cancer Res 2005; 11: 5694-5699.

20 Klussmann JP, Weissenborn SJ, Wieland U, Dries V, Kolligs J, Jungehuelsing M et al. Prevalence, distribution, and viral load of human papillomavirus 16 DNA in tonsillar carcinomas. Cancer 2001; 92: 2875-2884.

21 Chang YE, Pena L, Sen GC, Park JK and Laimins LA. Long-term effect of interferon on keratinocytes that maintain human papillomavirus type 31. J Virol 2002; 76: 8864-8874.

22 Herdman MT, Pett MR, Roberts I, Alazawi WO, Teschendorff AE, Zhang XY et al. Interferon-beta treatment of cervical keratinocytes naturally infected with human papillomavirus 16 episomes promotes rapid reduction in episome numbers and emergence of latent integrants. Carcinogenesis 2006; 27: 2341-2353.

23 White JS, Weissfeld JL, Ragin CCR, Rossie KM, Martin CL, Shuster M et al. The influence of clinical and demographic risk factors on the establishment of head and neck squamous cell carcinoma cell lines. Oral Oncol 2007; 43: 701-712.

24 Balló H, Koldovsky P, Hoffmann T, Balz V, Hildebrandt B, Gerharz CD et al. Establishment and characterization of four cell lines derived from human head and neck squamous cell carcinomas for an autologous tumor-fibroblast in vitro model. Anticancer Res 1999; 19: 3827-3836.

25 Brenner JC, Graham MP, Kumar B, Saunders LM, Kupfer R, Lyons RH et al. Genotyping of 73 UMSCC head and neck squamous cell carcinoma cell lines. Head Neck 2010; 32: 417-426.

26 Tang AL, Hauff SJ, Owen JH, Graham MP, Czerwinski MJ, Park JJ et al. UM-SCC-104: A new human papillomavirus-16-positive cancer stem cell-containing head and neck squamous cell carcinoma cell line. Head Neck 2012; 34: 1480-1491.

27 Steenbergen RD, Hermsen MA, Walboomers JM, Joenje H, Arwert F, Meijer CJ et al. Integrated human papillomavirus type 16 and loss of heterozygosity at $11 \mathrm{q} 22$ and $18 \mathrm{q} 21$ in an oral carcinoma and its derivative cell line. Cancer Res 1995; 55: 5465-5471.

28 Bouvard V, Storey A, Pim D and Banks L. Characterization of the human papillomavirus E2 protein: evidence of trans-activation and trans-repression in cervical keratinocytes. EMBO J 1994; 13: 54515459. 
29 de Roda Husman AM, Walboomers JM, van den Brule AJ, Meijer CJ and Snijders PJ. The use of general primers GP5 and GP6 elongated at their 3' ends with adjacent highly conserved sequences improves human papillomavirus detection by PCR. J Gen Virol 1995; 76 ( Pt 4): 1057-1062.

30 Weissenborn SJ, Funke AM, Hellmich M, Mallmann P, Fuchs PG, Pfister HJ et al. Oncogenic human papillomavirus DNA loads in human immunodeficiency virus-positive women with high-grade cervical lesions are strongly elevated. J Clin Microbiol 2003; 41: 2763-2767.

31 Weissenborn SJ, Wieland U, Junk M and Pfister H. Quantification of beta-human papillomavirus DNA by real-time PCR. Nat Protoc 2010; 5: 1-13.

32 Seedorf K, Krammer G, Durst M, Suhai S and Rowekamp WG. Human papillomavirus type 16 DNA sequence. Virology 1985; 145: 181-185.

33 Wentzensen N, Vinokurova S and von Knebel Doeberitz M. Systematic review of genomic integration sites of human papillomavirus genomes in epithelial dysplasia and invasive cancer of the female lower genital tract. Cancer Res 2004; 64: 3878-3884.

34 Lace MJ, Anson JR, Klingelhutz AJ, Harada H, Taniguchi T, Bossler AD et al. Interferon-beta treatment increases human papillomavirus early gene transcription and viral plasmid genome replication by activating interferon regulatory factor (IRF)-1. Carcinogenesis 2009; 30: 1336-1344.

35 Cooper K, Herrington CS, Stickland JE, Evans MF and McGee JO. Episomal and integrated human papillomavirus in cervical neoplasia shown by non-isotopic in situ hybridisation. J Clin Pathol 1991; 44: $990-996$.

36 Hopman AH, Kamps MA, Smedts F, Speel EJ, Herrington CS and Ramaekers FC. HPV in situ hybridization: impact of different protocols on the detection of integrated HPV. Int J Cancer 2005; 115: 419-428.

37 Hopman AH, Smedts F, Dignef W, Ummelen M, Sonke G, Mravunac M et al. Transition of high-grade cervical intraepithelial neoplasia to micro-invasive carcinoma is characterized by integration of HPV 16/18 and numerical chromosome abnormalities. J Pathol 2004; 202: 23-33.

38 Speel EJ, Hopman AH and Komminoth P. in In Situ Hybridization Protocols Methods in molecular biology (eds Darby IA \& Hewitson TD) 33-54 (Humana Press, 2006).

39 Hopman AH, Kamps MA, Smedts F, Speel EJ, Herrington CS and Ramaekers FC. HPV in situ hybridization: impact of different protocols on the detection of integrated HPV. Int J Cancer 2005; 115: 419-428.

40 Lopez JR, Claessen SM, Macville MV, Albrechts JC, Skogseid B and Speel EJ. Spectral karyotypic and comparative genomic analysis of the endocrine pancreatic tumor cell line BON-1. Neuroendocrinology 2010; 91: 131-141.

41 Vinokurova S, Wentzensen N, Einenkel J, Klaes R, Ziegert C, Melsheimer P et al. Clonal history of papillomavirus-induced dysplasia in the female lower genital tract. J Natl Cancer Inst 2005; 97: 1816 1821.

42 Basic Logical Alignment Search Tool (BLAST). National Center for Biotechnology Information (NCBI). 2011; http://blast.ncbi.nlm.nih.gov/.

43 Map Viewer. National Center for Biotechnology Information (NCBI). 2011; http://www.ncbi.nlm.nih. gov/mapview/. 
44 Luft F, Klaes R, Nees M, Durst M, Heilmann V, Melsheimer P et al. Detection of integrated papillomavirus sequences by ligation-mediated PCR (DIPS-PCR) and molecular characterization in cervical cancer cells. Int J Cancer 2001; 92: 9-17.

45 Chow LT and Broker TR. In vitro experimental systems for HPV: epithelial raft cultures for investigations of viral reproduction and pathogenesis and for genetic analyses of viral proteins and regulatory sequences. Clin Dermatol 1997; 15: 217-227.

46 Primer-BLAST. National Center for Biotechnology Information (NCBI). http://www.ncbi.nlm.nih. gov/tools/primer-blast.

47 Swarts DR, Henfling ME, Van Neste L, van Suylen RJ, Dingemans AM, Dinjens WN et al. CD44 and OTP are strong prognostic markers for pulmonary carcinoids. Clin Cancer Res 2013; 19: 2197-2207.

48 Olthof NC, Straetmans JM, Snoeck R, Ramaekers FC, Kremer B and Speel EJ. Next-generation treatment strategies for human papillomavirus-related head and neck squamous cell carcinoma: where do we go? Rev Med Virol 2012; 22: 88-105.

49 Klaes R, Woerner S, Ridder R and Wentzensen N. Detection of high-risk cervical intraepithelial neoplasia and cervical cancer by amplification of transcripts derived from integrated papillomavirus oncogenes. Cancer Res 1999; 6132-6136.

50 Ragin CCR, Reshmi SC and Gollin SM. Mapping and analysis of HPV16 integration sites in a head and neck cancer cell line. Int J Cancer 2004; 110: 701-709.

51 Kraus I, Driesch C, Vinokurova S, Hovig E, Schneider A, von Knebel Doeberitz M et al. The majority of viral-cellular fusion transcripts in cervical carcinomas cotranscribe cellular sequences of known or predicted genes. Cancer Res 2008; 68: 2514-2522.

52 Vinokurova S, Wentzensen N, Kraus I, Klaes R, Driesch C, Melsheimer P et al. Type-dependent integration frequency of human papillomavirus genomes in cervical lesions. Cancer Res 2008; 68: 307313.

53 Lace MJ, Anson JR, Klussmann JP, Wang DH, Smith EM, Haugen TH et al. Human papillomavirus type 16 (HPV-16) genomes integrated in head and neck cancers and in HPV-16-immortalized human keratinocyte clones express chimeric virus-cell mRNAs similar to those found in cervical cancers. J Virol 2011; 85: 1645-1654.

54 Huebbers CU, Preuss SF, Kolligs J, Vent J, Stenner M, Wieland U et al. Integration of HPV6 and downregulation of AKR1C3 expression mark malignant transformation in a patient with juvenile-onset laryngeal papillomatosis. PLoS ONE 2013; 8: e57207.

55 Wiest T, Schwarz E, Enders C, Flechtenmacher C and Bosch FX. Involvement of intact HPV16 E6/ E7 gene expression in head and neck cancers with unaltered $p 53$ status and perturbed $p R b$ cell cycle control. Oncogene 2002; 21: 1510-1517.

56 Yoshida T, Sano T, Oyama T, Kanuma T and Fukuda T. Prevalence, viral load, and physical status of HPV 16 and 18 in cervical adenosquamous carcinoma. Virchows Arch 2009; 455: 253-259.

57 Li H, Yang Y, Zhang R, Cai Y, Yang X, Wang Z et al. Preferential sites for the integration and disruption of human papillomavirus 16 in cervical lesions. J Clin Virol 2013; 56: 342-347. 
58 de Boer MA, Jordanova ES, Kenter GG, Peters AA, Corver WE, Trimbos JB et al. High human papillomavirus oncogene mRNA expression and not viral DNA load is associated with poor prognosis in cervical cancer patients. Clinical cancer research : an official journal of the American Association for Cancer Research 2007; 13: 132-138.

59 Arias-Pulido H, Peyton CL, Joste NE, Vargas H and Wheeler CM. Human papillomavirus type 16 integration in cervical carcinoma in situ and in invasive cervical cancer. J Clin Microbiol 2006; 44: 1755-1762.

60 Ziegert C, Wentzensen N, Vinokurova S, Kisseljov F, Einenkel J, Hoeckel M et al. A comprehensive analysis of HPV integration loci in anogenital lesions combining transcript and genome-based amplification techniques. Oncogene 2003; 22: 3977-3984.

61 Gammoh N, Grm HS, Massimi P and Banks L. Regulation of human papillomavirus type 16 E7 activity through direct protein interaction with the E2 transcriptional activator. J Virol 2006; 80: 1787 1797.

62 Ganguly N and Parihar SP. Human papillomavirus E6 and E7 oncoproteins as risk factors for tumorigenesis. J Biosci 2009; 34: 113-123.

63 Narisawa-Saito M and Kiyono T. Basic mechanisms of high-risk human papillomavirus-induced carcinogenesis: roles of E6 and E7 proteins. Cancer Sci 2007; 98: 1505-1511. 


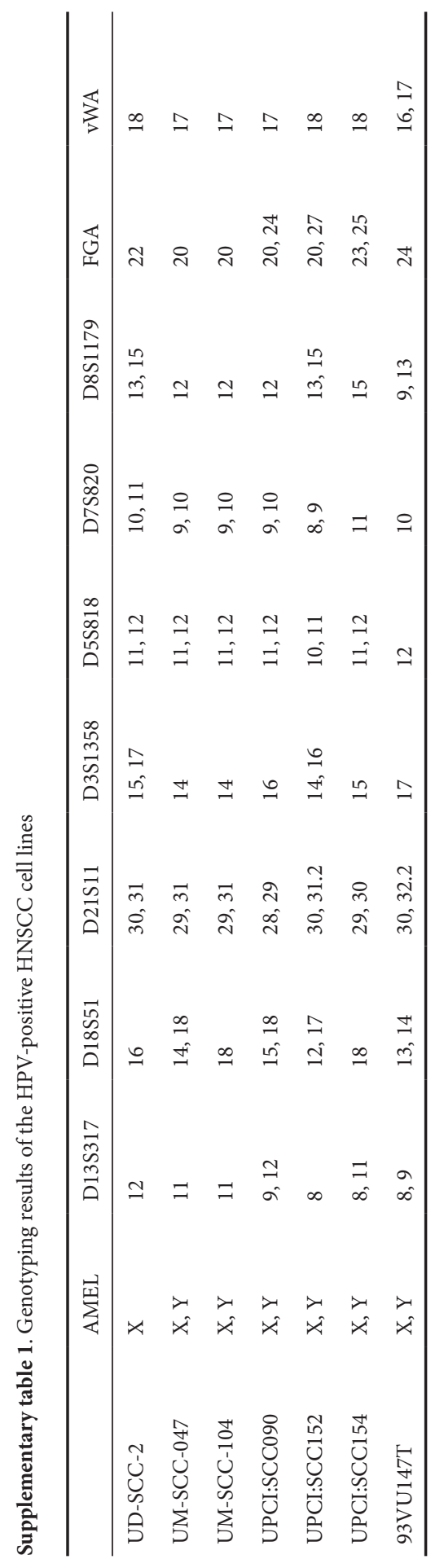




\section{Chapter 6}

\section{Radiosensitivity and effect of hypoxia in HPV positive head and neck cancer cells}

\section{Brita Singers Sorensen ${ }^{1}$, Morten Busk ${ }^{1}$, Nadine C. Olthof ${ }^{2,3}$, Ernst-Jan M. Speel ${ }^{3,4}$, Michael R. Horsman ${ }^{1}$, Jan Alsner ${ }^{1}$, Jens Overgaard ${ }^{1}$}

\footnotetext{
'Department of Experimental Clinical Oncology, Aarhus University Hospital, Denmark;

2Department of Otorhinolaryngology and Head and Neck Surgery;

${ }^{3}$ Department of Molecular Cell Biology and

${ }^{4}$ Department of Pathology, GROW-School for Oncology and Developmental Biology,

Maastricht University Medical Centre, the Netherlands
}

Radiotherapy and Oncology 2013; in press 


\section{Abstract}

Background and purpose: HPV associated head and neck squamous cell carcinoma (HNSCC) represent a distinct subgroup of HNSCC characterized by a favorable prognosis and a distinct molecular biology. Previous data from the randomized DAHANCA 5 trial indicated that HPV positive tumors did not benefit from hypoxic modifications by Nimorazole during radiotherapy, whereas a significant benefit was observed in the HPV negative tumors. However, more studies have demonstrated equal frequencies of hypoxic tumors amongst HPV-positive and HPV-negative tumors. The aim of the present study was to determine radiosensitivity, the impact of hypoxia and the effect of Nimorazole in HPV positive and HPV negative cell lines.

Materials and Method: The used cell lines were: UD-SCC-2, UM-SCC-047 and UPCI:SCC090 (HPV positive) and FaDu $\mathrm{DD}$, UT-SCC-33 and UT-SCC-5 (HPV negative). Cells were cultured under normoxic or hypoxic conditions, and gene expression levels of previous established hypoxia induced genes were assessed by qPCR. Cells were irradiated with various doses under normoxia, hypoxia or hypoxia $+1 \mathrm{mM}$ Nimorazole, and the clonogenic survival was determined.

Results: The HPV positive and HPV negative cell lines exhibited similar patterns of upregulation of hypoxia induced genes in response to hypoxia. The HPV positive cell lines were up to 2.4 times more radiation sensitive than HPV negative cell lines. However, all HPV positive cells displayed the same response to hypoxia in radiosensitivity, with an oxygen enhancement ratio (OER) in the range 2.3-2.9, and a sensitizer effect of Nimorazole of 1.13-1.29, similar to HPV negative cells.

Conclusions: Although HPV positive cells had a markedly higher radiosensitivity compared to HPV negative cells, they displayed the same relative radioresistance under hypoxia and the same relative sensitizer effect of Nimorazole. The clinical observation that HPV positive patients do not seem to benefit from Nimorazole treatment is not due to inherent differences in hypoxia sensitivity or response to Nimorazole, but can be accounted for by the overall higher radiosensitivity of HPV positive cells. 


\section{Introduction}

Head and neck squamous cell carcinoma (HNSCC) can be linked to the human papillomavirus (HPV) $)^{1,2}$ and it has become evident that HPV associated HNSCC represent a distinct subgroup of HNSCC characterized by a distinct molecular biology, epidemiology, and better prognosis ${ }^{3-6}$, leading to HPV being the most important independent prognostic factor in $\mathrm{HNSCC}^{7}$.

The use of HPV-associated $p 16$ expression as a retrospective stratification parameter in the randomized DAHANCA 5 trial indicated a differentiated response to hypoxic modification dependent on the HPV status of the tumors ${ }^{8}$. Hence, HPV positive tumors did not benefit from hypoxic modification with Nimorazole during radiotherapy, whereas a significant benefit was observed in the HPV negative tumors. A possible explanation for this could be that HPV-positive tumors might be characterized by less hypoxia, which could explain both the overall improved prognosis and the lack of association with hypoxic modification. However, a study using a 15-gene hypoxia gene expression profile demonstrated the same frequencies of hypoxia amongst HPV-positive and HPV-negative tumors in HNSCC patients ${ }^{9}$. Furthermore, a study evaluating the hypoxic status in HNSCC patients using FAZA PET scans confirmed that the HPV-positive and the HPVnegative tumors were equally hypoxic ${ }^{10}$.

Previous in vitro studies addressing the radiosensitivity of HPV positive cell lines reached contradicting conclusions, with more studies pointing towards HPV positive cell lines being more radiosensitive than HPV negative cell lines ${ }^{11-13}$, and one study, indicating that HPV positive cell lines are more resistant to radiation ${ }^{14}$.

There is a range of unresolved questions regarding the different biology and clinical outcome of HPV positive HNSCC, and the purpose of the present study was to explore the biological background for the clinical observations. Using a panel of HPV positive and HPV negative HNSCC cell lines we examined the hypoxia induced gene expression, to reveal whether the different biology of HPV positive tumors and their lacking response to hypoxia in radiosensitivity could be mediated through the expression of hypoxia induced genes. Furthermore, the radiosensitivity, the Oxygen Enhancement Ratio (OER), and the Sensitivity Enhancement Ratio (SER) in response to Nimorazole of the different cell lines was determined. 


\section{Method}

\section{Cell lines}

The HPV-16 negative head and neck squamous cell carcinoma (HNSCC) cell lines used were: $\mathrm{FaDu}_{\mathrm{DD}}$ (a subline of $\mathrm{FaDu}$, an undifferentiated hypopharyngeal carcinoma), UTSCC-5 and UT-SCC-33 (both oral carcinomas, established by Dr. Reidar Grenman, University of Turku, Finland ${ }^{15}$ ), obtained from Dr. Michael Baumann, University of Technology, Dresden, Germany). Three HPV-16 positive HNSCC cell lines: UM-SCC-047 (from the lateral tongue, established by Dr. Thomas Carey, University of Michigan ${ }^{16,17}$ ), UD-SCC-2 (established by Dr. Thomas Hoffmann, University of Düsseldorff ${ }^{18,19}$ ) and UPCI:SCC090 (from the base of the tongue, established by Dr Susanne M Gollin, University of Pittsburgh ${ }^{20}$ ) were also used. Cells were cultured in DMEM with $10 \%$ fetal calf serum, 100,000 U/L penicillin, and $100 \mathrm{mg} / \mathrm{L}$ streptomycin, with $5 \% \mathrm{CO}_{2}$ in a well humidified incubator.

\section{HPV and p16 status}

The presence of HPV DNA was detected by PCR in all included cell lines using the consensus primer set GP5 $+/ 6+{ }^{21}$, followed by type-specific primers for HPV16. Five $\mu$ l of PCR product was separated on a $1.5 \%$ agarose gel and visualized using ethidium bromide staining. For immunohistochemistry, cells were trypsinized, pelleted, fixed in formalin and paraffin embedded. Immunohistochemistry for $\mathrm{p} 16^{\mathrm{INK} 4 \mathrm{~A}}$ was performed as previous described $^{5}$. Briefly, paraffin sections were cut at $5 \mu \mathrm{m}$, heated at $60^{\circ} \mathrm{C}$ for 1 hour, and deparaffinized with EZ prep solution (Ventana Medical Systems). Heat-induced antigen retrieval was carried out using Cell Conditioning 1 solution (CC1, Ventana Medical Systems). $p 16^{\mathrm{INK} 4}$ expression was detected by using the clone JC8 (sc-56330; Santa Cruz Biotechnology Inc, Santa Cruz, CA). Sections of p16-positive cervical carcinoma cells ( $\mathrm{SiHa}$ ) were used as positive controls.

\section{Gene expression quantification}

For hypoxia experiments, $2 \times 10^{5}$ cells were seeded into $60 \mathrm{~mm}$ glass Petri dishes three days prior to experiments. Hypoxia was achieved by continually gassing the cells in an airtight chamber with $0 \%$ oxygen or atmospheric air, supplemented with $5 \% \mathrm{CO}_{2}$ and nitrogen, at $37^{\circ} \mathrm{C}$ for 24 hours. This timepoint was based on previous data for gene expression under hypoxia $^{22,23}$. Gene expression levels were quantified using qPCR as described in $^{24}$. To detect transcripts of interest, 31 previously described hypoxia induced genes ${ }^{24,25}$, TaqMan Gene Expression assay ( $\mathrm{ABI}$ ) were used (all assay information can be found $\mathrm{in}^{25}$ ). Reactions were performed on an ABI Prism 7900 Sequence Detector (ABI). All reactions were performed 
in duplicate. Data were analyzed using Real-Time Statminer (Intergromics) and $\triangle \mathrm{Ct}$ values were generated by normalizing to the geometric mean of the 3 reference genes RPL37A, ACTR3 and NDFIP ${ }^{25}$. For the heatmap of gene expression levels Gene Cluster 2.11 (Michael Eisen, rana.lbl.gov/EisenSoftware.htm) (median centered levels) and Java Treeview (ver 1.1.3) was used. Results represent data from three independent experiments.

\section{Clonogenic assay and analysis of cell survival}

To analyze the effect of oxygen concentration on radiosensitivity, clonogenic assay was performed. By preplating, appropriate numbers (to achieve approximately 90 colonies per dish) of cells (in exponential growth) were seeded into $6 \mathrm{~cm}$ glass Petri dishes $20-24 \mathrm{~h}$ prior to irradiation. Cells were gassed for $1 \mathrm{~h}$ prior to irradiation in airtight chambers with either $0 \%$ oxygen or $21 \%$ oxygen, supplemented with $5 \% \mathrm{CO}_{2}$. Chambers were sealed during irradiation. For Nimorazole studies, $1 \mathrm{mM}$ Nimorazole (based on previous published in vitro data ${ }^{26-28}$ ) was added to the cell culture media immediately prior to the hypoxia treatment. Cells were irradiated with a single fraction of $1-10 \mathrm{~Gy}$ at a dose rate of $0.58 \mathrm{~Gy} / \mathrm{min}$ using a $240 \mathrm{kV}$ Philips X-ray machine. After irradiation, media was immediately changed, and the cells placed in a $5 \% \mathrm{CO}_{2}$ incubator at $37^{\circ} \mathrm{C}$. At $14-21$ days after irradiation the cells were fixed in methanol and stained with $50 \%$ toluidine blue (Merck). Colonies consisting of at least 50 cells were counted. The colonies were counted using Clono-Counter software $^{29}$ and the surviving fraction was calculated. Each data point is the mean of 6-12 samples from three independent experiments with the standard deviation shown. Survival curves were fitted to a linear-quadratic function using $\mathrm{R}$ (version 2.12.2). As control, the survival of cells treated with Nimorazole without irradiation was also determined.

\section{Results}

\section{HPV and p16 status of the cell lines}

The HPV-positive HNSCC cell lines have previously been characterized and demonstrated to be HPV16 positive ${ }^{16,17,19,30,31}$. Still, the HPV status of all included cell lines was validated using PCR. HPV was first detected using the general PCR-primer GP5+6+, which is able to detect HR-HPV types $16,18,31,33,35,39,45,51,52,56,58,59,66$, and 68 and LR-HPV types $6,11,40,42,43$, and $44^{21}$. This confirmed that UD-SCC-2, UM-SCC-047 and UPCI:SCC090 are HPV positive and the other included cell lines are HPV negative. Cell lines UD-SCC-2, UM-SCC-047 and UPCI:SCC090 were further tested using HPV16 specific primers. This showed HPV16 infection for the cell lines. The control cell line CaSki showed infection with HPV16 and control cell lines HeLa (HPV18 positive) remained negative, indicating good type-specificity (results not shown). 
The expression level of the HPV related marker p16 was evaluated by immunohistochemical staining in all the included cell lines ${ }^{32}$. The HPV positive cell lines displayed a clear overexpression of p16 (results not shown).

\section{Gene expression of hypoxia inducible genes}

To test whether HPV-positive cells exhibit a different gene expression pattern in response to hypoxia, gene expression levels following exposure of hypoxia of 31 previous described hypoxia responsive genes was examined in two HPV positive and two HPV negative cell lines ${ }^{24,25}$. It was found that there was a great difference between the fold difference in expression level between the individual genes, with $\mathrm{Ca} 9$ displaying a difference of up to thousand fold, and $A K 3 L 1$ being upregulated between 1.2-4.4 times. For the individual genes a difference in expression levels between different cell lines was also found, which is in line with previous studies of hypoxia induced gene expression levels in different cell lines ${ }^{22}$. However, the 31 genes were all upregulated by hypoxia in all four cell lines (figure1).

\section{Radiosensitivity and impact of hypoxia in HPV positive cell lines}

To reveal mechanisms in the clinically demonstrated difference in prognosis between patients with HPV positive and HPV negative tumors, the radio-sensitivity of the different cell lines in our panel was established using a clonogenic assay. It was observed that the HPV positive cell lines were distinctly more radiation sensitive compared to HPV negative cell lines, with an enhancement ratio at up to 2.4 (HPV positive cell lines: $\mathrm{SF}_{10 \%}$ at 2.2-2.4 Gy, HPV negative cell lines: $\mathrm{SF}_{10 \%}$ at 3.8-5.3 Gy) (figure $2 \mathrm{~A}$ ).

Furthermore, the impact of hypoxia on the radiosensitivity and the effect of $\mathrm{Ni}$ morazole were investigated. This revealed that the HPV positive and negative cells display the same response to hypoxia in radiosensitivity, with observed OERs ranging between 2.3 and 2.9. A clear increase in radiosensitivity by Nimorazole treatment during hypoxia exposure was seen with the HPV positive (SER 1.1-1.2) and HPV negative (SER 1.1-1.3) cell lines (figure 2B-2G).

Control experiments with cells treated with Nimorazole without irradiation demonstrated that Nimorazole by itself had no influence on clonogenic survival (results not shown). 

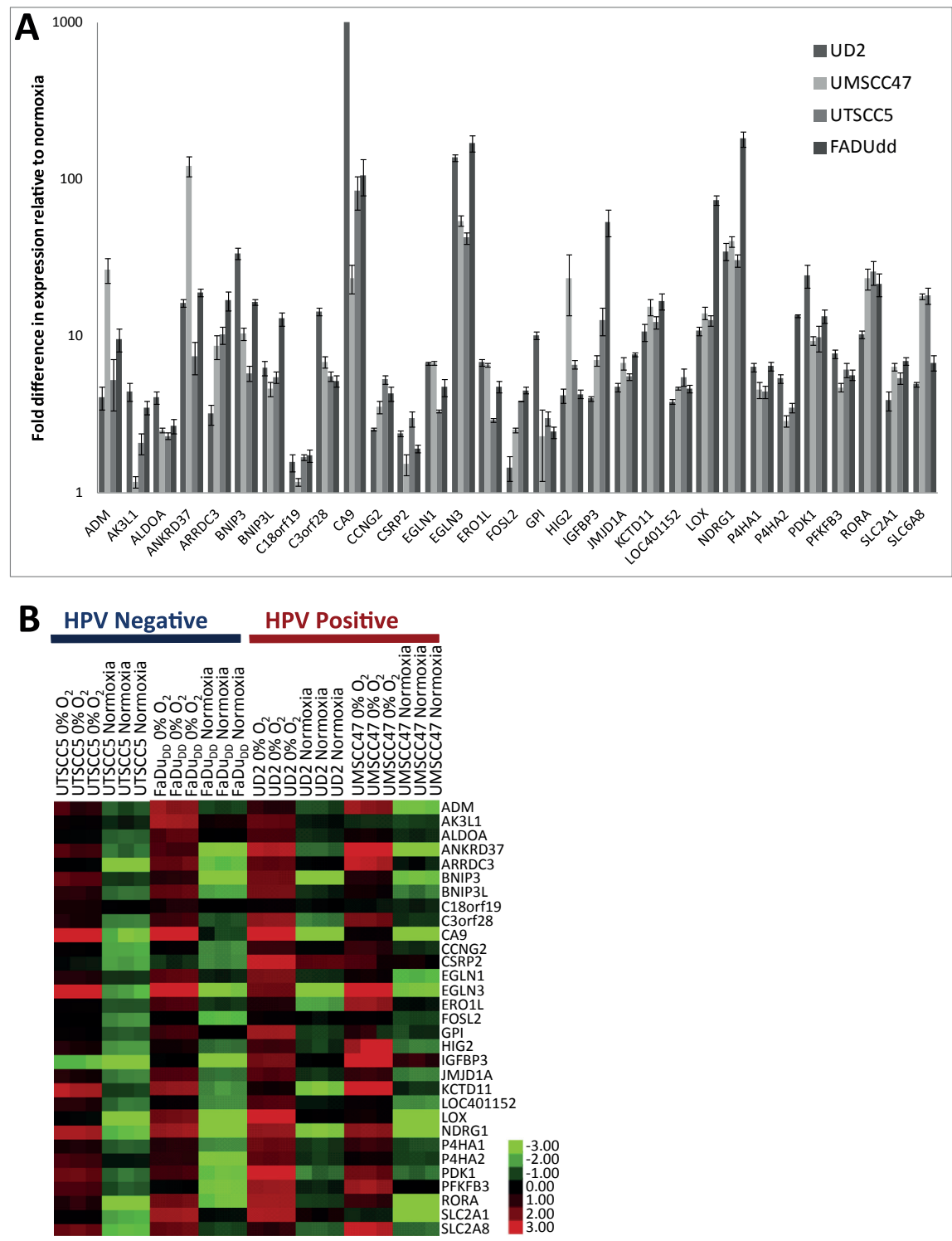

Figure 1.

A) Gene expression under hypoxia. Relative gene expression of 31 genes under hypoxia, normalized to the gene expression level under normoxia. Data are the mean values of three independent experiments. Error bars represents standard deviation $(n=3)$.

B) Heat map of the 31 genes. Data from three independent experiments are shown. The colour bar is showing the fold change relative to the median expression of each gene across all cell lines and conditions. Data is $\log 2$ transformed. 

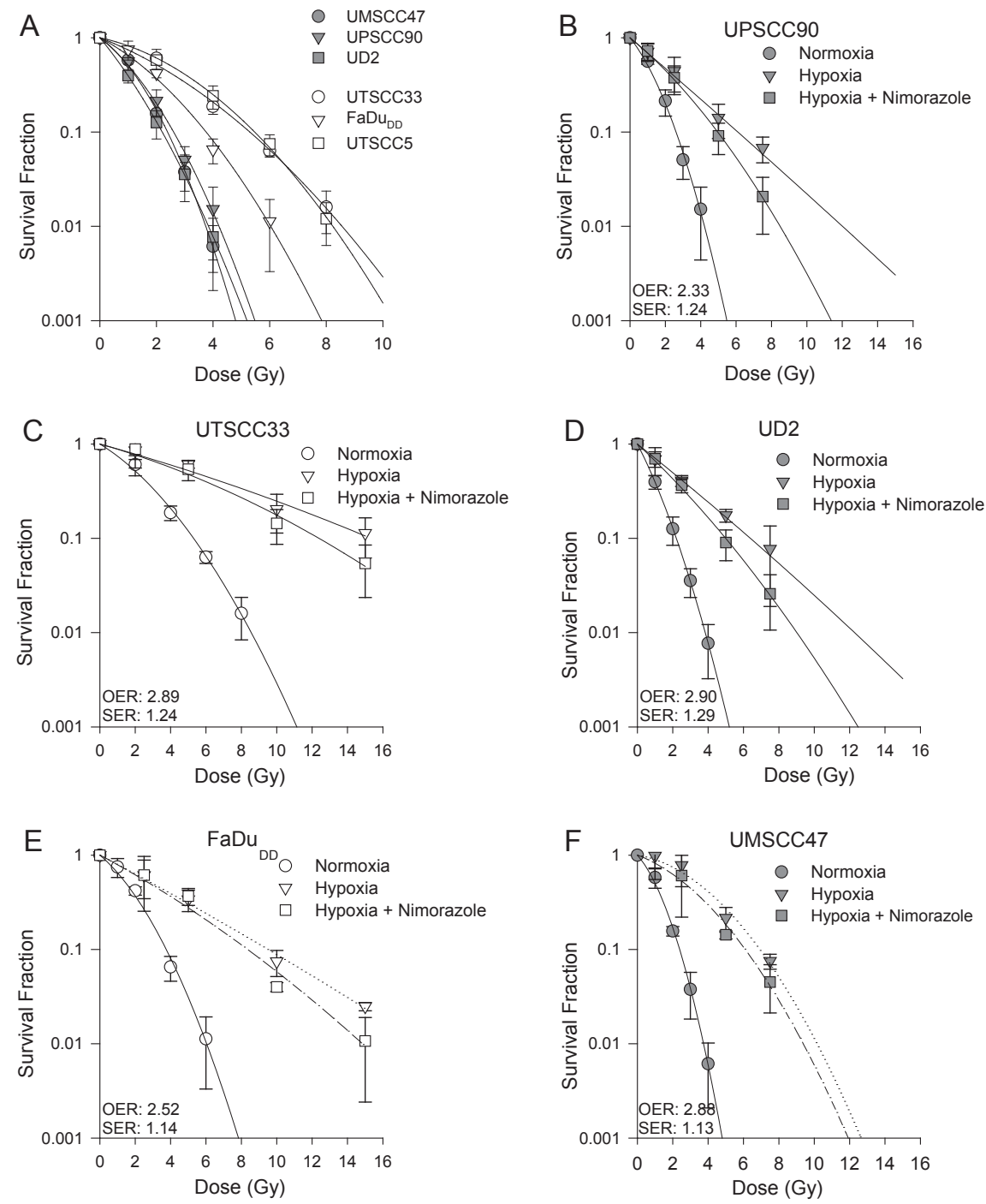

Figure 2. Radiosensitivity of cell lines.

A) Cell survival curves of all included cell lines under normoxia.

B-F) The individual cell lines cells after irradiation under either normoxic, hypoxic or hypoxia+ 1mM Nimorazole conditions. The linear quadratic model is fitted to the data. The OER and SER is calculated at SF10\%. The error bars represents the standard deviations $(\mathrm{n}=6-12)$. 


\section{Discussion}

There is a range of unresolved questions regarding the different biology and clinical outcome of HPV positive HNSCC, and the purpose of the present in vitro study was to explore the biological backgrounds for the clinical observations. In this study we have used a panel of HNSCC cell lines, including three HPV positive HNSCC cell lines, all three HPV16 positive. The UPCI:SCC90 and UM-SCC-047 cell lines have previously been shown to contain integrated HPV16 DNA while this is not confirmed for UDSCC-2 $2^{12,30,33}$. All three cell lines express the viral E6 and E7 genes ${ }^{31}$.

It is possible that the difference in patient outcome and sensitivity to hypoxia is mediated through hypoxia responsive genes, the key regulators of metabolic and cellular adaptation to hypoxia. Repression of the hypoxia induced pathways may severely compromise cell survival under hypoxia, leaving only the more oxygenated cells viable. The present study investigated the gene expression levels of a range of previous described hypoxia responsive genes, following exposure of hypoxia. It was found that for all cell lines, the investigated genes were upregulated during hypoxia. Many of the included genes, Ca9 for example, are HIF1 regulated, indicating that the function of HIF1 is not compromised in HPV positive cells. Fifteen of the tested genes are included in a hypoxia gene expression profile ${ }^{9,25,34}$, that has previously demonstrated to have predictive impact for hypoxic modification of radiotherapy in head and neck cancer. The results in the current study also confirm the use of this hypoxia gene expression classifier, regardless of HPV status.

The investigation of the effect of hypoxia and Nimorazole on the radiosensitivity of the different cell lines revealed that all cell lines exhibited a comparable OER and SER. This suggests that the clinical observation that HPV positive patients do not benefit from Nimorazole treatment is not due to a difference in hypoxia sensitivity or response to Nimorazole. We observed as SER with Nimorazole in the range of 1.13-1.29, which is in line with previous published data ${ }^{27,35}$. The concentration of Nimorazole used in this study $(1 \mathrm{mM})$ is comparable to the level in the tumor in patients treated with Nimorazole ${ }^{36-38}$.

Overall, the HPV positive cell lines exhibited a markedly higher radiosensitivity, which has also been reported for the same HPV positive cell lines in a very recent paper ${ }^{13}$, leading to HPV positive cells under hypoxia exhibiting approximately the same radiosensitivity as HPV negative cells under normoxia. This opens for the possibility, that with the current clinical radiation schedule, HPV positive tumors receive a radiation dose at a level that makes the use of Nimorazole unnecessary. It is therefore possible that the observed increased radiosensitivity may account for both the favorable clinical prognosis as well as the observed lack of effect of Nimorazole treatment in HPV positive patients. Due to the good treatment response, a dose reduction for patients with HPV-positive oropharyngeal cancers has been suggested. The finding that Nimerazole in principally 
active in HPV-positive HNSCC cells in vitro suggests that Nimerazole could be indicated and beneficial in HPV-positive HNSCC when treated with a lower total dose of radiation, than what is current practice.

\section{Acknowledgements}

The authors would like to thank Lene Bjerre Petersen, Mogens Jøns Johansen and Alice Baden for excellent technical help. Financial support was received from the Danish Cancer Society, the Danish Medical Research Council, EC FP7 project METOXIA (project no. 222741), and CIRRO - The Lundbeck Foundation Centre for Interventional Research in Radiation Oncology. 


\section{References}

1 D'Souza G, Kreimer AR, Viscidi R, Pawlita M, Fakhry C, Koch WM et al. Case-control study of human papillomavirus and oropharyngeal cancer. N Engl J Med 2007; 356: 1944-1956.

2 Gillison ML, Koch WM, Capone RB, Spafford M, Westra WH, Wu L et al. Evidence for a causal association between human papillomavirus and a subset of head and neck cancers. J Natl Cancer Inst 2000; 92: 709-720.

3 Fakhry C, Westra WH, Li S, Cmelak A, Ridge JA, Pinto H et al. Improved survival of patients with human papillomavirus-positive head and neck squamous cell carcinoma in a prospective clinical trial. J Natl Cancer Inst 2008; 100: 261-269.

4 Lassen P. The role of human papillomavirus in head and neck cancer and the impact on radiotherapy outcome. Radiother Oncol 2010; 95: 371-380.

5 Lassen P, Eriksen JG, Hamilton-Dutoit S, Tramm T, Alsner J and Overgaard J. Effect of HPV-associated $p 16^{I N K 4 A}$ expression on response to radiotherapy and survival in squamous cell carcinoma of the head and neck. J Clin Oncol 2009; 27: 1992-1998.

6 Weinberger PM, Yu Z, Haffty BG, Kowalski D, Harigopal M, Brandsma J et al. Molecular classification identifies a subset of human papillomavirus--associated oropharyngeal cancers with favorable prognosis. J Clin Oncol 2006; 24: 736-747.

7 Syrjanen S, Lodi G, von Bultzingslowen I, Aliko A, Arduino P, Campisi G et al. Human papillomaviruses in oral carcinoma and oral potentially malignant disorders: a systematic review. Oral Dis 2011; 17 Suppl 1: 58-72.

8 Lassen P, Eriksen JG, Hamilton-Dutoit S, Tramm T, Alsner J and Overgaard J. HPV-associated p16expression and response to hypoxic modification of radiotherapy in head and neck cancer. Radiother Oncol 2010; 94: 30-35.

9 Toustrup K, Sorensen BS, Lassen P, Wiuf C, Alsner J and Overgaard J. Gene expression classifier predicts for hypoxic modification of radiotherapy with nimorazole in squamous cell carcinomas of the head and neck. Radiother Oncol 2012; 102: 122-129.

10 Mortensen LS, Johansen J, Kallehauge J, Primdahl H, Busk M, Lassen P et al. FAZA PET/CT hypoxia imaging in patients with squamous cell carcinoma of the head and neck treated with radiotherapy: results from the DAHANCA 24 trial. Radiother Oncol 2012; 105: 14-20.

11 Gubanova E, Brown B, Ivanov SV, Helleday T, Mills GB, Yarbrough WG et al. Downregulation of SMG-1 in HPV-positive head and neck squamous cell carcinoma due to promoter hypermethylation correlates with improved survival. Clin Cancer Res 2012; 18: 1257-1267.

12 Gupta AK, Lee JH, Wilke WW, Quon H, Smith G, Maity A et al. Radiation response in two HPVinfected head-and-neck cancer cell lines in comparison to a non-HPV-infected cell line and relationship to signaling through AKT. Int J Radiat Oncol Biol Phys 2009; 74: 928-933.

13 Rieckmann T, Tribius S, Grob TJ, Meyer F, Busch CJ, Petersen C et al. HNSCC cell lines positive for HPV and $p 16$ possess higher cellular radiosensitivity due to an impaired DSB repair capacity. Radiother Oncol 2013; 107: 242-246. 
14 Spanos WC, Nowicki P, Lee DW, Hoover A, Hostager B, Gupta A et al. Immune response during therapy with cisplatin or radiation for human papillomavirus-related head and neck cancer. Arch Otolaryngol Head Neck Surg 2009; 135: 1137-1146.

15 Eicheler W, Zips D, Dorfler A, Grenman R and Baumann M. Splicing mutations in TP53 in human squamous cell carcinoma lines influence immunohistochemical detection. J Histochem Cytochem 2002; 50: 197-204.

16 Bradford CR, Zhu S, Ogawa H, Ogawa T, Ubell M, Narayan A et al. P53 mutation correlates with cisplatin sensitivity in head and neck squamous cell carcinoma lines. Head Neck 2003; 25: 654-661.

17 Brenner JC, Graham MP, Kumar B, Saunders LM, Kupfer R, Lyons RH et al. Genotyping of 73 UMSCC head and neck squamous cell carcinoma cell lines. Head Neck 2010; 32: 417-426.

18 Balló H, Koldovsky P, Hoffmann T, Balz V, Hildebrandt B, Gerharz CD et al. Establishment and characterization of four cell lines derived from human head and neck squamous cell carcinomas for an autologous tumor-fibroblast in vitro model. Anticancer Res 1999; 19: 3827-3836.

19 Gwosdz C, Balz V, Scheckenbach K and Bier H. p53, p63 and p73 expression in squamous cell carcinomas of the head and neck and their response to cisplatin exposure. Adv Otorhinolaryngol 2005; 62: 58-71.

20 Ragin CCR, Reshmi SC and Gollin SM. Mapping and analysis of HPV16 integration sites in a head and neck cancer cell line. Int J Cancer 2004; 110: 701-709.

21 de Roda Husman AM, Walboomers JM, van den Brule AJ, Meijer CJ and Snijders PJ. The use of general primers GP5 and GP6 elongated at their 3' ends with adjacent highly conserved sequences improves human papillomavirus detection by PCR. J Gen Virol 1995; 76: 1057-1062.

22 Sorensen BS, Alsner J, Overgaard J and Horsman MR. Hypoxia induced expression of endogenous markers in vitro is highly influenced by pH. Radiother Oncol 2007; 83: 362-366.

23 Sorensen BS, Hao J, Overgaard J, Vorum H, Honore B, Alsner J et al. Influence of oxygen concentration and $\mathrm{pH}$ on expression of hypoxia induced genes. Radiother Oncol 2005; 76: 187-193.

24 Sorensen BS, Toustrup K, Horsman MR, Overgaard J and Alsner J. Identifying pH independent hypoxia induced genes in human squamous cell carcinomas in vitro. Acta Oncol 2010; 49: 895-905.

25 Toustrup K, Sorensen BS, Nordsmark M, Busk M, Wiuf C, Alsner J et al. Development of a hypoxia gene expression classifier with predictive impact for hypoxic modification of radiotherapy in head and neck cancer. Cancer Res 2011; 71: 5923-5931.

26 Minn H, Clavo AC, Fisher SJ and Wahl RL. Effect of nitroimidazole sensitizers on in vitro glycolytic metabolism of hypoxic squamous cell carcinoma. Acta Oncol 2000; 39: 199-205.

27 Sugie C, Shibamoto Y, Ito M, Ogino H, Suzuki H, Uto Y et al. Reevaluation of the radiosensitizing effects of sanazole and nimorazole in vitro and in vivo. J Radiat Res (Tokyo) 2005; 46: 453-459.

28 Watts ME and Jones NR. The effect of extracellular $\mathrm{pH}$ on radiosensitization by misonidazole and acidic or basic analogues. Int J Radiat Biol Relat Stud Phys Chem Med 1985; 47: 645-653.

29 Niyazi M, Niyazi I and Belka C. Counting colonies of clonogenic assays by using densitometric software. Radiat Oncol 2007; 2: 4. 
30 Ferris RL, Martinez I, Sirianni N, Wang J, Lopez-Albaitero A, Gollin SM et al. Human papillomavirus-16 associated squamous cell carcinoma of the head and neck (SCCHN): a natural disease model provides insights into viral carcinogenesis. Eur J Cancer 2005; 41: 807-815.

31 Wald AI, Hoskins EE, Wells SI, Ferris RL and Khan SA. Alteration of microRNA profiles in squamous cell carcinoma of the head and neck cell lines by human papillomavirus. Head Neck 2010; 33: $504-$ 512.

32 Lassen P and Overgaard J. Scoring and classification of oropharyngeal carcinoma based on HPVrelated p16-expression. Radiother Oncol 2012; 105: 269-270.

33 Steenbergen RD, Hermsen MA, Walboomers JM, Joenje H, Arwert F, Meijer CJ et al. Integrated human papillomavirus type 16 and loss of heterozygosity at 11q22 and 18q21 in an oral carcinoma and its derivative cell line. Cancer Res 1995; 55: 5465-5471.

34 Toustrup K, Sorensen BS, Alsner J and Overgaard J. Hypoxia gene expression signatures as prognostic and predictive markers in head and neck radiotherapy. Semin Radiat Oncol 2012; 22: 119-127.

35 Overgaard J, Overgaard M, Nielsen OS, Pedersen AK and Timothy AR. A comparative investigation of nimorazole and misonidazole as hypoxic radiosensitizers in a $\mathrm{C} 3 \mathrm{H}$ mammary carcinoma in vivo. Br J Cancer 1982; 46: 904-911.

36 Overgaard J. Clinical evaluation of nitroimidazoles as modifiers of hypoxia in solid tumors. Oncol Res 1994; 6: 509-518.

37 Overgaard J, Overgaard M and Timothy AR. Studies of the pharmacokinetic properties of nimorazole. Br J Cancer 1983; 48: 27-34.

38 Timothy AR, Overgaard J and Overgaard M. A phase I clinical study of Nimorazole as a hypoxic radiosensitizer. Int J Radiat Oncol Biol Phys 1984; 10: 1765-1768. 



\section{General Discussion and \\ Future Prospects}



Head and neck carcinomas are the sixth most common cancer by incidence worldwide and their mortality rate ranges from $40-50 \%{ }^{1}$. Most of them arise from the mucosa of the upper aerodigestive tract (oral and nasal cavity, paranasal sinuses, pharynx, larynx, and the trachea) and about $90 \%$ of these malignancies are head and neck squamous cell carcinomas (HNSCC). For many decades the most important risk factors for the development of HNSCC were tobacco- and alcohol (ab)use and poor oral hygiene. However, in the last decades an increasing role of high-risk (HR) human papillomaviruses (HPV) in the carcinogenesis of HNSCC has become evident.

Remarkably, at the same time, the incidence of HNSCC in specific anatomical sites has declined with an annual change of $1.4 \%$ from $1992-2005^{2}$, which correlates to a decrease in the prevalence of smoking. In the US, the prevalence of smoking has declined from $42.4 \%$ in 1965 to $18.9 \%$ in $2011^{3}$. Not only do fewer people smoke, the number of smoked cigarettes per day has decreased as well ${ }^{3}$. However, the incidence of oropharyngeal carcinomas has increased. This was demonstrated by a study from the US, where a significant increase was shown for cancers arising from the base of tongue and tonsil from 1973-2004 4 and Swedish study showing an increased incidence of tonsillar cancers in the period between 1970 and $2006^{5}$ from $0.74 / 100.000$ person/years to $1.65 / 100.000$ person/years. This rise was accompanied by an increased prevalence of HPV in oropharyngeal cancers, and particularly in tonsillar carcinomas ${ }^{5,6}$.This suggests a prominent role for HPV infection in head and neck carcinogenesis. Since HPV is the most commonly sexually transmitted infection, the increasing frequency of HPV infections in general, and pharyngeal HPV infections in particular, might result from a change in sexual behavior.

Dillner and coworkers ${ }^{7}$ showed that seropositivity for HPV and for Chlamydia trachomatis could be used as markers for sexual behavior, in particular for the number of sexual partners. Since then, several studies have associated high-risk sexual behavior with HR-HPV infection ${ }^{8}$. Furthermore, these studies have unequivocally shown that infection with HR-HPV is a significant independent risk factor for the development of HNSCC ${ }^{-11}$.

HPV-related HNSCC differ from non-HPV-related HNSCC with respect to molecular and clinicopathological parameters. Patients with HPV-positive HNSCC tend to present with smaller primary tumors at first diagnosis, have a lower tobacco- and alcohol intake, and are diagnosed at a slightly younger age. HR-HPV-positive tumors furthermore show a more baseloid appearance, downregulation of p53 and pRb and overexpression of $\mathrm{p} 16^{\mathrm{INK} 4 \mathrm{~A}}, \mathrm{p} 14^{\mathrm{ARF}}, \mathrm{p} 18^{\mathrm{INK} 4 \mathrm{C}}$ and $\mathrm{p} 21^{\mathrm{Cip} 1 / \mathrm{WAF} 1}$ (chapter 1 ).

Patients with HPV-negative HNSCC almost always have a history of tobacco- and/ or alcohol (ab)use $\mathrm{i}^{12}$. However, there is a large sub-group of patients with HPV-positive carcinomas that also present with these risk factors ${ }^{12}$. Tobacco smoking has even been associated with an increased risk of HPV infection in men that do not show high-risk sexual behavior ${ }^{13}$. Although patients with HPV-related HNSCC generally have a lower 
risk to develop a second primary tumor (SPT) compared to patients with HPV-negative tumors, smoking was also shown to significantly increase the risk to develop SPTs in patients that were seropositive for HPV ${ }^{14}$.

Therefore, it is important to make a distinction between HPV-positive tumors and tumors that arise from a clinically relevant HPV infection. A helpful model for stratification has been proposed by Weinberger et. al. ${ }^{15}$. In this study, three biologically and clinically distinct classes of oropharyngeal squamous cell carcinomas are recognized. Class I tumors are associated with tobacco and alcohol consumption and do not contain HPV. Class II tumors are alcohol/tobacco-related, and also contain HPV DNA, but do not show overexpression of $\mathrm{p} 16^{\mathrm{INK} 4 \mathrm{~A}}$, the surrogate marker for HPV-infection. These tumors, although HPV DNA-positive, show clinicopathological characteristics that resemble alcohol/tobacco-related tumors, which indicates that infection of the tumor site with HR-HPV has after the onset of oncogenesis. Class III contains etiologically HPV-related tumors, as shown by the overexpression of $\mathrm{p} 16^{\mathrm{INK} 4 \mathrm{~A}}$. The reliability of a test algorithm for the detection of active HPV in FFPE tumor samples, consisting of p $16^{\mathrm{INK} 4 \mathrm{~A}}$ and subsequent detection of HR-HPV by GP5+/6+ on the positive cases, was recently validated ${ }^{16}$.

The differentiation between HPV-induced and tobacco/alcohol-associated HNSCC offers new opportunities for treatment stratification. For the patient population presenting with class III tumors this could implicate treatment deintensification, thereby reducing treatment-related morbidity without affecting outcome. It has already been shown in numerous studies that patients with HPV-positive carcinomas show a better prognosis as compared to HPV-negative cases. A recent review and meta-analysis ${ }^{17}$ established that patients with HPV-related HNSCC had a 54\% reduced risk of overall mortality. This is in line with the studies described in chapters 1 and 2, which show that HPVassociated HNSCC are more often diagnosed at a lower T-stage, making them more often eligible for radical local therapy, in most cases consisting of surgery followed by adjuvant radiotherapy. These patients had a far more favourable prognosis as compared to patients treated with primary radiotherapy. One could therefore argue that the better prognosis of HPV-positive patients might be caused by earlier detection of the primary tumor, due to early detection of metastases (chapters 1 and 2), thereby influencing disease outcome. These patients also tend to be younger, which might result in lower mortality rates ${ }^{18}$.

Studies in primary HNSCC as well as in cell line models, have shown that HPVpositive cells are more sensitive to radiation therapy than their HPV-negative counterparts ${ }^{19,20}$. Although hypoxia is an important factor that negatively influences prognosis of patients ${ }^{21}$, hypoxic modification by Nimorazole did not increase radiosensitivity in HPV-positive tumors, whereas it did improve therapeutic response in HPV-negative tumors ${ }^{19}$. This might indicate that HPV-positive cells intrinsically have a better response to radiotherapy, which might be caused by a compromised DNA repair capacity ${ }^{20}$. All in all, 
studies describing the efficacy of the different treatment modalities in HNSCC conclude that HPV-positive tumors have a better survival rate than HPV-negative tumors, irrespective of therapeutic approach ${ }^{22-27}$.

Since it is evident that patients with HPV-positive tumors have a better prognosis, an important question is whether this patient population would benefit from modified treatment protocols. However, many of the future treatment options for patients with HPV-positive tumors, as discussed in chapter 1, are still in a developmental phase and as such, cannot yet be implemented in the current treatment protocols. In addition, patients with HPV-associated HNSCC do not represent a homogenous cohort. Instead, this group comprises patients that may exhibit characteristics associated with a poor prognosis, such as a history of smoking or overexpression of EGFR in the tumor. Therefore, it is likely that smoking, alcohol, tumor hypoxia and HPV-infection all represent independent risk- and prognostic factors for the development and progression of HNSCC. So, rather than stratifying patients according to HPV-status of the tumor, a better option would be to develop personalized treatment protocols. A useful model for such an individualized approach has been introduced by Ang and coworkers ${ }^{22}$, which have divided patients with HNSCC into three risk groups, depending on HPV-status, nodal involvement and tobacco smoking. Whether patients classified as being low-risk according to these criteria could benefit from deintensified treatment protocols without affecting long-term survival, is a highly relevant question which still remains to be answered.

In addition to the conventional treatment protocols, development of antiviral therapies could be beneficial for all patients with HPV-induced carcinomas. The efficacy of these agents, however, may depend on the physical status of the virus, i.e. episomal or integrated. It was shown that interferon therapy can result in a selective growth advantage of cells with integrated HPV ${ }^{28,29}$. Strategies aiming at inhibition of viral replication, for example using artificial zinc fingers ${ }^{30,31}$, are only effective in episomal HPV infection.

It will thus be imperative to include the viral integration status in future studies concerning antiviral therapy. For HNSCC there is much controversy in reported integration frequencies and furthermore the question remains whether or not there are preferred sites for viral integration in these head and neck malignancies. Therefore, the HPV-integration status was retrospectively analyzed in a cohort of 75 patients (chapters 3 and 4 ) as well as in seven cell lines that were derived from HPV-associated HNSCC (chapter 5).

Viral integration appeared to occur randomly throughout the human genome, although integration was also detected in previously reported integration clusters ${ }^{32}$, in both primary tumors and cell lines. Viral E2, E6 and/or E7 gene expression was detected in all cell lines, and in all but three tumor samples, irrespective of the physical status of the virus. Gene expression varied widely, indicating that a constitutive, rather than a high expression of viral oncogenes is required for HPV-induced HNSCC. While vi- 
ral integration may perhaps not have a significant influence on the current treatment protocols, the integration status might still be a relevant factor in the treatment of these tumors with antiviral drugs.

A comparison between the results obtained in primary HPV-positive HNSCC and established HPV-positive HNSCC cell lines revealed that the detected integration frequency in primary tumor samples was considerably lower (40\%) than in the cell lines, where we detected integration in six out of seven cell lines.

On the one hand, the high percentage of integration in cell lines might suggest a preferential clonal expansion of tumor cells containing integrated viral DNA. On the other hand, it might also be explained by the inability of the used PCR technologies to detect all integration events, in particular in the primary tumors. A recent paper by Li et al. ${ }^{33}$ describes additional integration mechanisms which are not covered by the conventional procedures that were used in chapters 3,4 and 5 .

Furthermore, the FISH analysis usually shows only one or two signals per nucleus in the primary tumor samples where integration was detected (chapter 4), while most cell lines showed two or more integration signals per nucleus. This is most probably related to the chromosomal stability of the primary tumor cells, which has been described to be associated with HPV-positivity ${ }^{34}$. However, most cell lines showed copy number imbalances, indicating genomic instability, explaining the presence of multiple signals for integrated HPV.

For the development of new therapeutic options, as well as for a deeper understanding of the etiology and biological mechanisms involved in the development of HNSCC, cell line models are indispensable. However, it is important to keep in mind that cell lines are not a perfect representation of the initial tumor. Cell lines grow in a well-controlled and optimized environment, while tumors growth is influenced by a variety of factors. Furthermore, clonal expansion and therefore selection of tumor cells occurs with the establishment of a cell line, whereas primary tumors represent a heterogeneous cell population.

Moreover, it was shown that tumor and patient characteristics influence the success rate of HNSCC cell line establishment. A statistically significant positive association was found between the establishment of cell lines and 11q13 amplification, nodal status and alcohol consumption, while a negative association was found for HPV-positivity ${ }^{35}$. This suggests that cell lines can be more readily established from tumors with characteristics that are associated with a poor prognosis. The HPV-positive HNSCC cell lines used in chapter 5 were mostly established from metastatic tumors in patients with a history of smoking. Furthermore these cell lines all show elevated levels of EGFR expression when compared to primary tumors. These factors are again all indicators of a poor prognosis. Therefore the results obtained in studies testing new treatment options using these cell lines might be especially beneficial for the group of HPV-positive patients that respond poorly to current treatment modalities. 
An important factor in determining the response to treatment is the presence of hypoxic regions the tumor. In particular in head and neck carcinomas, hypoxia associated with a poor outcome ${ }^{21,36}$, and HPV-positive and -negative tumors were found to be equally hypoxic ${ }^{37}$. Since the effect of radiotherapy depends on the degree of tissue oxygenation, hypoxia is most extensively studied in relation to radiotherapy. Free radicals, produced by tissue irradiation, are stabilized by the presence of oxygen, leading to increased DNA damage. Therefore, compounds that mimic oxygen, such as nitroimidazols, can sensitize hypoxic cells to the effects of radiation therapy. In Denmark, one such compound, Nimorazole, is already being used in the standard treatment of patients with head and neck tumors. The combination of Nimorazole administration and radiotherapy for patients with HNSCC significantly reduced disease-specific death after 5 years $^{38}$. As expected, HPV-positive HNSCC patients showed significantly improved outcome after radiotherapy, but no effect of Nimorazole addition was seen ${ }^{39}$. This could indicate that hypoxia is less frequently present in HPV-positive tumors. To assess whether the lack of response to hypoxia modification in HPV-positive primary HNSCC could be explained by a difference in the expression levels of hypoxia-induced genes, a panel of HNSCC cell lines was studied (chapter 6), showing that HPV-positive and -negative cell lines exhibit similar expression levels of hypoxia-inducible genes. Despite this similarity, HPV-positive cell lines exhibited markedly higher radiosensitivity that HPV-negative cell lines, and show a better response to radiotherapy after addition of Nimorazole. These results indicate that Nimorazole could be beneficial in HPV-positive HNSCC when treated with a lower total dose of radiation therapy.

Mapping differences between HPV-positive and -negative tumors may provide additional possibilities for new therapeutic targets. In particular, a recent study showed a significant association of PIK3CA mutations or copy number alteration, as well as PTEN inactivation with HPV-status of the tumor. These genes are involved in the PI3K/AKT/ $m T O R$ pathway, and studies assessing the effectiveness of mTOR inhibitors have shown that xenografts of HPV-positive HNSCC cell lines in mice were highly sensitive to rapamycin and $\mathrm{RAD} 001^{40}$. A recent study also showed a significant association of FANCC and PTCH1 alterations with prognosis ${ }^{41}$, which might provide targets for molecular therapy irrespective of the tumor HPV-status.

All in all, it is evident that HPV-positive HNSCC show clinicopathological and molecular characteristics that are different from HPV-negative tumors. However, prognostic indicators such as tobacco and alcohol consumption, EGFR-overexpression, hypoxia as well as HPV-positivity of the tumor, cannot be seen as isolated factors. Although novel therapeutic options should definitely be explored to optimize patient treatment, another approach that should be examined is a more personalized protocol for individual patients by stratifying patients based on multiple prognostic factors. 


\section{References}

1 Carvalho AL, Nishimoto IN, Califano JA and Kowalski LP. Trends in incidence and prognosis for head and neck cancer in the United States: a site-specific analysis of the SEER database. Int J Cancer 2005; 114: 806-816.

2 Jemal A, Simard EP, Dorell C, Noone AM, Markowitz LE, Kohler B et al. Annual Report to the Nation on the Status of Cancer, 1975-2009, featuring the burden and trends in human papillomavirus(HPV)associated cancers and HPV vaccination coverage levels. J Natl Cancer Inst 2013; 105: 175-201.

3 Smoking and tobacco use. Centres for disease control and prevention (CDC). 2013; http://www.cdc. gov/tobacco.

4 Chaturvedi AK, Engels EA, Anderson WF and Gillison ML. Incidence trends for human papillomavirus-related and -unrelated oral squamous cell carcinomas in the United States. J Clin Oncol 2008; 26: 612-619.

5 Nasman A, Attner P, Hammarstedt L, Du J, Eriksson M, Giraud G et al. Incidence of human papillomavirus (HPV) positive tonsillar carcinoma in Stockholm, Sweden: an epidemic of viral-induced carcinoma? Int J Cancer 2009; 125: 362-366.

6 Rietbergen MM, Leemans CR, Bloemena E, Heideman DA, Braakhuis BJ, Hesselink AT et al. Increasing prevalence rates of HPV attributable oropharyngeal squamous cell carcinomas in the Netherlands as assessed by a validated test algorithm. Int J Cancer 2013; 132: 1565-1571.

7 Dillner J, Kallings I, Brihmer C, Sikstrom B, Koskela P, Lehtinen M et al. Seropositivities to human papillomavirus types 16,18 , or 33 capsids and to Chlamydia trachomatis are markers of sexual behavior. J Infect Dis 1996; 173: 1394-1398.

8 D'Souza G, Agrawal Y, Halpern J, Bodison S and Gillison ML. Oral sexual behaviors associated with prevalent oral human papillomavirus infection. J Infect Dis 2009; 199: 1263-1269.

9 Klussmann JP, Weissenborn SJ, Wieland U, Dries V, Kolligs J, Jungehuelsing M et al. Prevalence, distribution, and viral load of human papillomavirus 16 DNA in tonsillar carcinomas. Cancer 2001; 92 : 2875-2884.

10 Ragin CC and Taioli E. Survival of squamous cell carcinoma of the head and neck in relation to human papillomavirus infection: review and meta-analysis. Int J Cancer 2007; 121: 1813-1820.

11 van Houten VM, Snijders PJ, van den Brekel MW, Kummer JA, Meijer CJ, van Leeuwen B et al. Biological evidence that human papillomaviruses are etiologically involved in a subgroup of head and neck squamous cell carcinomas. Int J Cancer 2001; 93: 232-235.

12 Hafkamp HC, Mooren JJ, Claessen SM, Klingenberg B, Voogd AC, Bot FJ et al. P21 Cip1/WAF1 expression is strongly associated with HPV-positive tonsillar carcinoma and a favorable prognosis. Mod Pathol 2009; 22: 686-698.

13 Schabath MB, Villa LL, Lazcano-Ponce E, Salmeron J, Quiterio M and Giuliano AR. Smoking and human papillomavirus (HPV) infection in the HPV in Men (HIM) study. Cancer Epidemiol Biomarkers Prev 2012; 21: 102-110. 
14 Peck BW, Dahlstrom KR, Gan SJ, Caywood W, Li G, Wei Q et al. Low risk of second primary malignancies among never smokers with human papillomavirus-associated index oropharyngeal cancers. Head Neck 2013; 35: 794-799.

15 Weinberger PM, Yu Z, Haffty BG, Kowalski D, Harigopal M, Brandsma J et al. Molecular classification identifies a subset of human papillomavirus--associated oropharyngeal cancers with favorable prognosis. J Clin Oncol 2006; 24: 736-747.

16 Rietbergen MM, Leemans CR, Bloemena E, Heideman DA, Braakhuis BJ, Hesselink AT et al. Increasing prevalence rates of HPV attributable oropharyngeal squamous cell carcinomas in the Netherlands as assessed by a validated test algorithm. Int J Cancer 2013; 132: 1565-1571.

17 O'Rorke MA, Ellison MV, Murray LJ, Moran M, James J and Anderson LA. Human papillomavirus related head and neck cancer survival: a systematic review and meta-analysis. Oral Oncol 2012; 48: 1191-1201.

18 Nguyen NP, Ly BH, Betz M and Vinh-Hung V. Importance of age as a prognostic factor for tonsillar carcinoma. Ann Surg Oncol 2010; 17: 2570-2577.

19 Lassen P, Eriksen JG, Hamilton-Dutoit S, Tramm T, Alsner J and Overgaard J. Effect of HPV-associated $p 16^{I N K 4 A}$ expression on response to radiotherapy and survival in squamous cell carcinoma of the head and neck. J Clin Oncol 2009; 27: 1992-1998.

20 Rieckmann T, Tribius S, Grob TJ, Meyer F, Busch CJ, Petersen C et al. HNSCC cell lines positive for HPV and $p 16$ possess higher cellular radiosensitivity due to an impaired DSB repair capacity. Radiother Oncol 2013; 107: 242-246.

21 Nordsmark M, Bentzen SM, Rudat V, Brizel D, Lartigau E, Stadler P et al. Prognostic value of tumor oxygenation in 397 head and neck tumors after primary radiation therapy. An international multicenter study. Radiother Oncol 2005; 77: 18-24.

22 Ang KK, Harris J, Wheeler R, Weber R, Rosenthal DI, Nguyen-Tan PF et al. Human papillomavirus and survival of patients with oropharyngeal cancer. N Engl J Med 2010; 363: 24-35.

23 Fakhry C, Westra WH, Li S, Cmelak A, Ridge JA, Pinto H et al. Improved survival of patients with human papillomavirus-positive head and neck squamous cell carcinoma in a prospective clinical trial. J Natl Cancer Inst 2008; 100: 261-269.

24 Fallai C, Perrone F, Licitra L, Pilotti S, Locati L, Bossi P et al. Oropharyngeal squamous cell carcinoma treated with radiotherapy or radiochemotherapy: prognostic role of TP53 and HPV status. Int J Radiat Oncol Biol Phys 2009; 75: 1053-1059.

25 Fischer CA, Zlobec I, Green E, Probst S, Storck C, Lugli A et al. Is the improved prognosis of p16 positive oropharyngeal squamous cell carcinoma dependent of the treatment modality? Int J Cancer 2010; 126: 1256-1262.

26 Lassen P. The role of human papillomavirus in head and neck cancer and the impact on radiotherapy outcome. Radiother Oncol 2010; 95: 371-380.

27 Maxwell JH, Kumar B, Feng FY, Worden FP, Lee JS, Eisbruch A et al. Tobacco use in human papillomavirus-positive advanced oropharynx cancer patients related to increased risk of distant metastases and tumor recurrence. Clin Cancer Res 2010; 16: 1226-1235. 
28 Chang YE, Pena L, Sen GC, Park JK and Laimins LA. Long-term effect of interferon on keratinocytes that maintain human papillomavirus type 31. J Virol 2002; 76: 8864-8874.

29 Herdman MT, Pett MR, Roberts I, Alazawi WO, Teschendorff AE, Zhang XY et al. Interferon-beta treatment of cervical keratinocytes naturally infected with human papillomavirus 16 episomes promotes rapid reduction in episome numbers and emergence of latent integrants. Carcinogenesis 2006; 27: 2341-2353.

30 Mino T, Hatono T, Matsumoto N, Mori T, Mineta Y, Aoyama Y et al. Inhibition of DNA replication of human papillomavirus by artificial zinc finger proteins. J Virol 2006; 80: 5405-5412.

31 Mino T, Mori T, Aoyama Y and Sera T. Cell-permeable artificial zinc-finger proteins as potent antiviral drugs for human papillomaviruses. Arch Virol 2008; 153: 1291-1298.

32 Schmitz M, Driesch C, Jansen L, Runnebaum IB and Durst M. Non-random integration of the HPV genome in cervical cancer. PLoS ONE 2012; 7: e39632.

33 Li H, Yang Y, Zhang R, Cai Y, Yang X, Wang Z et al. Preferential sites for the integration and disruption of human papillomavirus 16 in cervical lesions. J Clin Virol 2013; 56: 342-347.

34 Mooren JJ, Kremer B, Claessen SM, Voogd AC, Bot FJ, Peter Klussmann J et al. Chromosome stability in tonsillar squamous cell carcinoma is associated with HPV16 integration and indicates a favorable prognosis. Int J Cancer 2013; 132: 1781-1789.

35 White JS, Weissfeld JL, Ragin CCR, Rossie KM, Martin CL, Shuster M et al. The influence of clinical and demographic risk factors on the establishment of head and neck squamous cell carcinoma cell lines. Oral Oncol 2007; 43: 701-712.

36 Brizel DM, Sibley GS, Prosnitz LR, Scher RL and Dewhirst MW. Tumor hypoxia adversely affects the prognosis of carcinoma of the head and neck. Int J Radiat Oncol Biol Phys 1997; 38: 285-289.

37 Mortensen LS, Johansen J, Kallehauge J, Primdahl H, Busk M, Lassen P et al. FAZA PET/CT hypoxia imaging in patients with squamous cell carcinoma of the head and neck treated with radiotherapy: results from the DAHANCA 24 trial. Radiother Oncol 2012; 105: 14-20.

38 Toustrup K, Sorensen BS, Nordsmark M, Busk M, Wiuf C, Alsner J et al. Development of a hypoxia gene expression classifier with predictive impact for hypoxic modification of radiotherapy in head and neck cancer. Cancer Res 2011; 71: 5923-5931.

39 Lassen P, Eriksen JG, Hamilton-Dutoit S, Tramm T, Alsner J and Overgaard J. HPV-associated p16expression and response to hypoxic modification of radiotherapy in head and neck cancer. Radiother Oncol 2010; 94: 30-35.

40 Molinolo AA, Marsh C, El Dinali M, Gangane N, Jennison K, Hewitt S et al. mTOR as a molecular target in HPV-associated oral and cervical squamous carcinomas. Clin Cancer Res 2012; 18: 2558-2568.

41 Ghosh A, Maiti GP, Bandopadhyay MN, Chakraborty J, Biswas J, Roychoudhury S et al. Inactivation of 9 q22.3 tumor suppressor genes predict outcome for patients with head and neck squamous cell carcinoma. Anticancer Res 2013; 33: 1215-1220. 
Summary 

The aim of this thesis was to enhance our understanding of clinical and biological features of HPV-associated oropharyngeal carcinomas.

The first chapter gives an introduction to the molecular and clinicopathological differences between HPV-positive and HPV-negative tumors. HPV-associated HNSCC are considered to form an etiologically distinct group of carcinomas with typical clinical and molecular features. HPV-positive tumors are characterized by overexpression of the oncoproteins E6 and E7, p16 $6^{\mathrm{INK} 4 \mathrm{~A}}, \mathrm{p} 18^{\mathrm{INK} 4 \mathrm{C}}$ and $\mathrm{p} 21^{\mathrm{Cip} 1 / \mathrm{WAF} 1}$ as well as downregulation of p53 and $\mathrm{pRb}$. Patients tend to be slightly younger and present with more advanced disease and smaller primary tumors at diagnosis. Current treatment modalities and the effect of HPV-status on disease outcome are discussed. In addition, benefits of prospective therapeutic options are reviewed.

Chapter 2 involves a clinical study in which the prognostic value of $\mathrm{N}$-status in a cohort of 81 patients with tonsillar cancer was examined. HPV-positive patients presented with significantly smaller tumors at diagnosis, whereas the frequency of nodal involvement was equal to HPV-negative patients. The presence of nodal involvement seemed to be related to an unfavourable prognosis in HPV-negative patients, but seemed to be related to a better survival in HPV-positive patients.

Chapter 3 describes the analysis of tumor biopsies from a cohort of 75 patients with $\mathrm{HPV}$-associated HNSCC to assess integration frequency and identify integration loci. An integration frequency of $39 \%$ was detected in these tumors using APOT- and DIPS-PCR. Integration loci were distributed throughout the genome, targeting most chromosomes except chromosomes 11, 16, 19, 20, 21 and X. Integration events occurred in transcribed regions in $73 \%$ of cases.

In chapter 4 the viral physical status was correlated to the expression of the viral E2, E6 and $E 7$ genes and to a number of virally-disrupted human genes. This showed that the expression of a gene invaded by HPV does not show significant differences when compared to the expression of that gene in samples where HPV has not disrupted it. Analysis of the viral gene expression showed large variation in the levels of E2, E6 and E7 expression, independent of the HPV integration status. Assessment of the viral load did not reveal any significant associations to the integration status or the expression of viral genes.

Chapter 5 involves the characterization of $7 \mathrm{HPV}$-associated HNSCC cell lines to further study integration and to establish a reliable cell line model for HPV-associated HNSCC cancers. Viral integration was shown in six of the seven cell lines using APOT- and DIPS- 
PCR as well as FISH. Identified integration loci were verified using double-target FISH analysis. Viral load and viral gene expression varied considerably amongst the cell lines and all cell lines expressed EGFR.

The effects of radiation and hypoxia were assessed in chapter 6 using a panel of HPVpositive HNSCC cell lines. These three cell lines displayed a markedly higher radiosensitivity but were equally affected by hypoxia-modification by Nimorazole treatment when compared to HPV-negative HNSCC cell lines.

Finally, in the general discussion and future prospects the results of the findings as described in chapters 1 to 6 are discussed in a broader context. Moreover, suggestions for future research are presented. 
Samenvatting 

Het doel van het huidige proefschrift was om het begrip van klinische en biologische eigenschappen van HPV-gerelateerde hoofd-halskankers te vergroten.

Het eerste hoofdstuk geeft een inleiding in de moleculaire en klinisch-pathologische verschillen tussen HPV-positieve en -negatieve tumoren. HPV-geassocieerde hoofd-hals plaveiselcelcarcinomen worden beschouwd als een etiologisch verschillende groep carcinomen met specifieke klinische en moleculaire eigenschappen. HPV-positieve tumoren worden gekenmerkt door overexpressie van de oncoproteinen E6 and E7, p16 ${ }^{\mathrm{INK} 4 \mathrm{~A}}$, $\mathrm{p} 18^{\mathrm{INK} 4 \mathrm{C}}$ en $\mathrm{p} 21^{\mathrm{Cip} 1 / \mathrm{WAF} 1}$ evenals downregulatie van p53 en pRb. De patiënten zijn jonger en worden gediagnosticeerd in een verdergevorderd stadium met een kleinere primaire tumor. De huidige behandelingsmogelijkheden en het effect van HPV op de uitkomst van de ziekte worden besproken. Daarnaast wordt een overzicht gegeven van prospectieve behandelingsopties.

In hoofdstuk 2 wordt een klinische studie behandeld, waarin de prognostische waarde van de $\mathrm{N}$-status wordt onderzocht in een cohort van 81 patiënten met tonsilcarcinomen. HPV-positieve patiënten hadden een significant kleinere tumor op het moment van diagnose, terwijl de lymfeklieren in gelijke mate aangedaan waren. De aanwezigheid van positieve lymfeklieren leek gerelateerd te zijn aan een ongunstige prognose in HPV-negatieve patiënten, terwijl dit gerelateerd was aan een betere overleving in HPV-positieve patiënten.

In hoofdstuk 3 wordt de analyse beschreven die uitgevoerd is op tumor biopsieën verkregen van een cohort van 75 patiënten met HPV-gerelateerde hoofd-halskanker, om de integratiefrequentie en integratielocus te bepalen. Een integratiefrequentie van $39 \%$ is in deze tumoren vastgesteld door middel van APOT- en DIPS-PCR. Integratieloci waren verspreid over het gehele genoom en alle chromosomen, met uitzondering van chromosoom 11, 16, 19, 20, 21 en X, waren aangedaan. Integratie werd in $73 \%$ van de gevallen gevonden in getranscribeerde chromosomale regio's.

In hoofdstuk 4 is gekeken naar de fysieke status van het virus in relatie tot de expressie van de virale genen E2, E6 en E7 en een aantal humane genen die door virale integratie verstoord zijn. Dit onderzoek heeft aangetoond dat de expressie van een gen dat door HPV is verstoord, niet verschilt van de expressie van dat specifieke gen in tumoren waar $\mathrm{HPV}$ dit gen niet heeft aangedaan. Analyse van de virale genexpressie liet een grote variabiliteit in de hoogte van E2, E6 en E7 expressie zien, onafhankelijk van de integratiestatus van HPV. Bepaling van het aantal virusdeeltjes per cel liet geen significante relatie zien met de integratiestatus van het virus, noch met de expressie van de virale genen. 
Hoofdstuk 5 beschrijft de karakterisatie van 7 HPV-gerelateerde hoofd-hals plaveiselcelcarcinoma cellijnen, waarin de virale integratie verder geanalyseerd wordt en de betrouwbaarheid als model voor HPV-gerelateerde hoofd-hals plaveiselcelcarcinomen werd vastgesteld. Virale integratie kon in zes van de zeven cellijnen worden aangetoond middels zowel APOT- en DIPS-PCR als FISH. De geïdentificeerde integratieloci werden geverifieerd met behulp van double-target FISH analyse. Het aantal virusdeeltjes per cel en virale genexpressie van de geanalyseerde cellijnen varieerden aanzienlijk en in alle cellijnen kon EGFR expressie worden aangetoond.

De effecten van bestraling en hypoxie werden geanalyseerd in hoofdstuk 6. Hiervoor werd gebruik gemaakt van een panel van HPV-positieve hoofd-hals plaveiselcelcarcinoma cellijnen. Deze drie cellijnen toonden een duidelijk hogere gevoeligheid voor bestraling maar werden in gelijke mate beïnvloed door hypoxie-modificatie door behandeling met Nimerazole in vergelijking met HPV-negatieve hoofd-hals plaveiselcelcarcinoma cellijnen.

Ten slotte worden in de algemene discussie en toekomstverwachtingen, de bevindingen, beschreven in de hoofdstukken 1 tot en met 6, in een bredere context bediscussieerd. Bovendien worden suggesties voor toekomstig onderzoek beschreven. 


\section{Dankwoord / \\ Acknowledgements}

Iedereen weet wel dat je een promotieonderzoek niet in je eentje kunt doen, vandaar dit dankwoord, aan iedereen die mij direct of indirect heeft geholpen bij het tot stand brengen van dit proefschrift. In het bijzonder wil ik de volgende personen bij naam bedanken:

Allereerst wil ik graag mijn promotor, Bernd Kremer, bedanken. Bernd, dank je wel dat je hebt me tijdens mijn promotieonderzoek alle gelegenheid gegeven om me te ontplooien, door het volgen van cursussen, presenteren op congressen en het volgen van stages in het buitenland. Je hebt altijd veel enthousiasme en interesse voor het onderzoek getoond, wat mij ook heeft gestimuleerd om zelf enthousiast te blijven over de behaalde resultaten. Daarnaast ben je een ontzettend betrokken baas, die zich niet alleen interesseert in de medewerker, maar ook in de mens die daarachter zit.

Daarnaast natuurlijk mijn promotor, Ernst-Jan Speel. Ernst-Jan, bedankt voor alle nuttige besprekingen, en voor de inzichten in het doen van onderzoek, en promotieonderzoek in het bijzonder, die je gegeven hebt tijdens enkele van onze autoritten. Hoewel je in mijn vierde jaar een uitdagende baan hebt aangenomen bij de pathologie, hebben onze werkbesprekingen en discussies daar niet onder geleden.

Ook wil ik graag mijn promotor, professor Ramaekers bedanken. Frans, de discussies die gevoerd zijn ten aanzien van de review waren zeker niet altijd gemakkelijk, maar ik heb er bijzonder veel van geleerd. Ook wat betreft de rest van het onderzoek heeft jouw kritische blik altijd gezorgd voor een nog beter resultaat. Ook erg bedankt voor de steun en begeleiding die je na het eindigen van mijn promotie-periode hebt gegeven aan het succesvol afronden van mijn promotie.

Dank ook aan de beoordelingscommissie onder leiding van professor Geraedts voor het lezen en beoordelen van mijn proefschrift. 
Van de afdeling KNO van het MUMC wil ik graag Jos Straetmans bedanken, omdat we toch maar samen even twee publicaties hebben geschreven!

Ook Jeroen Mooren, het was wel gezelllig in Vancouver toch? En dat we er een genoeg data voor minstens 1 goede publicatie aan over hebben gehouden is natuurlijk mooi meegenomen $(;)$.

Ester Paquay en Edith Berry, bedankt voor alle hulp en het luisterend oor dat jullie voor me hebben gehad.

Professor Hans Manni, ook u graag wil ik graag bedanken. U bent vrijwel altijd aanwezig geweest tijdens de diverse voordrachten die ik heb gegeven. Ik heb bewondering voor de interesse waarmee $\mathrm{u}$ nog altijd de voortgang van het $\mathrm{KNO}$-onderzoek volgt, en uw persoonlijk interesse in de mensen die achter het onderzoek zitten.

Van de afdeling moleculaire celbiologie wil ik de volgende mensen graag bedanken.

Annick, ten eerste omdat je een gezellige kamergenoot was toen we nog samen op $1 \mathrm{ka}-$ mer zaten. En daarnaast om wat je allemaal hebt gedaan. Niet alleen alle FISH kleuringen, maar ook alle hulp die je me op het lab hebt gegeven. En natuurlijk omdat je mijn paranimf wilt zijn.

Mieke, bedankt voor al je hulp met het kweken en kleuren van de cellijnen en de RT-PCRs. Jullie hebben me beiden ontzettend geholpen!

Marjolein, dank je wel voor de administratieve hulp, en natuurlijk het aanhoren van al mijn verhalen en frustraties.

Marie-Hélène, omdat je altijd voor iedereen klaarstaat met een vriendelijk woord en Bert D., gek, omdat je zo gezellig bent op het lab! Natuurlijk wil ik ook de rest van de moleculaire celbiologie bedanken, omdat ik altijd bij een ieder terecht kon met vragen. Jullie hebben er allemaal voor hebben gezorgd dat de werksfeer goed was en dat het gezellig was om zo nu en dan een babbeltje te maken bij het koffiezetapparaat.

Mede-promovendi Frederik, Wendy, Dorian en Rogier en post-doc Yvonne, bedankt voor alle gezellige lunches, en dat ik mijn hart bij jullie heb kunnen luchten over van alles en nog wat.

Sandra, bedankt voor de gezellige koffie-breaks en de praktische adviezen die je me altijd hebt gegeven! 
Yolanda, ook al ben je weg en hebben we weinig contact meer gehad, ik wil je toch bedanken voor alle steun die je hebt gegeven in een periode waarin je het zelf ook zo moeilijk had. Je bood altijd een luisterend oor, en waar nodig een zakdoekje of een welgemeende knuffel.

This thesis would not have been accomplished without the help of several collaboration partners, whom I would also like to thank.

Christian Hübbers, thank you for the great collaboration, it has been a pleasure to work with you. I always had to laugh when I heard Nayla through the speakers when we he had a Skype-meeting. Ich wünsche dir ganz viel Erfolg bei deine wissenschafltichen Karriere.

Jutta Kolligs, thank you for all the DIPS-and APOT-assays that you have done!

Professor Klussmann, thank you for the valuable collaboration. Es freut mich sehr dass wir zusammen zwei Papers geschrieben haben.

Robert Snoeck and Graciela Andrei. Thank you for the oppoprtunity to work in your lab for a couple of weeks and learn to do raft cultures. Robert, thank you for your input in the review.

Professor Wan Lam and all the lab members of Lam Lab! Thank you for the opportunity to work in your lab and all the hospitality. Wan, you have an amazing way of running your lab, it was truly a pleasure to work with you.

En dan naturlijk niet te vergeten mijn vrienden en familie.

Sabientje, Sabbel, Sabje, Dank je wel dat je altijd naar me hebt geluisterd, me hebt meegesleept op de oh-zo-nodige hardloop- of wielrenrondjes als ik weer eens moest afschakelen. Dat we nog maar vaak falafel mogen maken, die was heerlijk (na wat oefening :D)

Lieve Ans, ik vond het heerlijk om met je te wandelen en ik vond het ook geweldig dat je zo vaak de moeite hebt genomen om Onyx mee te nemen op je wandelingen met Catootje as ik het weer eens te druk had met andere dingen. Dank je wel!

En als het echte beestenmeisje dat ik ben (volgens Miriam) wil ik ook graag mijn beestjes bedanken. Kazic, je hebt voor altijd een bijzonder plekje in mijn hart. Mozzie en Izzie, omdat jullie altijd naar mijn gemopper hebben geluisterd. Onyx, overenthousiast en blij breng je altijd weer een lach op mijn gezicht als ik thuiskom. 
Ook wil ik mijn lieve schoonouders bedanken. Jean, ook al waren we het niet altijd over alles eens, ik heb je erg bewonderd om je krachtige mening. Je ging voor je gezin door het vuur en ik heb veel van je geleerd. Dank je wel! Gerda, jou wil ik graag bedanken omdat je me zo hartelijk in jullie gezin hebt verwelkomd en dat je nog steeds altijd voor ons klaarstaat. Jos, ook jou wil ik graag bedanken, want je staat altijd voor iedereen klaar en hebt steeds een goed advies en vriendelijk woord als iemand dat nodig heeft.

Lieve pap, ook al maak je niet meer mee dat ik mag promoveren, je wist in elk geval dat ik al een eind op de goede weg was. Dank je wel dat je me altijd hebt gesteund in alles wat ik deed en wilde bereiken en dat je me hebt gestimuleerd om het beste uit mezelf te halen. Lieve mam, voor jou geldt natuurlijk hetzelfde! Zonder jullie steun en liefde had ik het nooit zover geschopt.

Roberto, mijn lieve sjattie. Ik kan wel proberen je te bedanken, maar ik kan niet onder woorden brengen hoeveel je voor me betekent. Jouw aanwezigheid stelt me gerust, en in jouw armen ben ik pas echt thuis. Samen kunnen we de wereld aan!

En als laatste natuurlijk Dolf. Jij bent mijn grote kleine man, mijn liefste boef en ondeugendste schat. Ik hou ontzettend veel van jullie allebei! 


\section{Curriculum Vitae}

Nadine Cathérine Olthof werd geboren op 4 februari 1980 te Stadskanaal. Ze groeide op in Veendam en is vervolgens verhuisd naar Lelystad, waar zij in 1998 haar VWO af heeft gerond aan de Scholengemeenschap Lelystad. Daarna heeft zij een jaar de studie farmacie aan de Rijksuniversiteit Groningen gevolgd, waarna zij een jaar in Veyras, Zwitserland als au-pair heeft gewerkt. Hierna heeft zij de opleiding Hoger Laboratoriumonderwijs gevolgd aan de Hogeschool Zuyd te Heerlen welke ze in 2004 met goed gevolgd heeft afgesloten. In 2007 heeft zij de master Clinical Molecular Sciences behaald aan de Universiteit Maastricht. Tijdens deze masteropleiding heeft zij stage gelopen op de afdeling Neuropathologie aan de Universiteit Maastricht, onder begeleiding van dr. C. Schmitz. Vervolgens heeft zij 8 maanden gewerkt op de afdeling Neuropathologie van het Universitatsklinikum Aachen (Duitsland) binnen de groep van Prof. Dr. Weis. In maart 2008 is zij gestart met haar promotieonderzoek, beschreven in dit proefschrift, bij de afdeling KNO in samenwerking met de afdeling Moleculaire Celbiologie onder begeleiding van Prof. Dr. Bernd Kremer, Prof. Dr. Ernst-Jan Speel en Prof. Dr. Frans Ramaekers.

Nadine Cathérine Olthof was born on February 4, 1980 in Stadskanaal, the Netherlands. She grew up in Veendam and later moved to Lelystad, where she graduated from the Scholengemeeschap Lelystad in 1998. She studied pharmacy for a year at the Rijksuniversiteit Groningen, after which she worked for a year as an au-pair in Veyras, Switzerland. She received her bachelor degree in Applied Sciences from the Hogeschool Zuyd in Heerlen in 2004. In 2007 she obtained her Master's degree in Clinical Molecular Sciences at the University of Maastricht. During this master she did her internship at the Department of Neuropathology at the University of Maastricht, under the supervision of Dr. C. Schmitz. Subsequently, she worked for 8 months at the Department of Neuropathology at the Universitatsklinikum Aachen (Germany) in the group of Prof. Dr. Weis. In March 2008 she started her $\mathrm{PhD}$ research, described in this thesis, at the department of Otorhinolaryngology and Head and Neck Surgery, in collaboration with the department of Molecular Cell Biology Department under the supervision of Prof. Dr. Bernd Kremer, Prof. Dr. Ernst -Jan Speel and Prof. Dr. Frans Ramaekers. 



\section{List of publications}

Olthof NC, Straetmans JM, Mooren JJ, de Jong J, Speel EJ and Kremer B. Human papillomavirus reduces the prognostic value of nodal involvement in tonsillar squamous cell carcinomas. Laryngoscope 2009; 119: 1951-1957.

Olthof NC, Straetmans JM, Snoeck R, Ramaekers FC, Kremer B and Speel EJ. Next-generation treatment strategies for human papillomavirus-related head and neck squamous cell carcinoma: where do we go? Rev Med Virol 2012; 22: 88-105.

Sorensen BS, Busk M, Olthof NC, Speel EJ, Horsman MR, Alsner J and Overgaard J. Radiosensitivity and effect of hypoxia in HPV positive head and neck cancer cells. Radiother Oncol 2013; [E-pub ahead of print]. 
